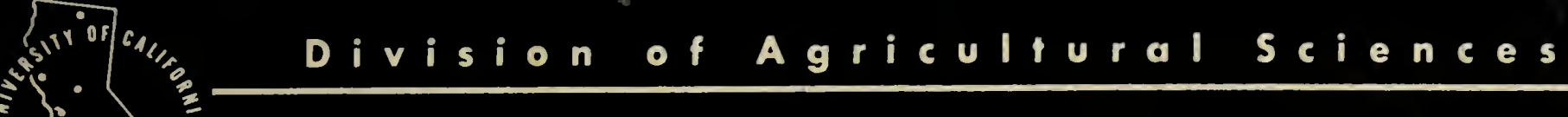
U N I VERS I T Y O F C A L IF O R N IA
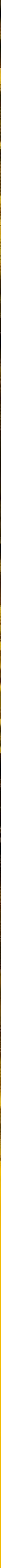

A HANDBOOK ON

J. E. E CKER T

IN CALIFORNIA

CALIFORNIA AGRICULTURAL

Experiment Station

Extension Service

MANUAL 15 
THIS MANUAL is one of a series published by the University of California College of Agriculture and sold for a charge which is based upon returning only a portion of the production cost. By this means it is possible to make available publications which, due to relatively high cost of production, or limited audience, would otherwise be beyond the scope of the College publishing program. 


\section{A HANDBOOK ON}

\section{$\begin{array}{llllllllll}\text { B } & \mathbf{E} & \mathbf{E} & \mathbf{K} & \mathbf{E} & \mathbf{E} & \mathbf{P} & \mathbf{I} & \mathbf{N} & \mathbf{G}\end{array}$}

\section{N C A I F OR N I A}

\section{J. E. ECKERT}

\section{CONTENTS}

The Fundamentals of Beekeeping $\ldots \ldots \ldots \ldots \ldots \ldots$

The Life Story of the Honeybee ................ 18

Manipulation of the Hive $\ldots \ldots \ldots \ldots \ldots \ldots$

General Manipulations ...................... 34

Miscellaneous Operations ................... 50

The Rearing of Queens . . . . . . . . . . . . . . . 57

Diseases and Enemies of Bees ..................66 61

Honey and Beeswax ..................... 77

References for Further Reading .............. 86

Index $\ldots \ldots \ldots \ldots \ldots \ldots \ldots \ldots \ldots \ldots \ldots \ldots$

This manual replaces the former Extension Circular 100

\section{LIBRARY}

UNIVERSITY OF CALIFORNIA

DAVIS 


\section{A HANDBOOK ON \\ B E E K E E P I}

This is a handbook for both the beginner and the experienced beekeeper.

It lists three sources of income-honey and beeswax; rentals for supplying bees for pollination; and sale of colonies, package bees, and queens.

It discusses the amount of investment you will need to make, how and when to start, and what returns to expect. It tells you what equipment to buy and how to assemble parts. It advises you to place your apiary near nectar and pollen plants, and to move the hives to fresh plant sources when necessary. It names the plants that are poisonous to bees.

It interprets the behavior of bees used in the pollination of agricultural crops to make them more fruitful and tells how bees communicate with each other to carry on their field duties.

The history of the queen, the drone, and the worker is told, and the "cycle of the year" described. Seasonal operations are discussed in detail, as are also feeding, both natural and artificial, and diseases with their treatment.

You are warned about bee stings and advised what to do about enemies of bees, such as skunks, bears, and wax moths.

Finally, to show you what to do with your product, marketing is discussed.

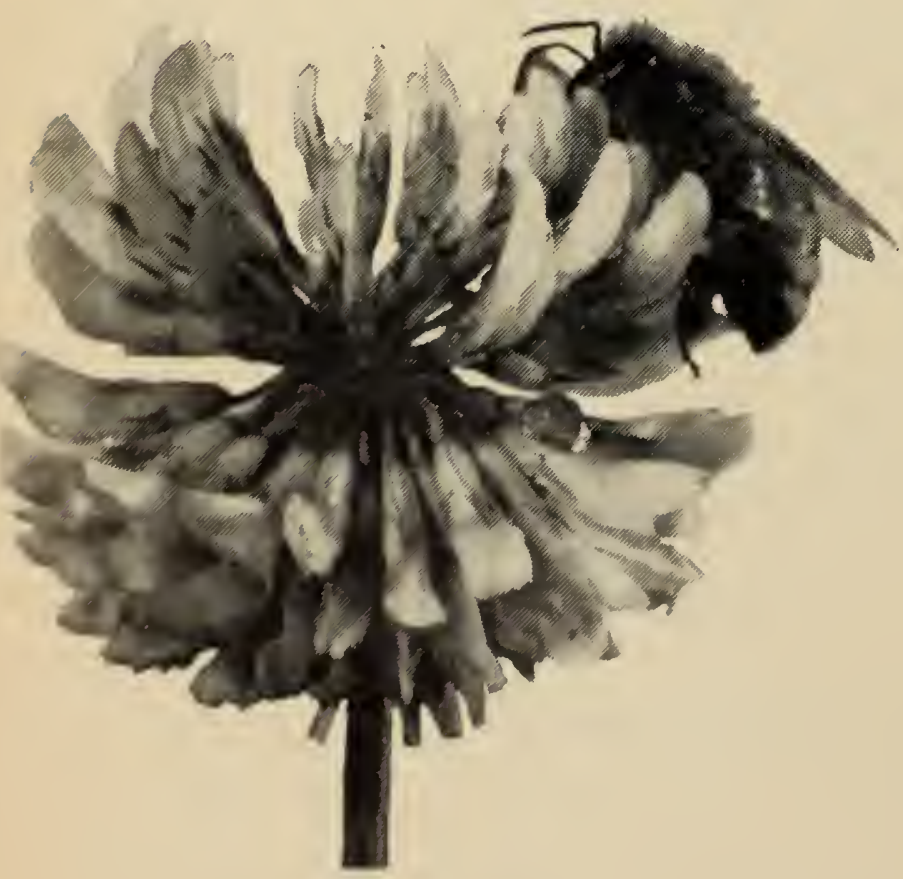

THE AUTHOR: J. E. Eckert is Professor of Entomology and Apiculturist in the Experiment Station, Davis. 
J. E. ECKERT

\section{THE FUNDAMENTALS OF BEEKEEPING . . . what you should know, have, and perhaps think about before taking up beekeeping as a hobby or profession}

The KeEPING of BeEs is such an old occupation you would naturally suppose that the honeybee is a native insect, but this is not true. Early records indicate that it was first imported into Virginia in 1621 and that beeswax and honey were abundant in that state by 1650 . The Daily Alta California reported on July 1 , 1852, that W. A. Buckley of Newburgh, N.Y., arrived in San Francisco with three hives of bees, one of which was "in fine condition." (There is no further record of this flourishing hive.) In the following spring Christopher A. Shelton bought 12 hives of bees from an unknown beekeeper in Aspinwall and managed to land the 12 in San Francisco with only enough bees to make one full hive. The colony was taken to San Jose, where it prospered to the extent of casting three swarms that spring. In December one of the colonies was sold at auction for $\$ 110$.* By additional importations and by natural increases, the number of colonies continued to expand in such volume that John S. Harbison, a pioneer beekeeper of the state, shipped the first carload of comb honey to Chicago in 1873. Mr. Harbison used the primitive

\footnotetext{
* Clyde Arbuckle, "Bee Line to California," Westways, Sept., 1952, pp. 8-9.
}

type of equipment shown below to produce this honey.

At present several thousand persons in California own 521,000 hives representing an investment of several million dollars. The number of colonies maintained by each beekeeper varies from one to several thousand. A few hundred individuals own and operate a major portion of the total colonies, while the majority

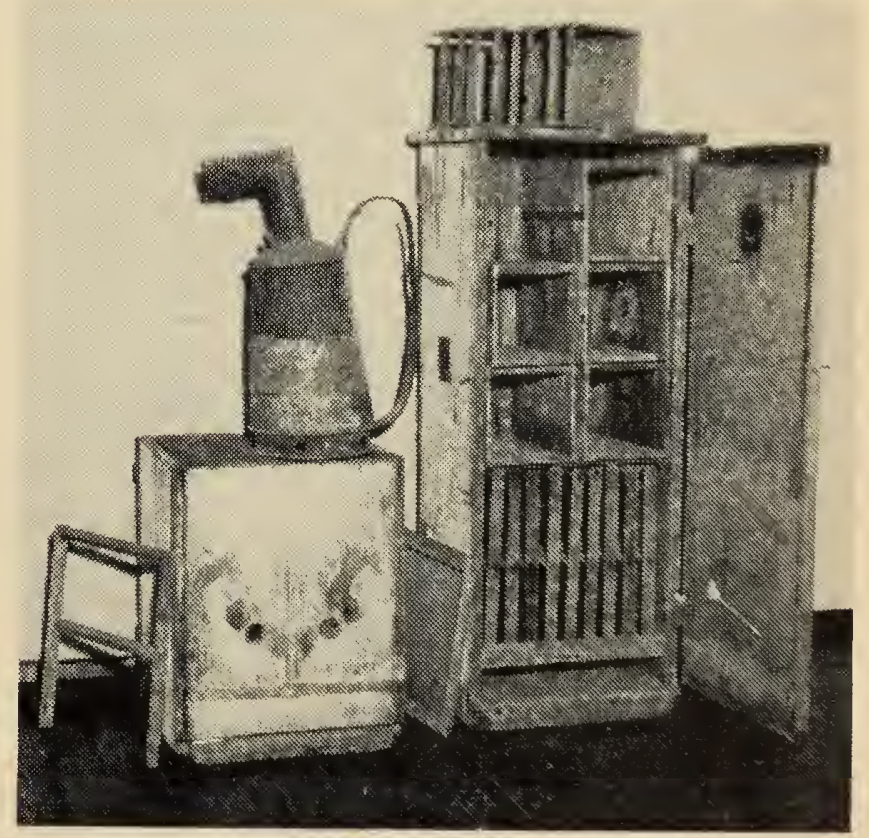

Two types of hives used by beekeepers in the early days of California beekeeping. The tall hive has three tiers for comb sections; the other is a single brood chamber that can be expanded vertically. The "stove" smoker is a forerunner of the bellows smoker. 
of beekeepers own less than 100 colonies each. Apiaries are found in all parts of the state where there are enough pollen and nectar plants to support the colonies, with a majority of the hives located in the irrigated sections.

\section{BEEKEEPING OFFERS THREE SOURCES OF INCOME}

In the early days honeybees were kept mainly for honey and beeswax and for the value of the natural swarms. Changing agricultural conditions have opened new sources of income, so that three opportunities are now available: production of honey and beeswax; sale of colonies, package bees, and queens; and rentals from colonies used for pollination.

\section{Production of honey and beeswax}

The honeybee will store pollen and honey as long as floral sources are available. The honey thus stored beyond the needs of the colony is taken by their keeper as a return for his labor and investment. Annual production of honey averages between 40 and 60 pounds for all colonies in the state, with seasonal variations. Commercial beekeepers who keep 500 or more colonies may average from 60 to 120 or more pounds per colony in a good year. The annual state production of honey also varies. In 1952 it was reported as 48,974,000 pounds, while the five-year average of 1947 to 1951 was $22,431,000$ pounds. California furnishes about one-tenth of the honey produced in the United States.

An important by-product of the honey industry is beeswax, which the bees produce from honey and use to build their combs and to seal the cells of honey and brood. The beeswax of commerce is made by melting the cappings cut from the honey combs in the process of extracting the honey, and by melting entire combs or pieces of comb. The amount of beeswax secured from each hive varies with the amount and kind of honey produced but averages from 1 to 2 pounds per hive, or about 1 pound for each 50 or 55 pounds of extracted honey. The amount of beeswax produced in California during the past ten years has varied from 321,000 to 480,000 pounds. Since the price of beeswax to the producer may average between 30 and 45 cents per pound, the beekeeper should save all wax produced in excess of the needs of each colony.

\section{Sale of colonies, package bees, and queens}

Another source of income is the sale of bees and queens to beginners and to established beekeepers. These are generally sold as colonies established in hives or in screened cages by the pound or package. The average cost of an established colony will vary with the value of the equipment, condition and type of bees, and strength of the colony. Established colonies are often bought for less than the value of the initial equipment.

Beekeepers in favored locations in northern California have developed a business of selling bees by the pound, with or without queens, to established beekeepers to restock hives for pollination or honey production. Since these bees are shipped in screened wooden cages, they are known as package bees. Approximately 100,000 or more packages of bees are shipped annually out of northern California to the northwestern and Rocky Mountain states and to Canada. A package usually contains from 2 to 4 pounds of bees with one queen and enough sugar syrup to maintain the bees until they reach their destination. There are between 3,000 and 4,500 bees to the pound, depending on the amount of food in their digestive systems at the time they are weighed.

The cost of a package of bees usually averages around $\$ 1.00$ a pound for the bees, $\$ 1.00$ for the queen, and the cost of the package-or between $\$ 3.50$ and $\$ 5.00$ a package, depending on its size, method of delivery, and other factors. 
Approximately 75 beekeepers in California produce queens for sale to other beekeepers for requeening their colonies. California queens are shipped to practically every state in the United States, to various provinces in Canada, and to many foreign countries. Between 250,000 and 300,000 queens are produced and sold annually by California queen producers at an average price of $\$ 1.00$ to $\$ 1.50$ each for untested queens, and $\$ 2.50$ to $\$ 5.00$ or more for tested queens and breeders. (See further discussion of queens, page 58.)

The production of package bees and queens requires a greater amount of skill in handling bees than the production of honey and beeswax. The package bee industry is centered in northern California because of generally favorable conditions for building up colony strength in the spring several weeks before the normal honey flow.

\section{Rentals for pollination services}

A majority of our orchard and field crops are either dependent upon insect pollination to be fruitful, or their production is increased when an adequate number of pollinators are present during the blooming period. The honeybee is the only pollinator that can be controlled, multiplied in numbers, and moved as needed for pollination purposes. The leveling of former pastures and wastelands to bring them under cultivation and the greatly increased use of chemicals in the control of weeds and insect pests have reduced the number and value of other pollinating insects and made agriculture more dependent on the beekeeping industry for this essential service.

Since it is usually not practical for a farmer or orchardist to maintain a large number of colonies of bees to pollinate his various crops throughout the year, he has to depend on the beekeeper to supply the number of colonies needed. For best results in the pollination of orchard blossoms one colony per acre is required, al- though two per acre might be better for almonds. Bees gather little or no surplus of marketable honey from fruit trees; hence the orchardist usually pays the beekeeper a rental for the use of the bees. Rentals of $\$ 1.50$ to $\$ 5.00$ per colony for orchard pollination are quite common, the price depending usually on whether the bees are placed in one location or distributed through the orchard.

In legume-seed production, a concentration of one colony per acre for trefoil, alsike, ladino, and red clovers and an average of three colonies per acre for alfalfa are generally considered adequate. In very heavy stands of alfalfa four and five colonies per acre are used. This concentration of bees is greater than is used for commercial honey production, and little surplus honey can be expected except in very favorable years. The red clovers provide only pollen for the pollinators.

Rentals for the use of the bees are usually based on: 1) what the bees might normally make from honey production; 2) the cost of moving the hives into the seed area and the manner in which the hives are distributed in or around the fields; 3 ) the hazards of chemical poisoning involved; and 4) the production and value of the seed crop. Since it has been found that seed production is greatly increased by having an adequate bee population in the seed fields, other factors being favorable, seed growers and beekeepers usually enter into contracts to cover the pollination services.

The rentals paid for colonies used in seed production vary with the type of crop, number of hives, and potential crop values. Contracts are generally written for a minimum amount to cover moving costs when the bees are moved in, and the balance is estimated at so much per colony based on the amount of clean seed produced. The contracts also stipulate the strength of colonies to be provided, method and time of placing the hives, avoidance of injury to the colonies from 
the application of pesticides, etc. Some beekeepers specialize in providing bees for pollination services and manage their colonies accordingly.

The increasing use of pesticides for the control of weeds and insect pests constitutes a hazard to pollinating insects, and both the beekeeper and the seed grower must be alert to this danger at all times for their mutual benefit.

\section{BEGINNERS ...}

\section{CHECK THESE POINTS}

The keeping of bees attracts people of all classes. Often a person who has found a stray swarm becomes interested enough in the habits of bees to buy additional colonies. The pleasure and profit that come from this venture vary according to the interest of the beekeeper and the experience he gains. The beginner seldom knows that much information is available on the subject. He gets his experience painfully and expensively without advice. Because the main part of the colony is hidden in its hive and the worker bees come and go, some beginners think that the bees do all the work and that the beekeeper merely profits by their labors. This is far from the truth. For beekeeping to be profitable, the requirements of the colonies must be known and must be supplied at the proper time.

Before making an initial investment in bees or equipment, measure your interest and ability to invest by the following considerations.

\section{Reactions to bee stings}

The sting of the honeybee generally hurts even the seasoned beekeeper. A first sting usually causes a swelling that will last for a varying period of timeseldom more than two or three days. Immunity to the poison can be gradually acquired until the effect is not noticeable after a few minutes. The pain of being stung is always felt for an instant after the stinger is thrust into the flesh. The stinger should be wiped or scraped off immediately. Pulling or twisting it out injects the contents of the poison sac into the wound. With suitable clothing, properly adjusted, and with a knowledge of bee behavior, you can usually avoid being stung by handling bees properly. The number of stings required to effect immunity will vary with the individual; some persons seem naturally immune, whereas others may require many stings over a long period to develop immunity.

In rare instances-where the individual is hypersensitive-the sting of a bee may result in a more serious reaction than simply local pain and swelling. Such a person should not work with bees until he has been immunized to bee venom under a doctor's supervision. If a sting causes a marked change in pulse rate, difficult breathing, loss of consciousness, or hives on various parts of the body, consult a doctor immediately. Adrenalin is a specific antidote when a person becomes generally affected by bee poison. It should be administered by a physician immediately, when the general symptoms appear, or as soon as the sensitive person is stung.

Some persons who are highly allergic to bee stings have found that ephedrin, taken in a capsule by mouth as soon as they are stung, is a good antidote to a general systemic reaction. Capsules containing $3 / 8 \mathrm{gr}$. of ephedrin and $3 / 4 \mathrm{gr}$. of amytal are available at most drugstores, and an adult can take two such capsules with safety after being stung by bees. Benedril, in $50 \mathrm{mg}$. capsules, is another antidote for bee poison that can be kept on hand for emergency use. Capsules are easier to take and to self-administer than adrenalin under conditions where medical attention is not available.

\section{Amount of investment}

The investment in a beekeeping project depends on whether you start with all new equipment and package bees or buy used equipment and established colonies; it depends also on the amount of equipment 
involved. If you plan to keep only a few colonies, there will be no need for such facilities as a warehouse, workshop, trucks, and the extensive honey extracting and processing equipment essential to commercial operations. On the basis of ten 3-story colonies operated for extracted honey, where all new equipment is involved, the investment for hives, bees, tools, and a small extractor and honey tank amounted to approximately $\$ 23.00$ per colony at 1952 prices. Used equipment can usually be bought for less than the original price, depending on the condition of the equipment as well as the urgency of the need to make the sale.

\section{How to start}

You may become familiar with the management of bees by studying the current literature on beekeeping and bee behavior while working with one or more colonies of bees. In all cases it is desirable to have an instructor or experienced beekeeper first demonstrate how bees and equipment can be handled and explain precautions necessary to keep the bees under control while a hive is being manipulated. If you want to go into beekeeping on a commercial scale you should serve as a helper to an experienced beekeeper for one or more seasons in order to gain the experience needed to operate 500 or more colonies. Hives of bees can be moved from one location to another according to the desire of the beekeeper to live or operate in certain sections of the state.

In buying established colonies, you should require an inspection certificate from the county apiary inspector, which insures freedom from disease. You should also examine the hives to see the condition of the equipment for each colony. It is an advantage for a beginner to have colonies already established in hives. If you buy package bees, however, it is practical to start with new equipment. Then you can watch the progress of the bees in building new

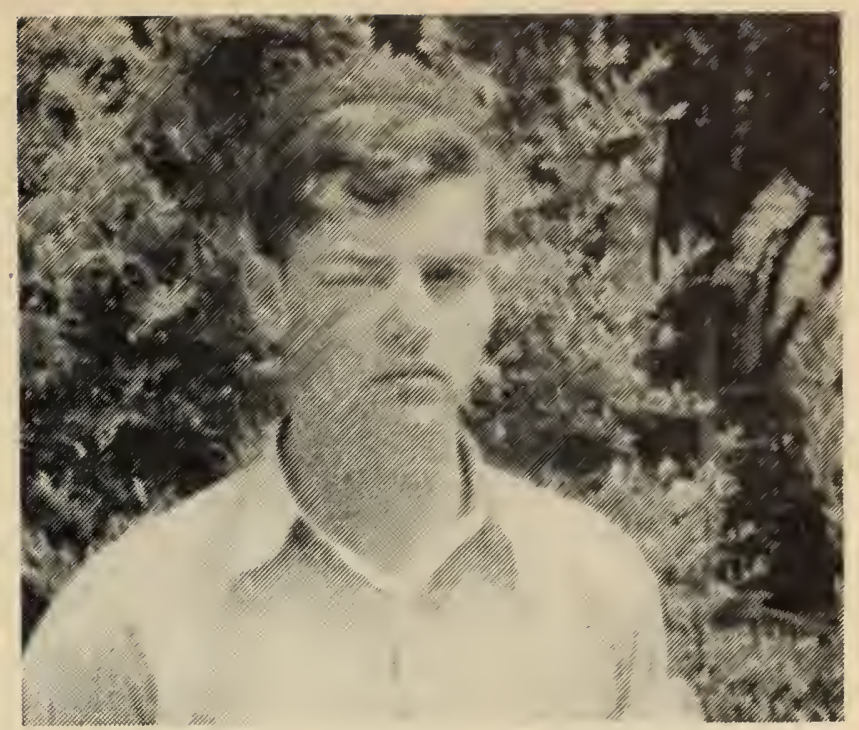

Local effect of a sting near the eye of a novice. These results are temporary and do not recur when the beekeeper develops immunity to the poison.

combs, starting their brood nest, and pursuing the natural cycle of activities in a new hive. There is no danger of acquiring diseased colonies when package bees are installed on frames of foundation.

\section{When to start}

The climate varies so greatly in different parts of California that the best time of year to start differs from one region to another. A practical plan is to study beekeeping literature during the fall and winter, then to acquire the first colony in the spring, when blossoms will supply the food requirements for brood rearing and colony maintenance. The problems of spring management, swarm control, and supering for the nectar flow are usually very interesting to the beginner, but they are problems you must handle wisely. Unless you know something about the habits of bees and their care and have surveyed the possibilities of your location, the colony may try to solve its own problems by swarming. Of course, beekeeping can be started at any season, provided you know the needs of the colony at that time and manage accordingly. General directions for managing colonies during the different seasons are given in the section on general manipulations, pages 34-35. 


\section{What returns to expect}

The amount of profit in bees depends to a large extent on the availability and abundance of nectar- and pollen-producing plants and on favorable weather conditions while the flowers are in bloom. It also depends on the number of bees in each colony, on the skill used in handling bees and equipment, and on marketing conditions. The three sources of possible profit have already been listed-sale of honey and beeswax; sale of colonies, package bees, and queens; and rentals for pollinating services. The income of the beekeeper is not fixed like that of the worker with a given salary. It varies from season to season but averages from $\$ 3.00$ to $\$ 10.00$ or more per colony per year. You may get additional income from marketing the honey in retail packages, or direct to the consumer at retail prices.

To have an apiary site in territory where one or more major honey plants occur in abundance is of great importance. In California the blooming period of a nectar-producing plant is relatively short in comparison with the period when the bees are active. For this reason beekeepers engaged in producing honey must, as a rule, move their colonies about in order to keep the bees in a nectar flow. Commercial apiarists often move their colonies from two to five times within a single year. This system is called migratory beekeeping. Although the average permanent location may yield enough nectar for the colony and some surplus besides, this good fortune cannot always be expected, except in some irrigated regions where the nectar-secreting plants are not dependent on rainfall for moisture, or where the location borders both a natural source of nectar and a cultivated area.

Normal average colony production in California varies from 40 to 60 pounds annually. Some colonies must be fed sugar syrup in order to remain alive dur- ing a dearth of nectar. Colonies in more favorable locations may average 100 to 200 pounds or more of surplus. In addition to yield, the amount of profit on the season's operations of course depends on production and marketing costs and market price.

Besides the money return, the beekeeper generally takes into consideration the pleasure of working under healthful outdoor conditions. Many people keep colonies solely because of an absorbing interest in the life history and habits of bees. Thus beekeeping may become a diversion for the professional or office worker. Bees may be kept in an outapiary some miles distant in the country and visited regularly in conjunction with a city occupation. Beekeeping is an avocation that may also fit in well with such occupations as fruit growing and poultry raising.

\section{These are the \\ success factors}

As a rule, success in beekeeping follows in direct proportion to the beekeeper's knowledge of bee behavior and hive operation and his acquaintance with nectar plants. This must of course be coupled with business ability. Beekeeping requires persistent effort and promptness in meeting the demands of the occupation. It is not a business for a careless or a lazy person. Honeybees meet with many hazards. They are attacked by spiders and many insects, by birds, mammals, toads, bacteria, protozoans, and fungi. They are subject to specific diseases, many of which are very destructive. They are also liable to be poisoned by chemical sprays through the increased use of pesticides; in fact, chemical poisoning has become a greater hazard than bee diseases. The welfare of the bees therefore depends not only on favorable plant and climatic conditions, but also on the care essential to their very existence. 


\section{Choosing your \\ apiary site}

Important nectar and pollen plants. In locating an apiary, you should know the nectar- and pollen-bearing plants and their blossoming dates. California has nectar-producing plants of wide variety and seasonal distribution. These plants may be found in varying abundance, both at sea level and high in the mountains. The more important plants are listed in table 1 . Each nectarsecreting plant produces a honey characteristic of that plant, not only in color but also in flavor. Since the bees frequently work on only one major honey plant during its blooming period, you may, if you like, keep separate the various honeys produced.

An ideal apiary location is one that furnishes enough spring flowers yielding pollen and nectar for the bees to build up their colonies rapidly for a major nectar flow of long duration. Later plants should provide stores for the bees during the winter. In many localities of California the climate encourages brood rearing over the greater part of the year. The blossoming periods of the more important honey plants are usually short, however, seldom lasting longer than two months and often not longer than three weeks. Some plants produce a fine grade of table honey; others, the strongerflavored honeys, used chiefly in the bakery trade.

At least half the honey produced in California is gathered from wild flowers; adequate rainfall, therefore, is important in its production. Atmosphere and soil likewise affect the quantity and quality of nectar produced by any particular plant. For this reason, a good nectar source in one locality may be of less value in another. A distance of only a few miles may make a marked difference in nectar production. Many cultivated plants, such as citrus, alfalfa, and cotton, are so sensitive to climatic conditions that their an-
A location where the bees can gather surplus from two or more major plants is very desirable; it is probably as profitable, over a period of years, as the migratory system.

nual nectar production varies greatly. In the foothills surrounding the great valleys of northern California, including the northern slope of the Tehachapi range, the California buckeye (Aesculus californica), whose pollen is poisonous to the honeybee, covers a wide area that would otherwise make excellent bee territory. Fortunately, this plant does not extend into the more important sage and buckwheat locations of southern California. Many sections in the Coast Range cannot be used for beekeeping because fogs are usually present when the honey plants are in bloom.

As ideal year-round locations are hard to find, many beekeepers move their colonies from two to five times a year. This migratory system tends to provide the bees with a continuous nectar flow. Such a practice is expensive and calls for considerable labor and equipment.

Sometimes bees are kept primarily for pollination purposes or as a hobby, with surplus honey of secondary importance. Then almost any irrigated region and many mountain locations will provide a nectar flow sufficient for them to store honey and to provide some surplus for their keeper.

General considerations. The location of both permanent apiaries and outapiaries must be given intelligent consideration. Hives in permanent apiaries are usually placed on concrete or stone foundations to prevent damage by dry rot and termites. Hives in outapiaries are often placed directly on the ground in double rows, back to back, with enough space between each two rows for a truck to pass through. Hives located in groups of twos or fours, in straight rows, make a 


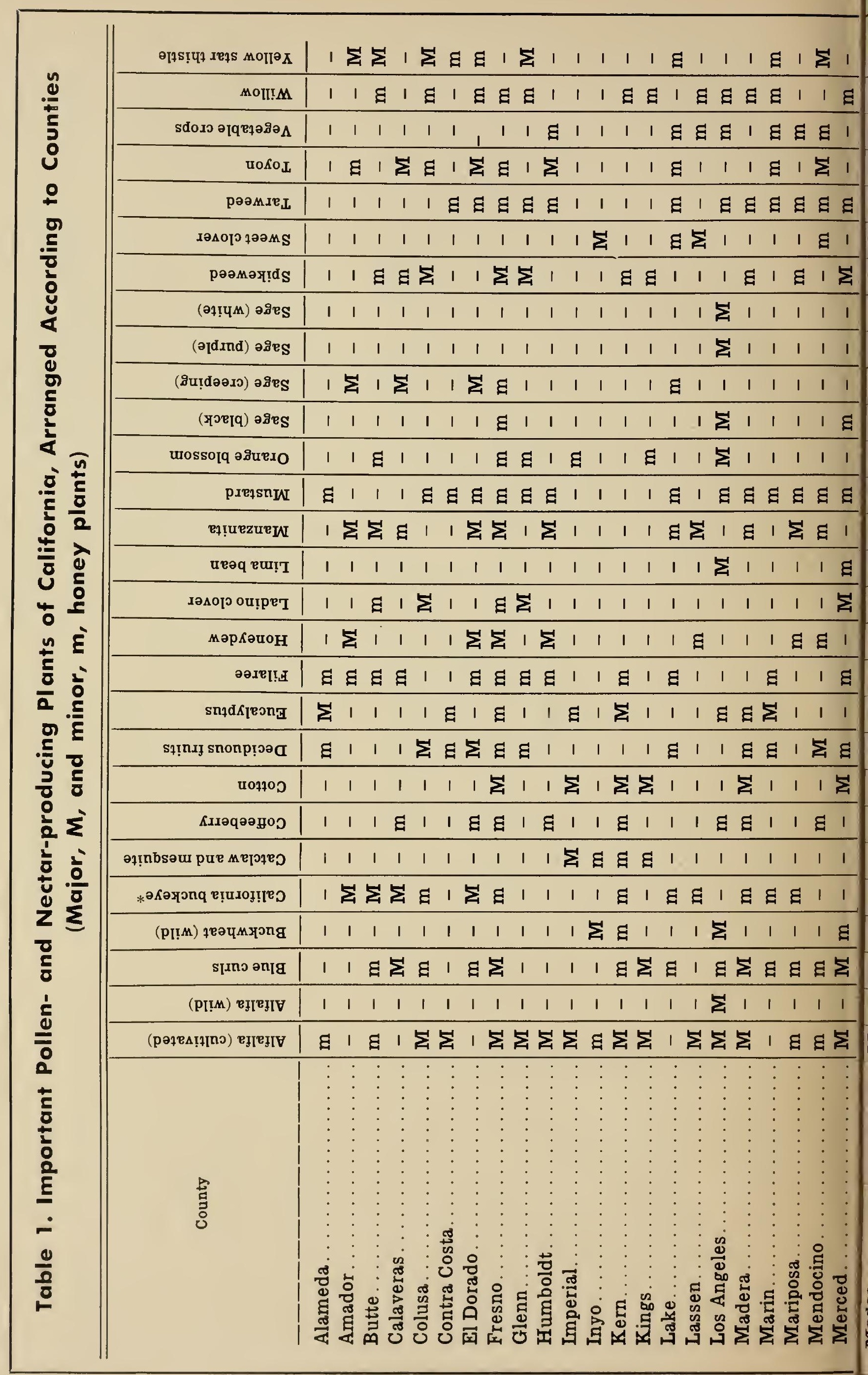


better-looking apiary than hives scattered about; however, this arrangement often causes the young bees and the returning field bees to drift with the wind into hives other than their own. Since, in California, outapiaries are generally temporary locations, beekeepers often place their colonies in irregular rows as the truck is unloaded. This tends to reduce undesirable drifting of bees from one end of a row to another.

As a rule, the hive entrance should face away from the direction of the prevailing winds. This is less necessary where windbreaks are provided. If natural sources of water are not readily accessible, water should be provided near the bees. Water is especially necessary in desert locations.

Provide an economic surplus of honey and pollen. A desirable location should have sufficient pollen and nectar plants to keep the colonies in good condition and to produce a surplus for their keeper. Locations that produce good quality table honey are to be preferred to those that produce honey of an inferior grade. The territory should not be overstocked. Bees will fly an average distance of $1 \frac{1}{2}$ to 2 miles in search of nectar and pollen, and much farther if necessary. It is seldom practical to locate apiaries closer than a mile apart, unless the nectar production warrants. The number of colonies in a particular region will also influence the number that should be kept in each apiary. From 50 to 100 colonies is the general rule, enough to keep the beekeeper busy in each location for half or all of a day on each visit. Apiaries are generally located either within the nectar source or within a half mile of its borders.

Avoid areas infested with ants and other pests. Sometimes the hives in back-lot apiaries are placed on benches a foot or so off the ground to prevent damage from termites, ants, and dry rot. This is also advisable when toads, lizards, and skunks are abundant. For obvious reasons, do not locate hives in an area infested with troublesome ants or near dens of skunks. In mountain regions where there are bears, apiaries should be protected by an electric fence, as described on page 76. This repels not only bears but also other large animals.

Furnish climatic protection. Natural windbreaks of brush or trees are advisable wherever the prevailing winds interfere with the flight of bees. In sections of the state where the temperatures are above $95^{\circ} \mathrm{F}$ in the summer and fall, par-

Partial shade is essential for bees in the Imperial Valley and may be supplied by natural growth, such as mesquite, or by artificial shelters.

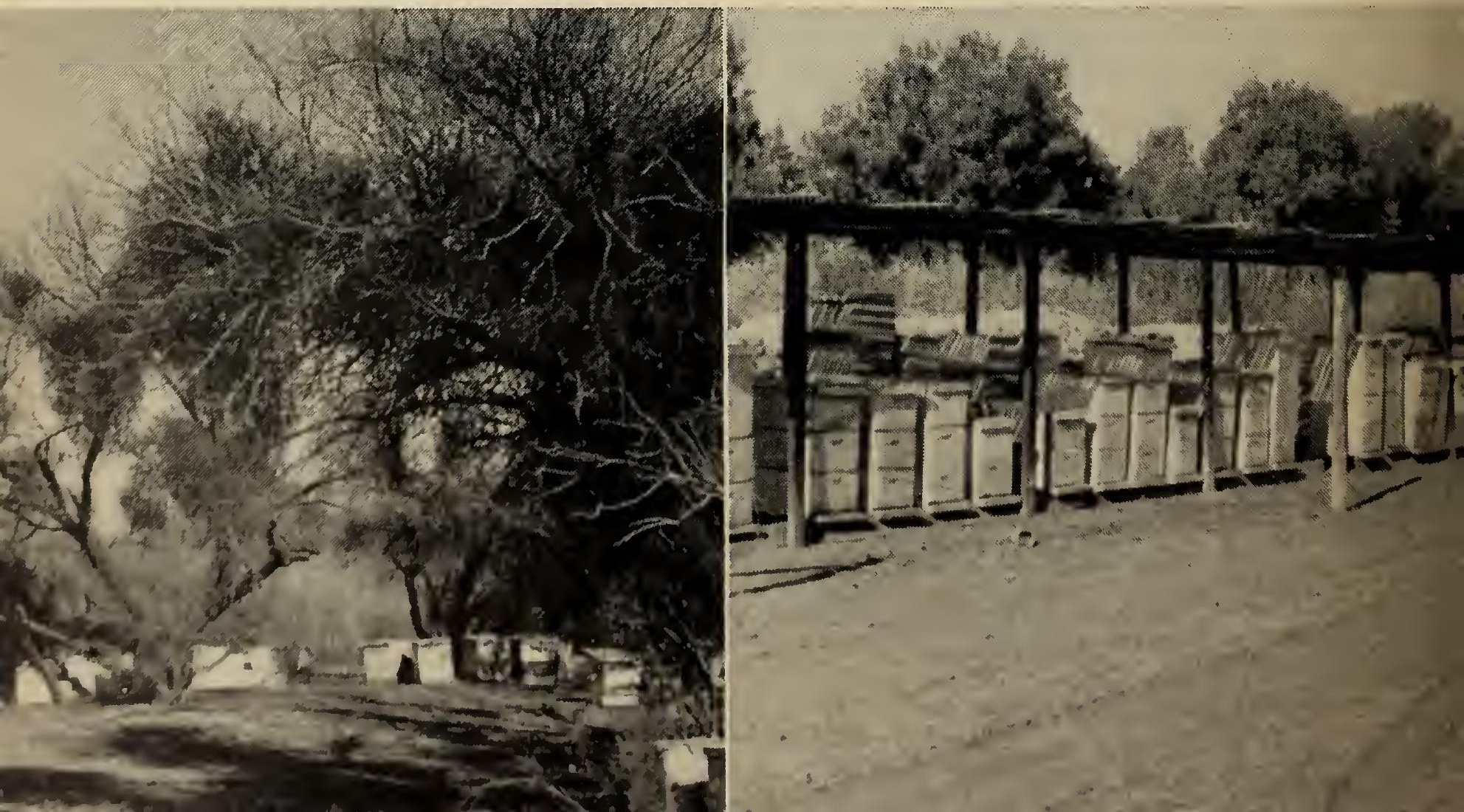


Alfalfa, Medicago sativa

Alfalfa (wild), Lotus scoparius

Blue curls, Trichostema lanceolatum

Buckwheat, Eriogonum, spp.

Cotton, Gossypium spp.

Deciduous fruits

Eucalyptus, Eucalyptus spp.

Filaree, Erodium spp.

Ladino clover, Trifolium repens var. latum

Lima bean, Phaseolus sp.

Manzanita, Arctostaphylos spp.

Mesquite, Prosopis juliflora var. glandulosa
Mustard, Brassica spp.

Orange, Citrus sinensis

Sage (black), Salvia mellifera

Sage (creeping), Salvia sonomensis

Sage (purple), Salvia leucophylla

Sage (white), Salvia apiana

Spikeweed, Centromadia spp.

Sweet clover, Melilotus alba

Tarweed, Hemizonia spp.

Vegetable crops (onion, carrot, and asparagus)

Willow, Salix spp.

Yellow star thistle, Centaurea solstitialis

\section{NECTAR AND POLLEN PLANTS OF SECONDARY IMPORTANCE ${ }^{1}$}

Black locust, Robinia pseudoacacia

Button-willow, Cephalanthus occidentalis

California buckeye, Aesculus californica $a^{2}$

California honey plant, Scrophularia californica

Cantaloupe

Carpet grass, Lippia spp.

Cascara sagrada, Rhamnus purshiana

Catclaw, Acacia greggii

Cedar, Libocedrus decurrens ${ }^{3}$

Chia sage, Salvia columbariae

Coffeeberry, Rhamnus californica

Hollyberry, Rhamnus crocea

Jackass clover, Wislizenia refracta

Madrone, Arbutus menziesii

Mountain misery, Chamaebatia foliolosa

Oak, Quercus spp. ${ }^{4}$

Olive, Oleaeuropaea
Pentstemon spp.

Phacelia spp.

Poison oak, Rhus diversiloba

Rabbit brush, Chrysothamnus nauseosus

Snowberry, Symphoricarpos albus

Sumac, Rhus laurina

Tamarisk, Tamarix spp.

Trefoil, Lotus spp.

Toyon, Photinia arbutifolia

Wild lilac, Ceanothus spp.

Yerba santa, Eriodictyon califormicum

${ }^{1}$ Data assembled with the assistance of George H. Vansell, U.S.D.A. Bee Culture, Davis.

2 This plant is listed here primarily because of its poisonous nature to bees and not because of the surplus honey it may produce at the expense of the bee population.

"Source of abundant honeydew in favorable years.

"Source of pollen and honeydew. 


\section{Minimum equipment for the beekeeper}

Type of hive. Before acquiring colonies, decide what type of beekeeping best suits your locality. This decision will indicate the type of equipment you will need.

Undoubtedly the easiest kind of honey to produce is extracted honey or comb honey in shallow frames. This calls for the 10-frame Langstroth hive, which is standard among the great majority of beekeepers in the state, although some successfully use the 8-frame hive or other sizes. Each hive should consist of a bottom board, a brood chamber, at least two standard 10-frame hive bodies of the same dimensions as the brood chamber, and an outer cover. If you expect to keep only five colonies or less, then each hive might well consist of two 10-frame hive bodies and two to four shallow supers, together with hive tops and bottoms. Such equipment will permit the production of honey in shallow frames so that it can either be cut out of the frames in comb form or extracted. An extra bottom board and top for use with a hive body, to take care of an increase of one swarm, are also desirable. Eight-frame equipment is recommended for women beekeepers.

Queen excluder. This piece of equipment is recommended, to confine the queen to the brood chambers. A queen excluder makes colony management easier in many ways; it is essential where

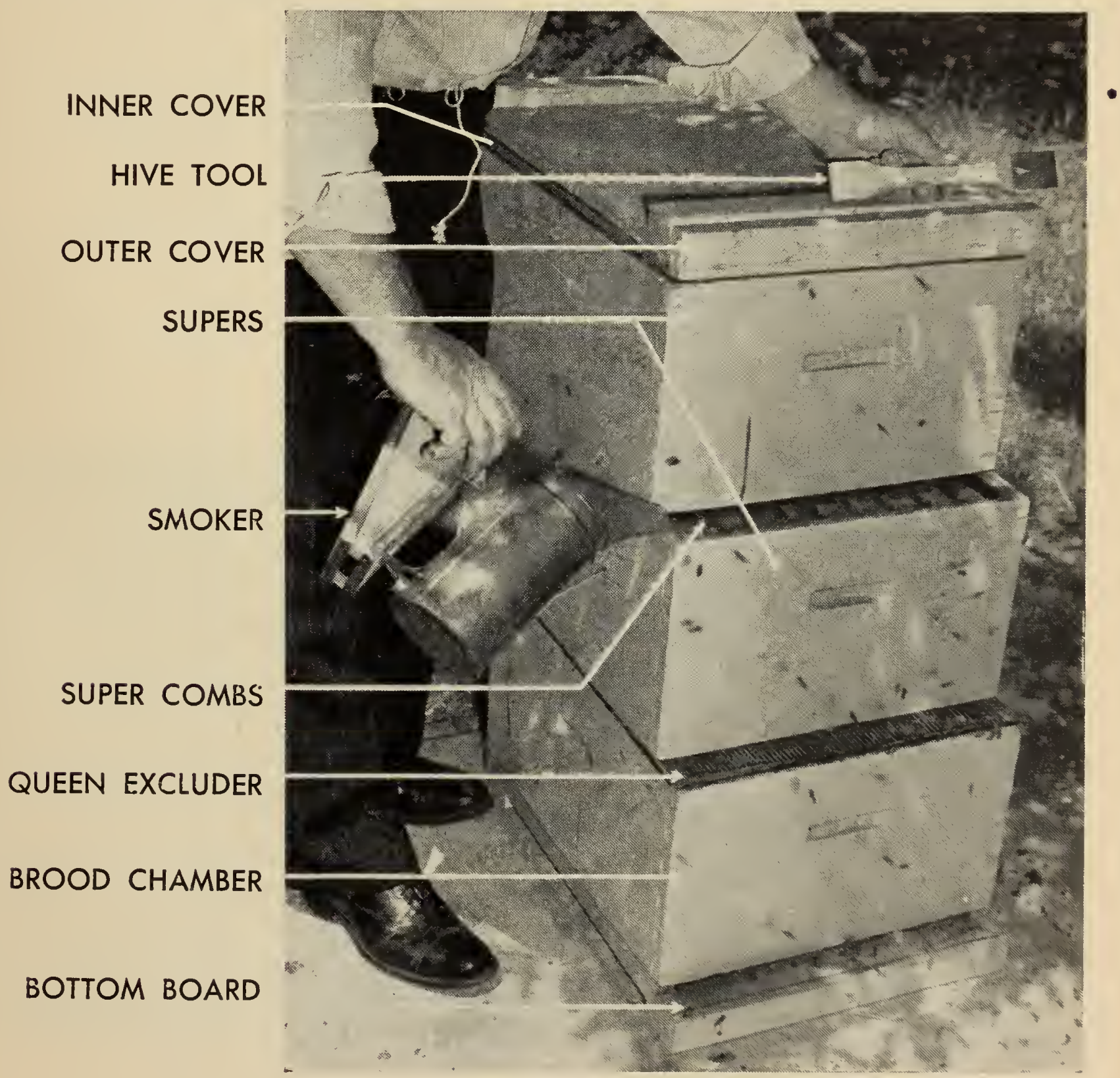

The parts of a 3-story Langstroth hive. 
shallow frames are used to produce bulk or cut-comb honey. Many commercial beekeepers equip their hives with queen excluders in the production of extracted honey.

Hive cover. The two principal kinds of hive covers are those fitting flat on top of the hive and those telescoping a few inches down over its sides. With the former covers no inner cover is needed; but with the telescoping type, an inner cover of wood is essential, although some beekeepers use burlap or canvas instead. For migratory beekeeping the flat cover is the best.

Smoker. The smoker, one of the most useful tools in the apiary, should be kept in good repair. The standard or jumbo type is recommended. In the selection of a smoker, it is well to remember that copper, if given proper care, lasts longer - than tin.

Hive tool. The hive tool is used to pry the supers apart, to loosen frames, and to scrape burr and bridge combs and propolis from the frames and hive. Although various kinds are used, the 10 inch Root hive tool, or one of similar pattern, is the one most commonly used. A serviceable hive tool can be made from spring steel and fitted with a wooden handle. The scraping edge of the tool should be square and the corners rounded-not sharpened to a cutting point as is too frequently done. Square edges and rounded corners will neither splinter the wood nor cut the operator.

Bee suit. Special clothing may be worn in the apiary to protect the beekeeper against stings. The veil-of first consideration - should be of dark material, either wire or tulle, in order that the worker may have the clearest possible vision. The folding wire veils sold by most manufacturers and supply houses are generally satisfactory. The cotton tulle veil, with a silk tulle front, gives especially clear vision. Whichever kind is used, the veil should be fastened down securely over the head and neck to be entirely bee-tight even when the wearer is bending over the hive. Straw hats or hats covered with cotton cloth, instead of felt, should be worn in the apiary, since bees tend to sting felt or flannel.

Light-colored clothing is preferable to dark, and cotton to wool or flannel. A zipper coverall fastened at the wrists and ankles makes a very serviceable outfit. High-topped shoes or boots are generally

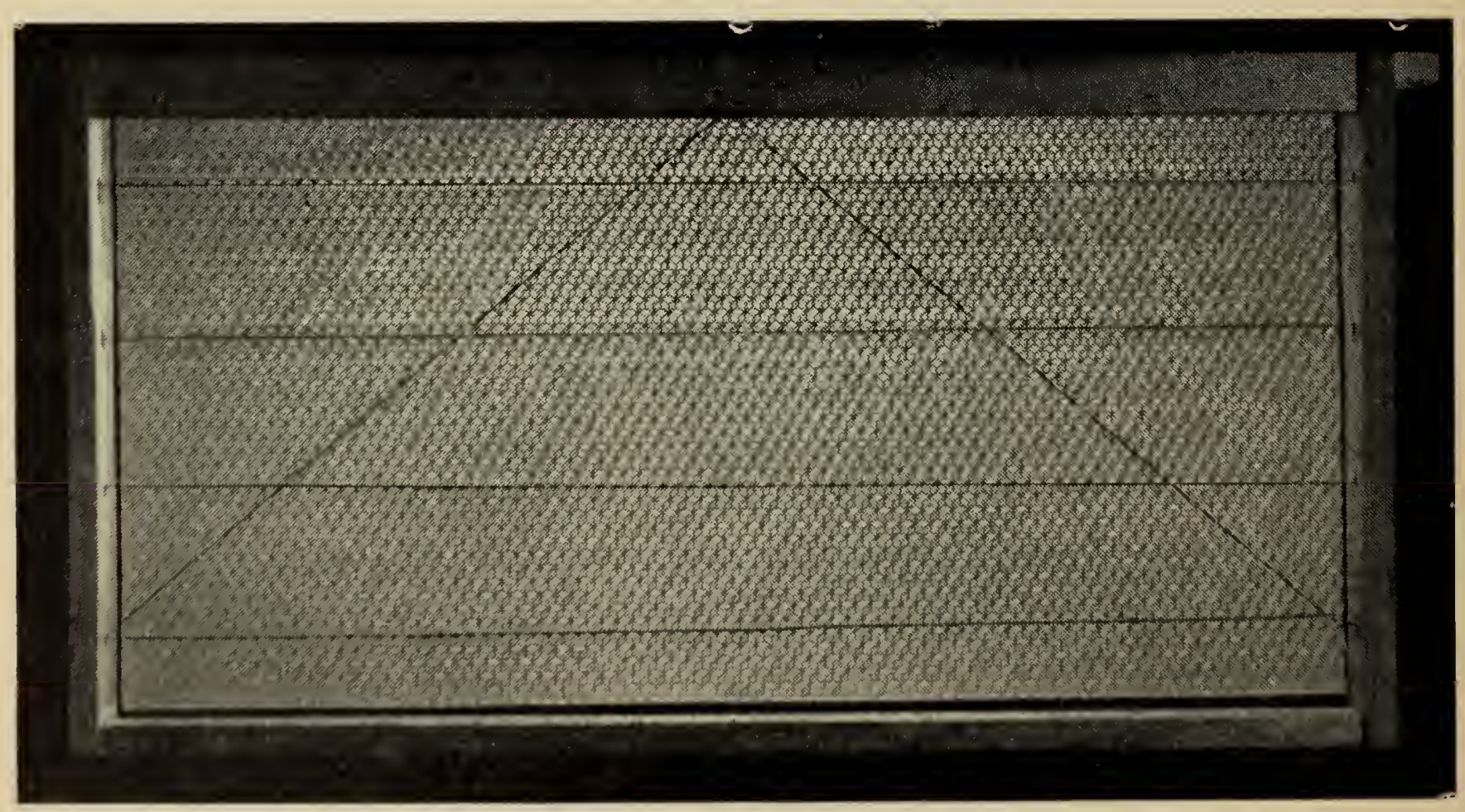

One method of wiring a frame to supply support for the comb. 
worn as a protection against stings. Sometimes elbow-length bee gloves made of heavy cloth are worn, although usually only when the bees are exceptionally cross. The experienced beekeeper, however, often works with sleeves rolled up and probably does not receive any more stings, on the average, than if the sleeves were fastened at the wrist.

Comb foundation. Comb foundation normally consists of sheets of pure beeswax embossed on both sides with hexagonal cell bases of the size built for worker bees. Three principal types of foundation are now available at most bee supply dealers: light, medium, or heavy brood; 3-ply; and thin super. Wired foundation has vertical wires embedded in the sheet of beeswax by the manufacturers. The thin super foundation is used for comb sections or for the production of comb honey in shallow frames. Straight combs of worker cells are essential to the proper management of bees, and these can be secured only where the frame is properly wired and full sheets of foundation are fastened in each frame.

Wire-embedded foundation is to be recommended, especially if combs are subjected to strenuous movement in the migratory system of beekeeping prac. ticed in so many sections of the state. The vertically embedded wires, supported by two to four horizontal wires, also prevent the cells in the upper part of the comb from stretching out of shape with the weight of honey during the heat of summer. The 3-ply Airco foundation is also stronger than regular foundation and is used by many beekeepers to prevent the cells from stretching out of shape.

Bee brushes. Bee brushes are used mostly at extracting time to brush the bees off the combs. Two types of brushes are used. One is a whisk broom of long pliable strands, soft enough not to injure the bees. The other type is a horizontal, long-handled brush with soft bristles ap- proximately $2 \frac{1}{4} \times 8$ inches; this brush comes in both a single and double row of bristles.

Miscellaneous equipment. In assembling the equipment received knocked down (KD) from the factory, framenailing, wiring, and embedding devices will be needed. The beginner can purchase these, or can make them from the patterns used by established beekeepers.

Bee escapes, although helpful in removing surplus honey, are seldom used by the commercial beekeeper in California. He prefers to shake or brush the bees from the combs, or to drive them off by the chemical means described later. Top and entrance screens for hives are recommended if colonies are to be moved from one location to another with the greatest safety (see also the section on moving, page 50 ).

Extracting equipment consists of an extractor, an uncapping knife, a cappings box, a strainer, honey tanks, and a steam generator. Extractors vary in size from 2- to 50-frame capacity. All but the 2- or 4-frame extractors are power-driven and generally have honey pumps attached for pumping the honey from the extractor to the tanks. The 2-frame extractor is very satisfactory for a small number of colonies. A bee-tight solar wax extractor which melts the wax by the heat of the sun is a desirable piece of equipment even in a small apiary; it saves much wax that would otherwise be thrown away.

\section{How to assemble the equipment}

If the hive is to be assembled, the beginning beekeeper will need the following equipment:

One-story, 10-frame, standard dovetailed hive, complete with Hoffman selfspacing frames, metal rabbets, and nails

One or two hive bodies with frames

Two shallow extracting supers with frames (if desired instead of full-depth supers) 
Medium brood foundation, 20 sheets (wired, 3-ply, or plain)

Thin super foundation for shallow frames, 20 sheets

Tinned wire, 1/4-pound spool

Frame-wiring outfit

Spur wire embedder or an electric embedder

Queen excluder

Standard smoker

Folding wire bee veil

Hive tool

Paint

3-pound package of bees and queen or the equivalent in a natural swarm

Nailing the frames. You should find it easy to assemble the different hive bodies, tops, and bottoms. You may, however, be puzzled at first by the frames themselves. The frames should be nailed square with the aid of the frame-nailing device, which is sold by bee supply manufacturers or can be made at home.

The end bars of Hoffman frames are pierced with four holes in each for the tinned frame wire that holds the foundation in place; wiring devices are useful in placing the wire in the frames. Diagonal wires in addition to horizontal wires add greater strength to the frame; they also aid in keeping the drawn comb from stretching near the top bar. The wires should be tight enough to sing when thumbed during stringing, yet not so tight as to cut into or bend the end bars. Metal eyelets are sometimes placed in the holes to prevent wires from cutting into the wood. The frames are placed in the frame-wiring device, with the top bars next to the operator and with the cut-out portion of the top bar uppermost. Then the foundation can be fastened into the frame by nailing down the strip in the top bar without removing the frame from the device.

If a good grade of glue is used to fasten the parts of the frame together during the nailing process, a stronger frame will result even though only four nails are used for each frame. Other hive parts can be glued to advantage before being nailed. Further, instead of using metal eyelets in the holes of the end bars, you can use $3 / 16$-inch staples driven into the end bars $1 / 8$ inch from the holes before the frames are assembled. Another method of preventing wires from cutting into the end bars is to drive two or three l-inch nails through each end bar with the inner points bent so the frame wire can be fastened to the nails. Beekeepers who use this system have a gadget for driving and bending the nails at the desired angle at one operation. They also use a l-frame holding device for wiring the frames and a special device for electrically embedding the wires.

Embedding the wires. The most satisfactory way to embed wires in the foundation is to heat them by electricity until they are hot enough to sink halfway through the sheets of wax. The frame should be placed on the embedding board with the comb foundation beneath the wire. The electric current will heat the wires and cause them to sink into the foundation, at which point the contact should be broken, and the wires held in place until the melted wax congeals and fastens the wires securely in the foundation. The wires should not be too hot or held in place too long while hot or they will burn through the foundation.

The spur embedder or dry-cell battery units are used to embed wires when electric current is not available. The spur embedder is also a convenient tool when foundation is embedded electrically; with it one can fasten down portions of wire that are not properly embedded.

Wires should not be embedded when the foundation is cold; and frames containing foundation should not be stored in cold rooms, since contraction and later expansion of the wax will cause the foundation to pull loose from the wires. 
While most beekeepers use factorymade equipment, many like to construct their own beehives or hive parts. If this is done, it is desirable to secure a complete hive of standard make and to duplicate the dimensions of all parts as ac- curately as possible. Unless all dimensions are accurate, the various parts may not be interchangeable. As a consequence, the bees will build combs and add propolis in places where manipulation of the parts will be made difficult.

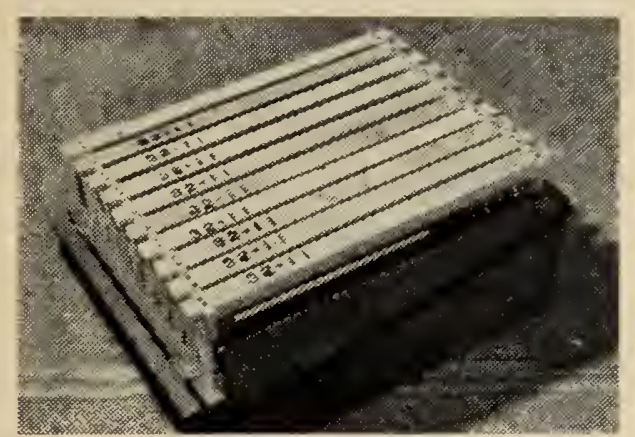

\section{EQUIPMENT YOU MAY FIND USEFUL}

One type of frame nailing device to hold the frame parts square during the nailing process.
A frame wiring device. Courtesy Diamond Match Company, Chico, California.

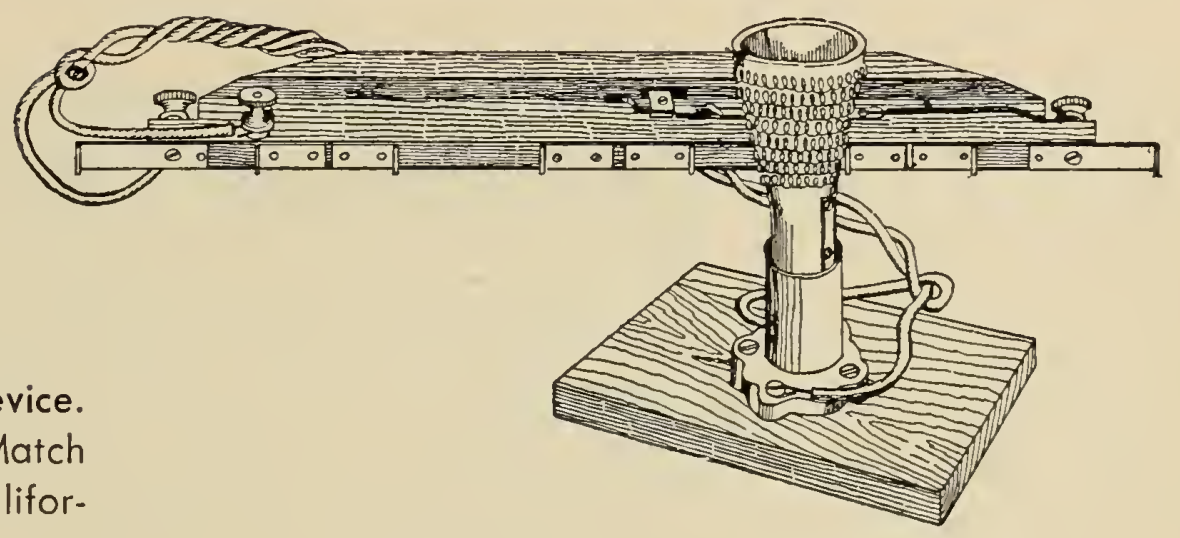

A spur embedder for pressing wires into the comb foundation. Courtesy Diamond Match Company.

An electric device for embedding wires in comb foundation, one at a time. Courtesy A. I. Root Company, Medina, Ohio.

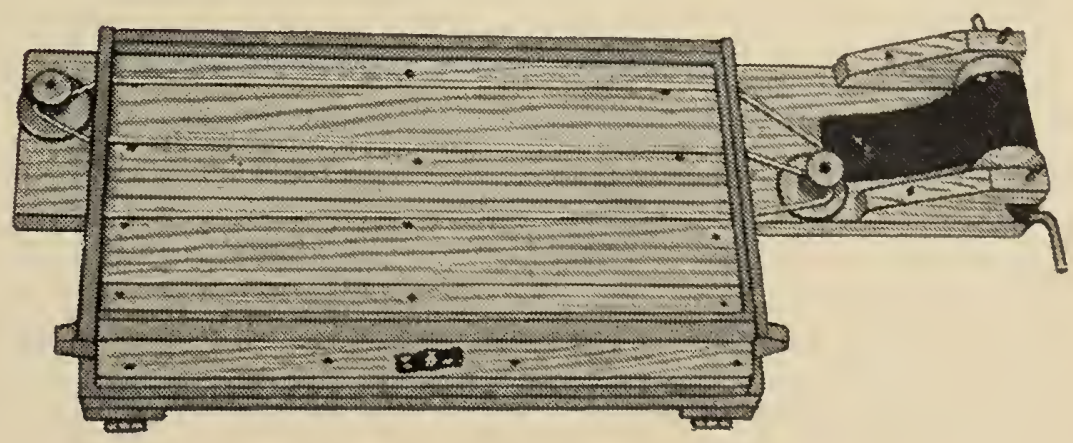




\section{THE LIFE STORY OF THE HONEYBEE . . . habits and requirements of different kinds of bees and how they act at different times of the year}

\section{RACES OF HONEYBEES}

In the United States all varieties of the honeybee belong to a single speciesApis mellifera Linnaeus. All hive bees were imported from foreign countries, the first being the German black. This variety was followed by importations of others, commonly called races since they all interbreed. The German blacks were gradually replaced by the Italian race, primarily because of its resistance to European foulbrood, its bright color, and its quieter disposition. Of the many races tried, only three have met with last- ing favor in the United States: the Italian, the Caucasian, and the Carniolan. All three races have been produced in different sections of California. At present the Italian is the most popular, the Caucasian second, and the Carniolan, because of its tendency to swarm, a weak third.

\section{Italian}

The Italian race of bees in this country is characterized by three to five bands of yellow on the abdomen. The head, most of the thorax, and the remainder of the

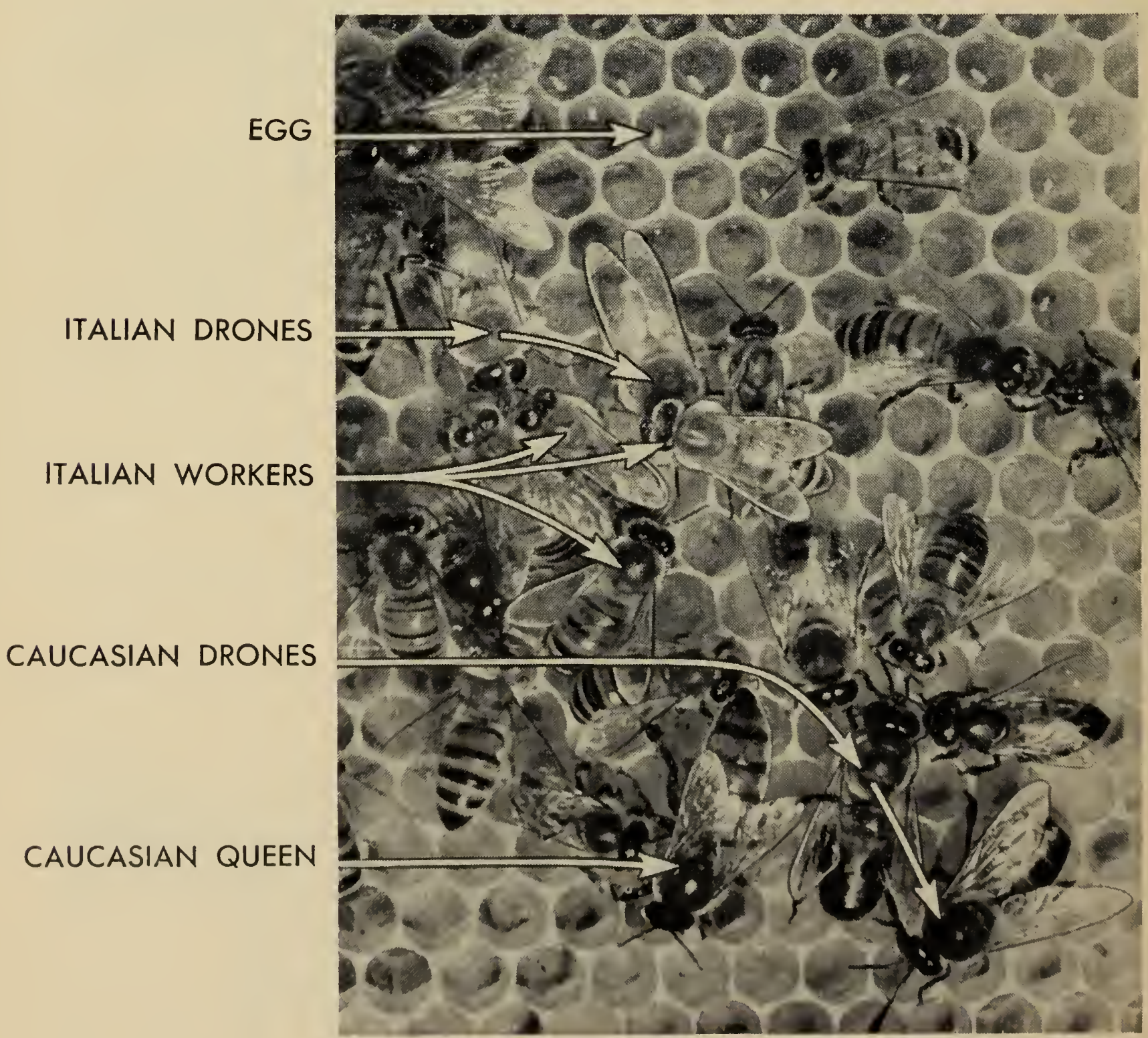

Caucasian queen with Caucasian and Italian workers and drones. 
abdomen are black, with yellowish pubescence. The darker strains of this race are commonly called leather-colored, or three-banded, Italians, while the lightercolored strains are known as five-banded, or golden, Italians. All have been so interbred that distinctive strains are not easy to find. During recent years, the trend in the selection of breeding queens has been toward the production of the lightercolored strain, although the leather-colored, or three-banded, bee is very popular. The Italian bees, which winter well, are prolific and industrious, and are usually gentle when purebred. Many strains are comparatively resistant to European foulbrood. Italian queens are easier to find than those of the darker races. First crosses between the Italian and Caucasian or the Italian and Carni- olan races, or the reciprocal crosses, are generally as desirable in behavior as the original strains; but second and third crosses are usually undesirable.

\section{Caucasian}

There are two fairly distinct strains of the Caucasian race of bees, which originated in the Caucasus region of Europe. One strain is yellow, somewhat resembling the Italian in appearance, the other black with grayish pubescence. In California the gray Caucasians are the only accepted strain of this race. Purebred Caucasians are gentle and prolific, do not swarm excessively, and winter well. They have the longest tongues of any race of honeybee. They provision their brood nests well and regulate their brood-rearing activities to suit seasonal conditions

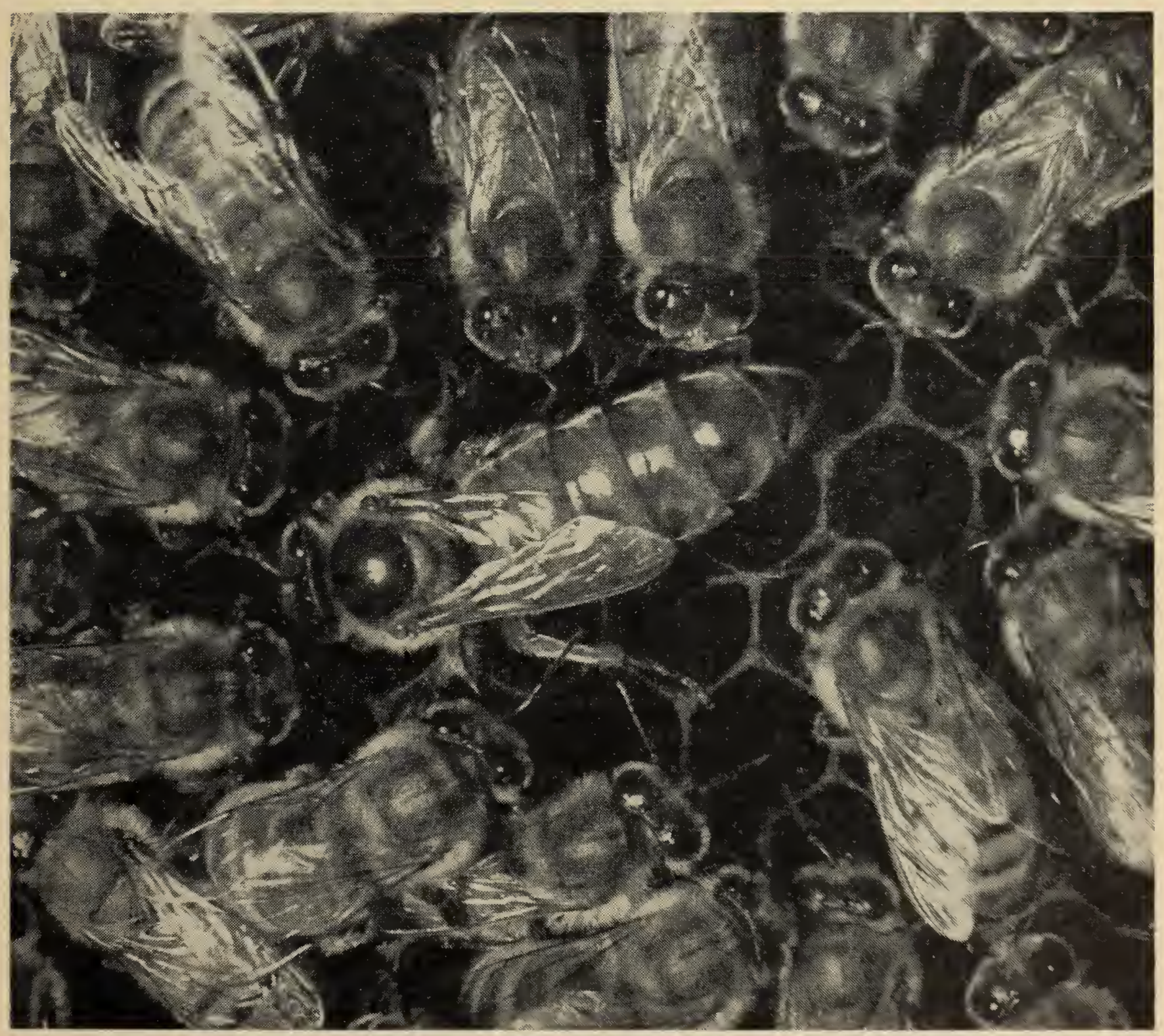

Italian queen and nurse bees. The queen has her right wings clipped. 
better than most races. They are economical in using their stores during the winter. Purebred Caucasians and their crosses with Italians have been kept successfully in regions where European foulbrood is common. Other tests have also shown that they are resistant to the disease, although possibly not to the same degree as the most resistant strains of Italians.

Caucasian bees will seldom bother the beekeeper by flying angrily in numbers about the head, as do the Italians. They will sting, however, when sufficiently provoked, and probably because their longer legs give them more leverage they seem to sting more effectively.

The greatest eriticism against the Caucasians is their tendency to build burr and bridge combs between the frames, which interfere with speed in handling combs. They also gather and use greater amounts of propolis-bee glue made of a resinous material collected by bees from plants - than do any of the other races; but this is of less consequence than the fault just mentioned. Caucasians seem to drift to other hives less often than do Italians; hence they might be less likely to spread brood diseases.

\section{Carniolan}

The Carniolan race is found in Carinthia, neighboring Carniola, and in Yugoslavia down to Dalmatia. The bees resemble, to a certain extent, the gray Caucasians. The segments of the abdomen are black, bounded by grayish rings covered with whitish pubeseence. Carniolans are the gentlest of bees. They are extremely prolific. Colony population increases rapidly in the spring, a fact that often leads to excessive swarming. This race undoubtedly builds more swarm eells than either the Italian or Caucasian.

The Carniolan-Italian eross results in an unusually prolific bee with many desirable characteristies of both races. It winters well. This cross appears some- what more resistant to the effects of buckeye poisoning (see page 73) than other strains.

\section{The best race?}

Which is the best race of honeybee? This question will always be argued among beekeepers. Probably the answer is for a beekeeper to give each race a sufficient trial to become accustomed to its special characteristics, and then to choose the one most satisfactory to him. There is a distinct advantage in having only one race in any particular location, especially if the region is suitable for commercial queen rearing.

The German black, or Holland, bees, introduced into this country some two hundred years before the Italian, are now difficult to find in most parts of the United States. The Italians were popularized for 25 years or longer before the Caucasians and met with great favor because of color and resistance to European foulbrood. The Caucasians and Carniolans have been handicapped, to a great extent, by the fact that they are black-a color wrongly associated with lack of resistance to European foulbrood.

The Carniolans cap honey cells whiter than either of the other two races, but because of their tendency to swarm they have met with less favor than the Italians or the Caucasians. Some enthusiasts elaim that the Caucasians will store more honey than other races, but this has not been conclusively demonstrated for the different sections of California.

\section{LIFE HISTORY AND HABITS}

A colony of honeybees usually consists of a queen, a few hundred drones, and several thousand workers. During the summer, when bees are busily working on flowers, the colony may consist of from 10 to 15 pounds of bces, with the drones more numerous than in early spring or fall. Each caste, or class, has special duties, but the dominating impulse of the entire colony is apparently 
to insure the survival of the species rather than that of the individual. None of the three castes can live very long through individual effort.

\section{The queen}

Under normal conditions there is only one queen to a colony and her sole duty is to lay eggs. Although she is the mother of all the bees in her colony, she is lacking in mother instinct, apparently taking no interest in her eggs or in the resultant larvae. She is in no sense a ruler but is purely an egg-laying machine. Although she resembles the worker, the queen is normally much longer than either the worker or the drone, especially during the egg-laying period when her abdomen is greatly distended. Her wings appear shorter than the worker's because of the greater proportionate length of her abdomen; her thorax is slightly larger than the worker's but smaller than the drone's. She has neither pollen baskets, functional brood food, nor wax glands. Her sting is longer than the worker's, has fewer and shorter barbs, and is curved.

The queen is fed almost entirely on a semiliquid food elaborated from pollen and honey by the young workers known as nurse bees. This food, called royal jelly, resembles that fed to very young larvae of queen, drones, and workers. The number of eggs laid by a normal queen depends largely on the amount and kind of food she receives and on a favorable temperature in the hive. The quantity and quality of this food in turn depends mostly on the environmental conditions affecting the colony. So, although the queen can lay worker or drone eggs "at will," her activities are governed by factors that affect the colony as a unit.

During a scarcity of nectar and pollen, brood rearing is retarded or may stop entirely. In most sections of California no brood will be found in normal colonies during certain periods of late fall and winter. The queen lays drone eggs in drone cells early enough in the spring and during the summer to provide adult drones by the time the colony would normally swarm, whereas few, if any, drones are reared in late fall or during a nectar shortage.

The queen is reared in a special cell that is usually suspended vertically from either the surface or the lower part of the comb. She develops from the same kind of egg as the worker; but because of the special food she is fed, she emerges in a shorter time than either the worker or the drone. The increased quantity and quality of the food received by the developing larva in the royal cell influence the development of the organs characteristic of the queen. Usually within 5 to 10 days after leaving the cell, the queen takes one or more flights and mates with a drone while in the air. She may mate more than once before starting to lay. Since she may mate with any drone flying at the time, controlled breeding is difficult. The drone dies at the time of copulation, and the queen returns to her hive. The sperms received from the drone, or drones, are stored within a special organ of the queen, called the spermatheca, from which they are released to fertilize worker eggs. As the queen ages, she

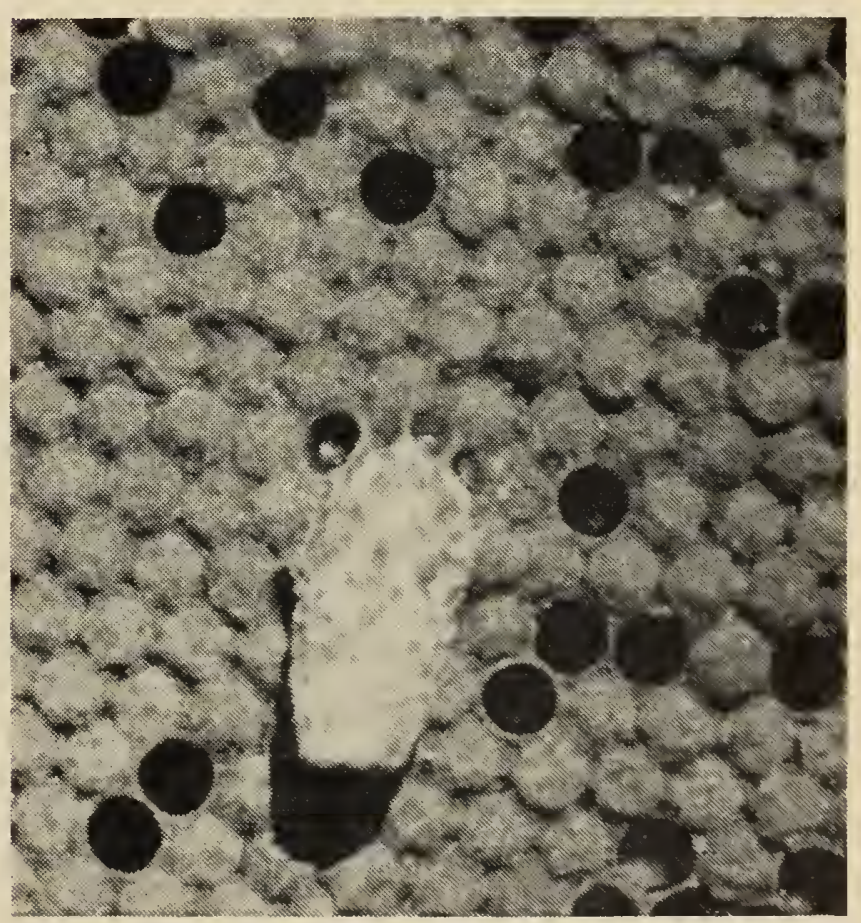

A supersedure queen cell built on the surface of a comb of brood. This is not necessarily the best type of queen cell. 
gradually depletes her supply of spermatozoa and may lay an increasing number of drone eggs. If for any reason she fails to mate, all her progeny are drones.*

When a queen shows any sign of failing, the worker bees usually begin the production of another queen to replace her and thus prolong the life of the colony. They construct one or more queen cells around larvae generally on the surface of the comb. The first new queen to emerge from her cell usually tears an opening into each of the other cells, stinging and thus killing the young queens. She then mates, starts laying, and takes over or augments the work of the old queen.

It is not uncommon for mother and daughter queens to be present in a colony for some time after a supersedure queen has been reared. In fact, failure to recognize this situation often results in the loss of a queen introduced into the colony after the old queen has been killed.

Queens will live, as a rule, from one to three or more years, although most beekeepers find it profitable to change queens every year, or at least every other year. A queen's longevity depends on the

* It has been discovered recently that in sone instances about one unfertilized egg in a thousand produces a female bee instead of a drone. amount of work she does, as well as on her vitality and other inherited characteristics. She transmits to the colony every quality exhibited by the workers and thus controls such important factors as temper, color, industry, character of comb building, and resistance to disease. It is important, therefore, to keep only good queens of the best strains. As a rule, a colony is no better than its queen. The morale of a colony is definitely influenced by the presence or absence of the queen.

Although the queen has a longer sting than the worker, she rarely uses it except in combat or in killing other queens. Instances of a beekeeper being stung by a queen are very rare. The queen does not lose her sting in killing other queens.

\section{The drone}

The drone is larger and heavier than the worker but not so long as the queen. Its large, compound eyes come together at the top of the head, while those of the queen and the worker are on the sides of the head. The drone is the only male bee in the colony and its sole function in life, apparently, is to mate with the queen. The drone has no sting, nor has it the many useful structures of the worker bee, such as pollen baskets and wax glands. Although its tongue is short and func-

Left. Mother and daughter (supersedure) queen on the same comb of brood. Both queens are laying. The mother queen has her left wings clipped and is looking into a cell. Right. Worker pupae in drone cells. The eggs were laid by a fertile queen, indicating that the size of cell does not control the sex of the bee.

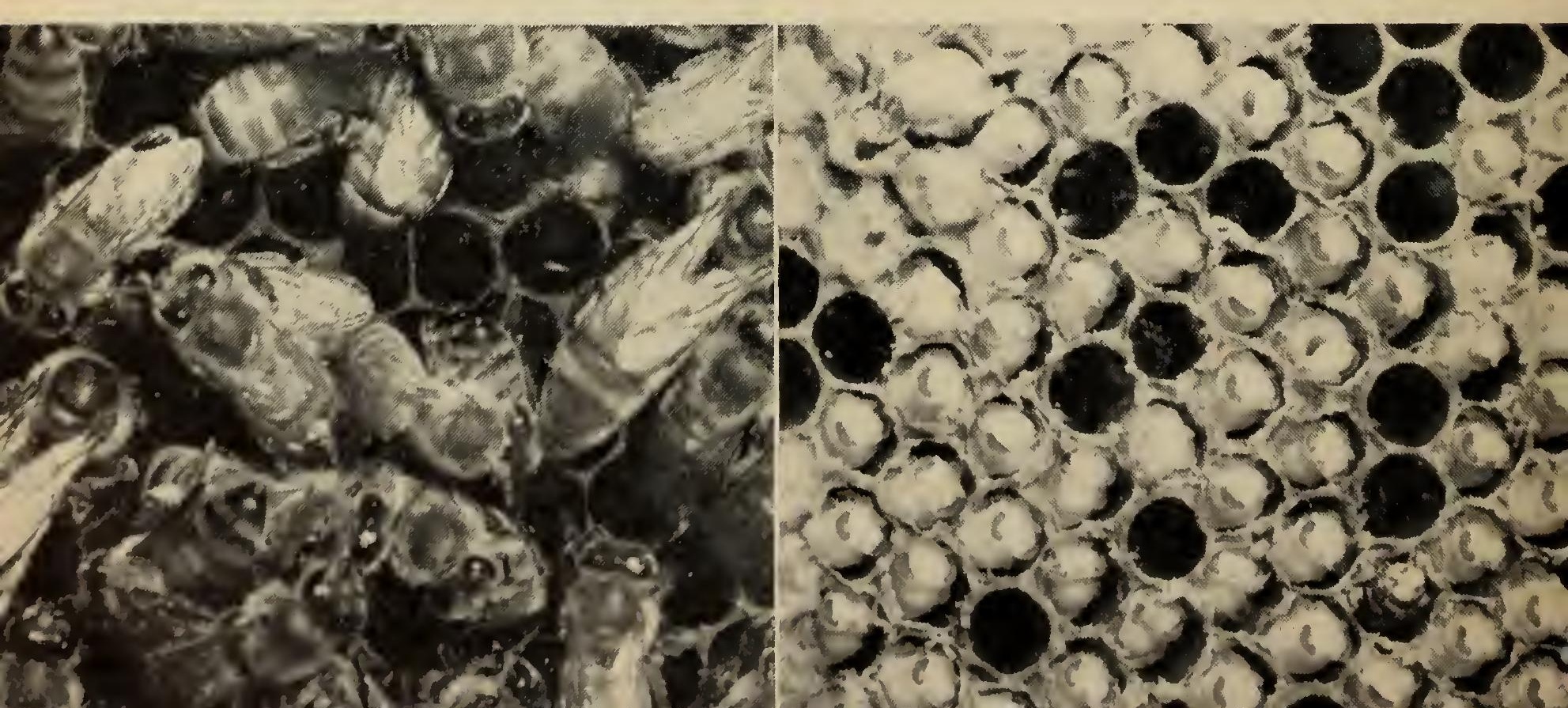




\section{Table 2. Average Number of Days in the Developmental Periods of the Honeybee}

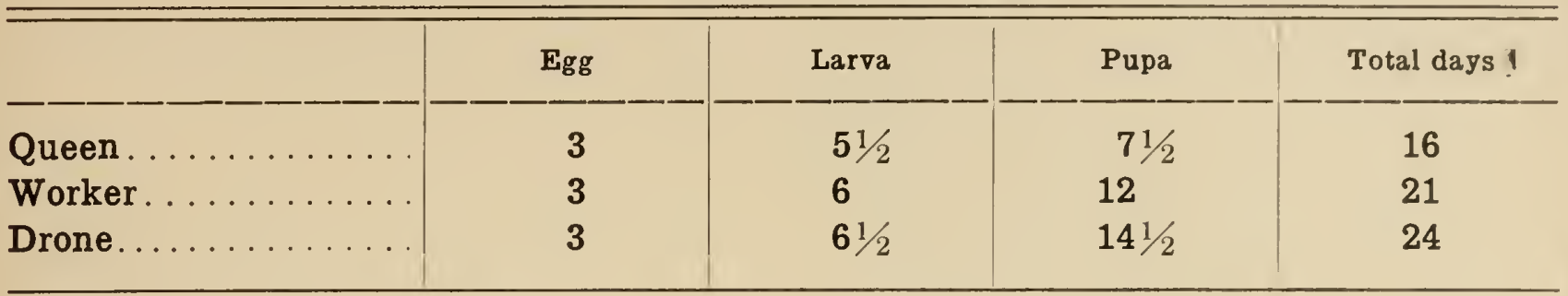

tional, the drone usually depends on being fed by the workers.

Under natural conditions, where colonies live in trees, each colony contains many drones. Domestically, however, few drones are needed or desired, since many colonies are usually kept in one place, or queens are reared and introduced in more controlled situations. During the nectar flow, the life of a drone, like that of a worker, is approximately 6 to 8 weeks. Drones may live over winter in queenless colonies.

\section{The worker}

The worker bees, although females, lack the fully developed reproductive organs of the queen. They are produced from fertilized eggs laid in worker cells, although occasionally worker bees may be produced in drone-sized cells. It takes longer to develop the worker and the drone than the queen.

The workers perform all the labor of the hive in a fairly definite routine. First, after emerging, they comb themselves and eat honey and pollen to gain strength. Then, during successive periods, they clean out the cells, feed the older larvae, then the younger larvae, take orientation flights, clean the hive, evaporate nectar, build comb, and act as sentinels and ventilators. Finally, they engage in the field duties of carrying water, pollen, nectar, and propolis. They also serve as scout bees in finding these materials and

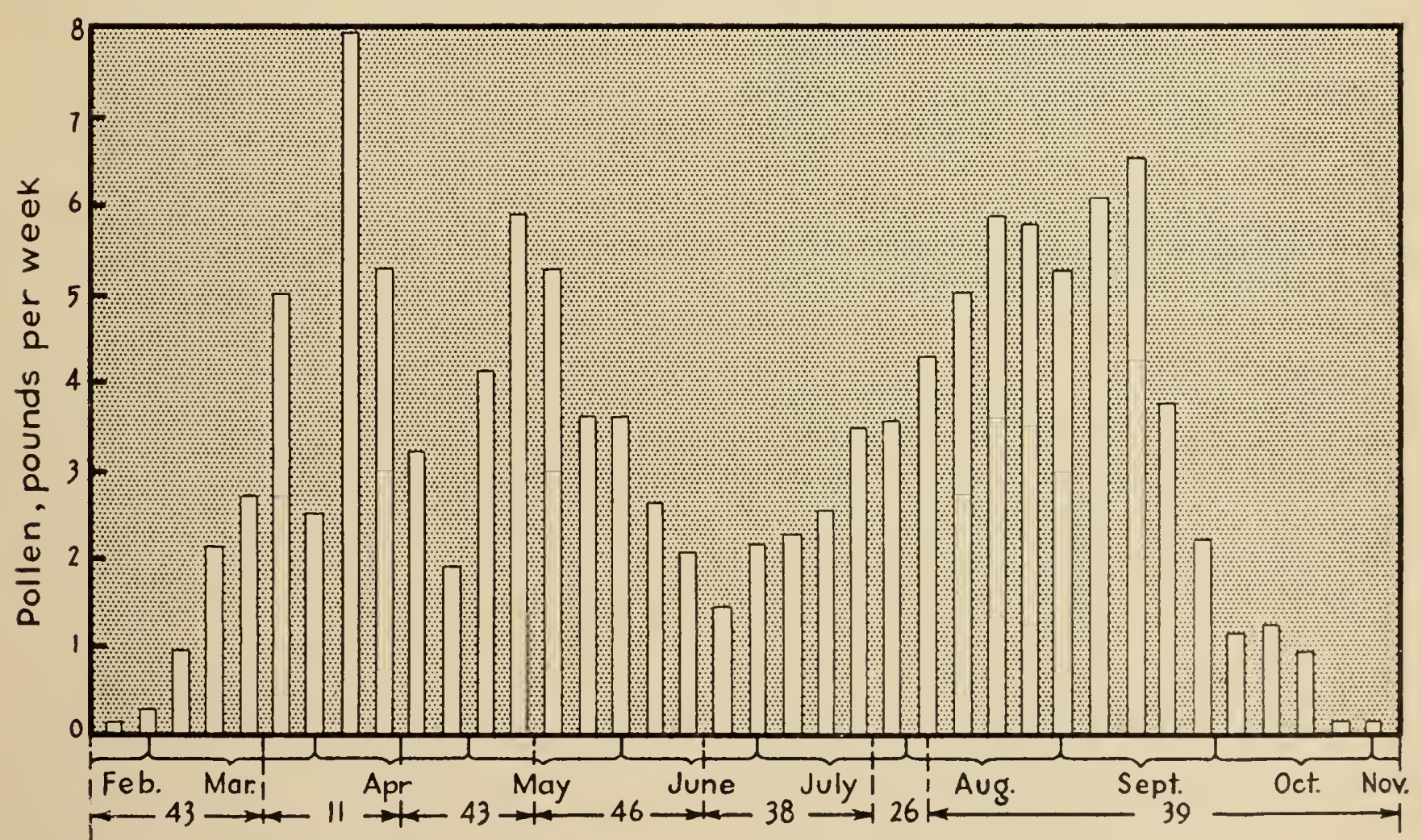

A record of the number of pounds of pollen collected by a normal colony during continuous periods at Davis in 1940. 
in locating a future home site for the swarm. When necessary, the worker bees may perform various functions as the need arises after their various glands develop and at varying ages. Their normal life period, which depends on the amount of work they do, generally lasts for 6 to 8 weeks during the seasons of active flight. In winter, when they are less active, they may live for several months. Usually enough workers survive to carry on in the spring until others have been reared to take their places.

\section{Food requirements}

Honeybees get their natural food materials from pollen, nectar, and water. The pollen provides the bee with the protein that is absolutely essential to the growth of the larvae, and nectar provides the carbohydrates. Both pollen and nectar provide minerals and other substances essential to the bee's diet. Worker bees can live on honey or on syrup made from beet or cane sugar and apparently require little pollen except to rear the brood. The nurse bees, on the other hand, who elaborate the very rich food, royal jelly, which is fed to all larvae under 2 days of age and to queen larvae during the entire feeding period, need honey, pollen, and water. When the worker and drone larvae are 2 days old, they receive coarser food consisting of honey and pollen mixed with the brood food secreted by the food glands located in the head of the nurse bees and always in less quantity than is fed to larvae in queen cells.

The amount of food required by a colony during the year is difficult to determine; estimates of 170 to 300 pounds of honey a year have been made. It is generally agreed that a frame of honey and one of pollen are needed for every frame of brood produced. The amount of pollen needed to rear an adult bee has been estimated at $0.1449 \mathrm{gram}$ (about one and one-half times the weight of a young field bec); or 9.58 pounds of pollen a month for each colony if a queen averages 1,000 eggs daily. In California, for the best interests of the colony a surplus of 20 to 30 pounds of honey and pollen should be present in the hives at all times.

\section{Arrangement of the colony nest}

If at the beginning of a nectar flow a 3 -pound package of bees is properly installed in a single-story hive on frames of foundation, it should be examined after 10 days or 2 weeks. Where normal development has taken place, many frames will be filled with comb containing brood, pollen, and honey. The brood should be in a compact arrangement in three or four frames, with pollen in cells next to the brood, while the honey will be stored above the pollen. As time goes on, all the foundation will be built into combs and the pollen will be concentrated, for the most part, in the outside combs of the brood chamber. Young worker bees will cut their way out of their cells 21 days after the first eggs are laid. After the cells have been polished by the hive bees, the queen will deposit eggs in them. In this way you may see in the same frame two or more cycles of brood, ranging from eggs to emerging bees.

A good queen will keep her brood in compact arrangement and, if given wellbuilt combs, will have very few empty cells among the brood. The eggs are attached by the queen to the bottom of each cell and extend upward. The pearly white larvae that hatch remain coiled in the bottom of the cell until they have finished the feeding stage. Then they extend lengthwise of the cell and are sealed in by the worker bees with a finely porous capping of wax. The larvae line their cells with a silken cocoon and change to pupae.

In a new comb, capped brood cells are a light straw yellow; they become darker, however, as more generations are reared in the cells. The cappings of honey cells are normally white. They may become travel-stained with propolis and pollen, 
or tı. . lay look water-soaked if the cappings touch the honey beneath. Pollen cells are usually only partially filledhence are seldom sealed. Sometimes, however, they are f.Jed with honey and are then sealed so that on the surface they look like cells of honey.

When a colony is established in a 2story hive without a queen excluder, the brood nest may extend into the second story and include brood in ten or more frames. If the space for brood rearing is limited to one or two stories, some frames may be entirely filled with brood, the honey and pollen being crowded to the outside combs. If the brood nest occurs in the second story only-as often happens in early spring in a colony wintered in two stories-much of the pollen will be stored in the lower hive body.

The walls of the cells thicken somewhat with age. The silken cocoons are so thin, however, and the cells are so thoroughly cleaned and polished each time after a bee emerges that the brood combs can be used for many years without any noticeable effect on the size of the bees produced in them. Old brood combs are very dark-almost black-and are considerably heavier in the midrib than newly built combs. Although darkened with use, the cells are clean and do not add color to honey stored in them.

The drone cells are usually confined to the lower corners of the frames if full sheets of foundation are used, or to parts of the combs that have been stretched or injured. Sometimes beginners attempt to economize by using only half-sheets of foundation. This is false economy since many cells in the resulting combs will be drone cells.

From top to bottom. A comb of worker brood with some drone cells in the lower left-hand corner and a sealed queen cell in the lower right-hand corner. A comb showing the typical arrangement of pollen next to the brood and honey above. A portion of comb containing only pollen; the cells are only partly filled by the bees.
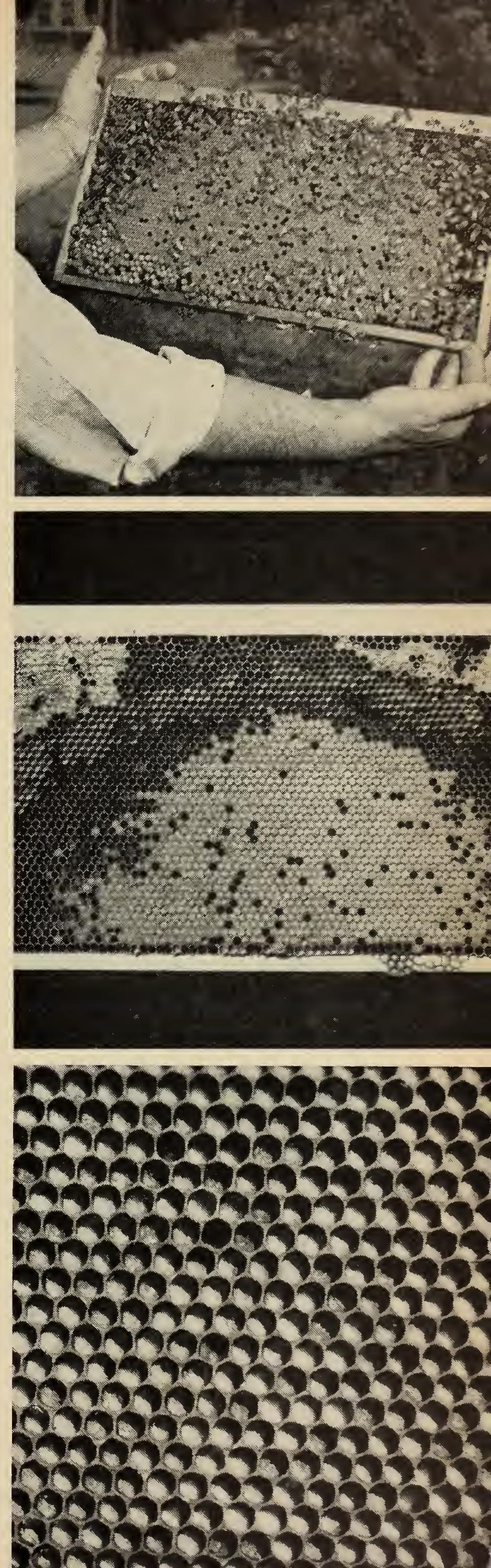
When queen excluders are used to confine the queen to the lower part of the hive, only a small amount of pollen is carried above the excluder into the super combs unless frames of brood are transferred from the brood chamber to the super. Pollen in the supers is not objectionable unless comb honey is produced in sections or in shallow frames. Normally, surplus honey is stored above the brood.

\section{The cycle of the year}

The various activities of a colony throughout the year are known as the cycle of the year. In describing the development of a colony or in observing its activities, we may begin the cycle at any season. It is most interesting, however, to begin in the spring, when activities are getting under way after the winter period.

If a colony has enough pollen and honey, brood rearing may begin in the center of the bee cluster some weeks before the first spring flowers are in bloom. This constitutes a heavy drain on the pollen supply, and brood rearing will be retarded later if the supply is not replenished from fresh sources.

With the opening of the first flowers,

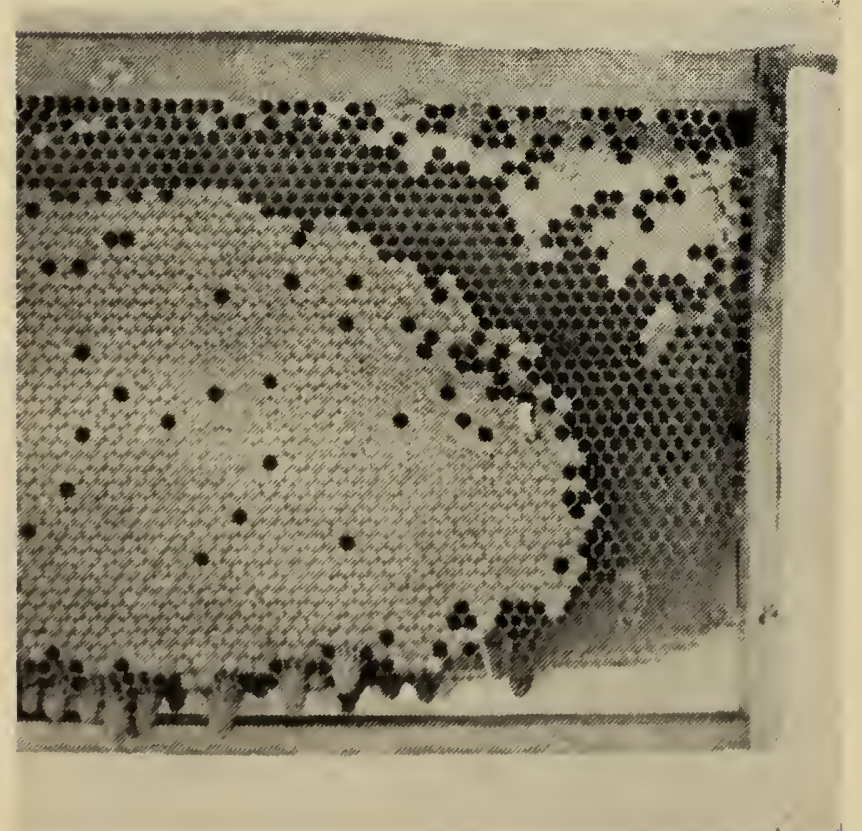

A portion of a comb of brood with many sealed queen cells, three of which have been cut open to show their contents. the bees will eagerly seek what pollen and nectar they can find. They will also carry water to mix with the honey in making the larval food. The first pollen and nectar of the year greatly stimulate brood rearing. The young bees usually increase faster than the old bees die off, so that the population of the colony gradually increases. If the brood chamber becomes crowded by the production of more brood and honey, preparations will be made to divide the colony naturally by swarming. Queen cells will be built along the bottoms and sides of the brood combs-many more than are needed to assure production of the queen destined to become the mother of the colony after the swarm and the old queen leave.

Some days before the swarm is to issue, interesting developments other than the building of queen cells will take place. The nurse bees feed the queen less and she gradually tapers off in the number of eggs she lays; this reduces her weight for flying. Scout bees go out and actively seek a place in which the swarm can locate and build a new home. More workers will remain in the hive, so that the colony begins to loaf, and many bees may cluster on the front of the hive. When the hive is on a stand above the ground, the clustering bees may form a beard below the entrance, or if the hive rests on the ground, the bees may gather on the front or shady side of the hive.

Then, at any time after the first queen cells are sealed, or even earlier, the majority of the field bees and many hive bees that are able to fly will sally forth with a great whirl and roar. The air in the immediate vicinity of the hive will be filled with excited, swirling, happy bees, creating a high-pitched swarm tone which, once heard, is seldom forgotten. After a few minutes of flying, small groups of bees will begin to cluster here and there; finally all will form a large cluster in one place.

Hammering on pots and pans will not induce swarming bees to cluster; in fact, 


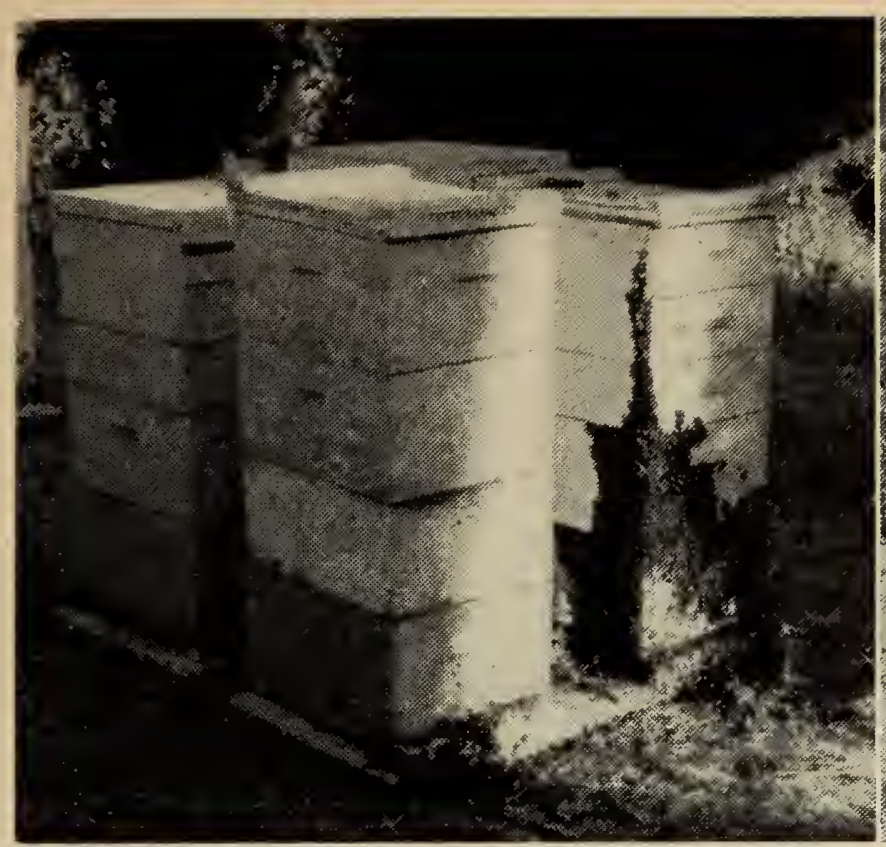

Bees clustering out because of crowded conditions within the hive or in preparation for

the bees are in no way affected by such mechanical din. After the swarm has clustered, it can be shaken into a box or otherwise carried to a hive and allowed to run into its new home. If the queen's wings have been clipped, she may be found on the ground in front of the hive from which she came. After a few minutes of clustering, the swarm will return to its old home. If the queen is with the swarm, the bees will hang in the cluster for a few minutes to an hour or more before taking wing again, then will fly directly to their new home in one continuous flight. In some instances a swarm will remain clustered overnight or will even build combs at the point of clustering. Such open-air colonies produce large clusters of combs and, where the winter conditions are not too severe, may live thus for more than one season.

The hive from which the swarm has gone will contain many frames of brood, a fair population of bees, and several queen cells in different stages of development. Some of the cells may be ripe, with the queens ready to emerge. The first queen to leave her cell often will go to the other queen cells, tear a little hole in the side of each, and sting the inmates. The worker bees will then tear the queen cells down, drag forth the dead queens, and

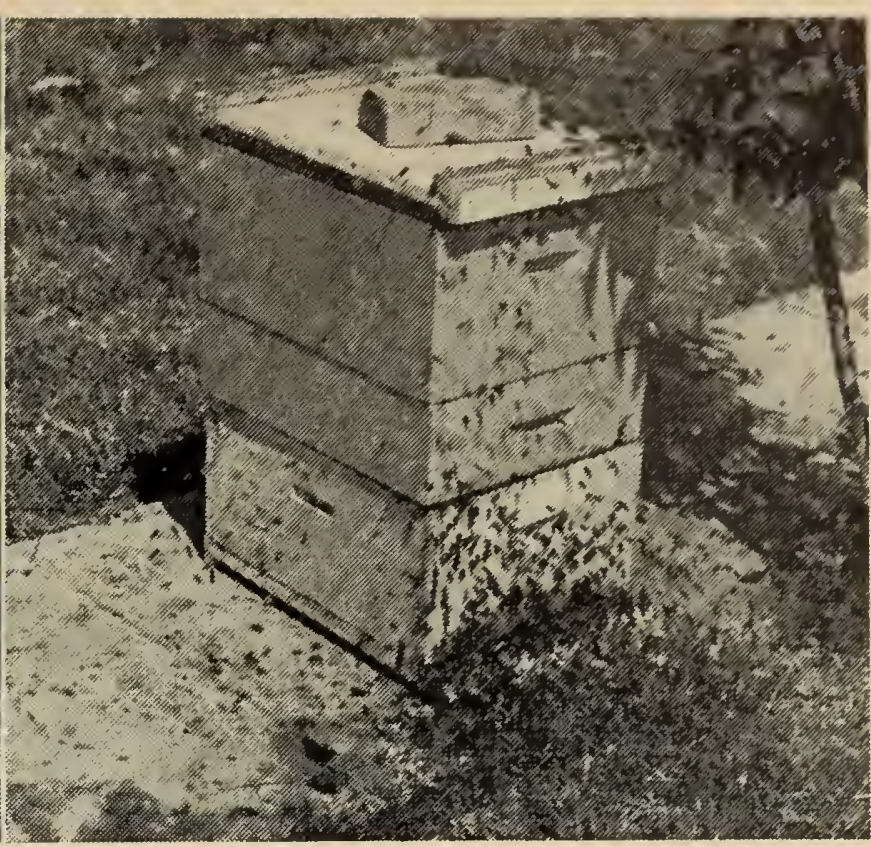

swarming; and at right, bees emerging from a hive at the time of swarming.

carry them from the hive. If a second swarm is to be cast, some of the queen cells will be protected from the wrath of the newly emerged queen by the worker bees clustering around the cells. When this happens, a secondary swarm will follow the first within a few days. If the laying queen's wings have been clipped and the colony persists in swarming, she will finally disappear and one or more young queens will emerge with the primary swarm. If no secondary swarm results and the new queen successfully

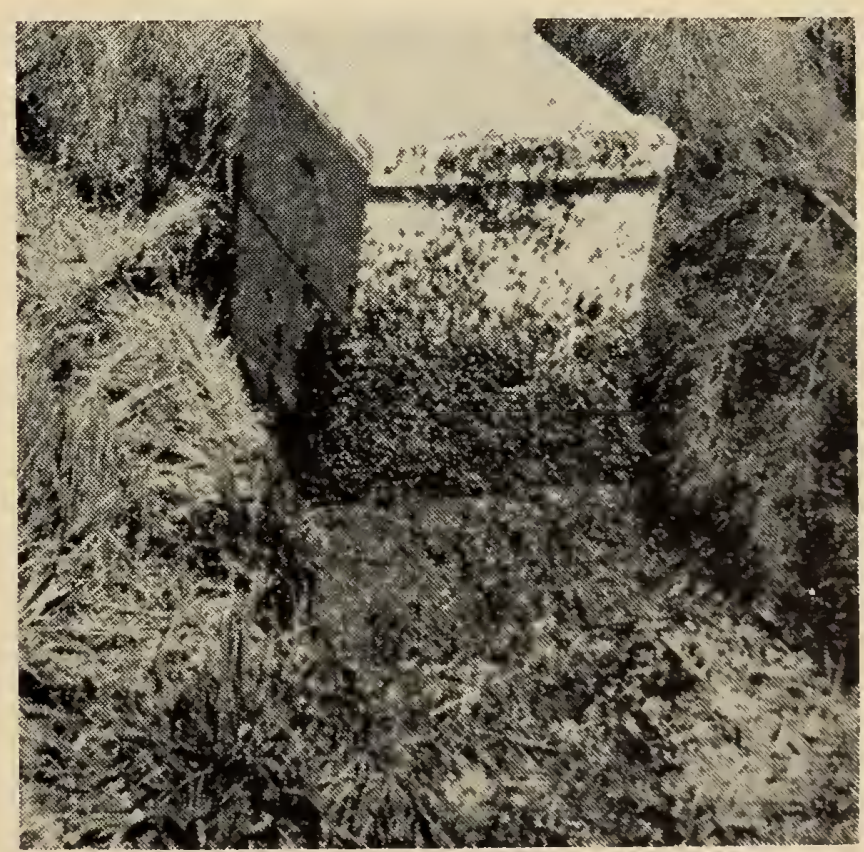

A swarm entering a hive after being shaken from a branch. 


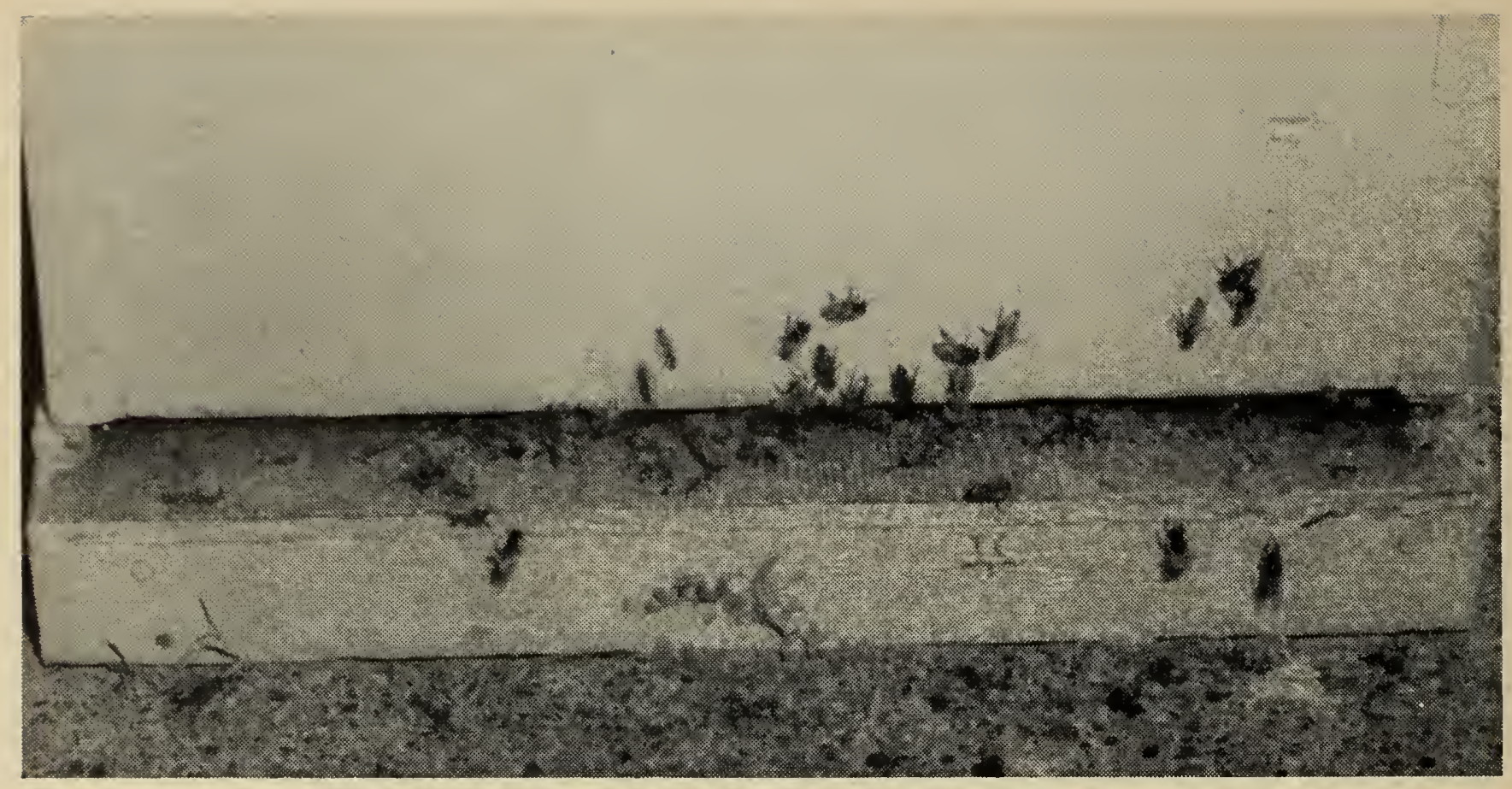

Drones being driven from a hive in the fall of the year.

mates, the population of the colony will soon be built up by the emerging brood, and work will continue as usual. As long as nectar is available it will be gathered as surplus if sufficient storage space is provided.

Toward the close of the nectar flow, the drones will be starved and driven out by the worker bees. This action of the colony is sure evidence of the end of the nectar flow. More bees will also seek watering places, since they will no longer have the excess moisture from the evaporation of nectar for their needs in brood rearing and in cooling the hive. Morc of the honey will be stored in the brood nest, and some already in the supers may be carricd down and stored in the brood combs. This trait is particularly characteristic of the Caucasian bee in the fall.

Somctimes during the active period, instead of building swarm cells, the colony will build only one or two queen cells, and thesc will usually be found on the surface of the combs. This indicates that the qucen is failing and that the becs arc starting to producc a new, or superscdure, queen to take her placc. Under such conditions the young quecn may emerge, mate, and begin to produce eggs while the old queen is still in the hive. The old queen may even continue to serve for several weeks. Sometimes in early spring both old and young queens are found in the same brood area of a colony. (See illustration, page 22.)

With the approach of fall, brood rearing is generally brought to a close. Many old bees die, and the colony gradually dwindles from a great strength of 60,000 or more bees to about one-third that number. This reduction is gradual, extending over several weeks. The worker bees carry an increasing amount of propolis to make their hives tight for the adverse season, which they evidently sense approaching. Caucasian bees generally stop brood-rearing activities before Italians and often reduce the size of the hive entrance and any other openings with larger amounts of propolis.

As the days grow colder, the bees become less active. Instead of hibernating, as most insects do, howcver, they gather closc together to form a tight cluster whenever the temperature of the air around them falls below $57^{\circ} \mathrm{F}$. If the temperature drops below this critical point, the bees gather still closer together. Through the insulating value of the cluster and the combs of wax, as well as the activity of the becs, the tempera- 
ture within the cluster gradually rises until at no point is it below $57^{\circ} \mathrm{F}$. The cluster is generally formed on combs containing some honey, and as the honey is used up the bees gradually move to other stores. In many places in California, bees are seldom confined to their hives for more than a few days at a time in the winter; for this reason, densely compacted clusters are formed only during the colder periods. Winter activity, however, may tend to shorten the lives of the workers and to reduce the strength of the colony. This is especially true in regions where bees work on the eucalyptus bloom or on other winter-blooming plants when the temperature is below the critical point for the bee.

\section{Communication among bees}

The duties of the worker bees include a search for new sources of nectar, pollen, water, and propolis and location of a new home for the colony at swarming time. The bees that engage in such activities are known as scout bees. The manner in which they communicate this information to the members of their colony was not known until Dr. Karl von Frisch published the results of his studies concerning the language of bees.

Dr. von Frisch demonstrated that the scout bees perform two types of dances in order to convey information they find as to food sources-a so-called "round dance" and a "tail-wagging dance." (These dances can be observed by anyone through the glass sides of an ob. servation hive.) When colonies are moved into a location in which they have not worked previously, scout bees and field bees take orientation flights to mark their hives and then seek sources of nectar, pollen, and water. As soon as bees find such food materials they mark the location and return to their hives and engage in one or the other of these dances on the combs of the brood chamber. If the food material is located within 50 to 100 yards of the hive, the dancing bee circles in a narrow space, first to the left and then to the right in the form of a figure 8 , with its head toward the center of the figure. The greater the amount of food available, the greater will be the number of bees engaged in the dances.

It is believed that a large number of bees will concentrate their efforts in the near vicinity of their hive for a time, gradually extending their activities as information is imparted by scout bees of new sources at greater distances. This is highly important to the management of colonies in the pollination of various crops.

When the source of supply is located beyond the 50- to 100-yard range, the returning scout bees engage in a tailwagging dance in which the bee first turns rapidly in a half circle, then moves in a given direction for a short distance, and then circles in the opposite direction, actively wagging its abdomen while traveling in the straight line. Thousands of observations have indicated that the distance of the food source from the hive is related directly to the number of turns in the wagging dance that are made in a given time. The direction the scout bees had to fly is denoted by the straight portion of the dance, which is at the same angle to the force of gravity as they have flown with respect to the sun during the flight from hive to feeding place. If the dancer heads directly upward during the straight part of her dance on the honeycomb, it means that the feeding place is in the same direction as the sun; if the straight line is downward toward the bottom of the comb, the direction is away from the sun. If the bee had to fly to the right or left of the sun to reach the feeding place, the straight line will be at the same angle to the right or left, according to her flight. If the comb is held horizontally, the dancing bee will make the straight line in the same direction as she had to fly. (For further information on the language of bees, consult the reference list, page 86. ) 


\section{Fidelity of bees}

\section{to food sources}

Once a worker bee locates a food source on information provided by the scout bees or by herself, she will continue to fly to the same source as long as the material being gathered is available. She will seldom work more than one plant source on any one trip and will continue to work the same source as long as it produces. We do not know why bees distribute themselves over a given territory or why they may fly over many acres of the same blooming plant to work in a given field farther away, but we do know that this behavior is of great importance in the pollination of specific varieties of fruits, vegetables, and field crops. For example, two varieties of alfalfa may be grown for seed within a hundred yards or so of each other without much danger of any bees visiting both of the fields on any one trip or even on successive trips. Individual bees may confine their pollen- or nectar-gathering activities to only one or two fruit trees in an orchard; this indicates the necessity of having compatible varieties interplanted rather closely in order to effect the needed cross-pollination of the fruit blossoms.

\section{MANIPULATION OF THE HIVE ... the actual operations used in care of the bee colony and especially the handling of the queen}

\section{Preparations to make}

Handling bees is neither difficult nor 'angerous if reasonable precautions are taken. The veil should be securely arranged to protect the head and neck, and the bee suit or clothing to protect the ankles and body. If the bees are exceptionally cross, the beginner should use gloves, but he will probably soon discard them as being too clumsy. The smoker should be well lighted and smoldering properly. Although burlap sacking is probably the most common fuel used, rotten wood or shavings, excelsior, and cotton waste are usable.

\section{Opening the hive}

After all preparations have been made, approach a hive from the side-keeping out of the line of flight-and blow a puff or two of smoke into the hive entrance to disorganize the guards and distract the attention of the bees from the disturbance. Then pry up the cover and, before removing it entirely, blow a little smoke across the frames. If the bees still tend to fly out aggressively, puff more smoke down between the frames, then replace the cover for a few seconds. Use no more smoke than is necessary to subdue the bees. The beginner often uses so much smoke that a colony may be too disorganized to resume productive labor for hours.

Bees seal the frames together with propolis at every point of contact. Therefore, insert the hive tool between the outside frame and the hive wall to pry the frame toward the center, then loosen it from the next frame by prying it back again before trying to remove it. This frame should be set on end outside, against the opposite side of the hive, to facilitate the removal of the other frames. The frames should be held in vertical position when the comb is examinedpreferably so that sunshine or strong light will fall on the part being inspected. To examine the opposite side of the comb, lower one end of the frame and pivot it on the top bar, keeping the frame in a vertical position. Unless this precaution is taken, new combs may become rather plastic and stretch in hot weather. The 
combs can be withdrawn more readily when only nine frames are equally spaced instead of the usual number of ten.

From time to time during the examination of a hive it may be necessary to puff a little smoke across the frames to keep the bees in a state of subjection. Avoid jerky or nervous movements, and do not jolt or jar the hive. Replace the frames in the original position unless the condition of the colony can be improved by making a change. A frame should never be dropped into a hive, but should be set in without a jar and without killing any bees. Injured bees emit poison, the odor of which often causes other bees to sting. The safety of the queen should be always kept in mind. She is often injured by careless handling of frames. It is not good practice to set the frame containing the queen on the outside of the hive. If this is necessary, set out two frames with the queen on the inside surface.

Since the climate greatly influences the bees' temper, do not open the hive except under favorable conditions. If the day is warm, the bees usually will be less inclined to sting. A good nectar flow also improves their temper and simplifies the beekeeper's work. It gives the field bees and the house bees something to do; and busy bees are more contented than idle ones. A nectar flow also forestalls the danger of robbing. Avoid opening the hive when the temperature is so low that it will chill brood, or when it is much higher than that of the normal brood nest $-92^{\circ}$ to $95^{\circ} \mathrm{F}$. The experienced beekeeper can generally determine the condition of a colony by glancing at one or two combs, or by tilting a super to glance at the bottom of the combs and the top bars of the hive body beneath. This practice greatly reduces the time the hive is kept open. In order to become acquainted with bee behavior, the beginner should examine his colonies frequently. Nevertheless, hives ordinarily need not be opened except to provide enough room for brood rearing, to de- termine nectar storage, or to improve the general welfare of the colony. Periodic inspections for disease should be made, but these can be arranged in conjunction with other hive-tending practices. (See bee diseases, page 61.)

The results of each examination should be recorded, especially by the beginner, either on a special place on the hive itself or in a notebook. Such information, properly dated, becomes invaluable in correcting errors and in outlining future work. To save time, the experienced beekeeper ordinarily uses abbreviations and symbols in making records, such as Q- for queenless, Qcl for queen cell, VQ for virgin queen, LQ for laying queen, $\mathrm{SU}$ for super, etc.

\section{Care of the queen}

The welfare of a colony depends to a great extent on the excellence of the queen and on her care. Good queens may be injured or killed through the careless manipulation of frames or through faulty introduction in a colony. The queen breeder's responsibility should not be taken lightly. Since the queen is almost as important to a colony as the foundation is to a house, her value should be remembered whenever a hive is opened. Actually, success in beekeeping is largely dependent on the queen.

Finding the queen. Many beekeepers waste too much time in trying to find the queen in a hive. It is more important to recognize the work of a good queen than to find her on the combs. A proper amount of brood in all stages for the season, regularly placed in the combs, indicates that she is functioning properly. The colony then need not be disturbed further than by an examination of one or two frames of brood. But if the queen must be found, the hive should be opened as gently as possible and with no more smoke than necessary. If there is likely to be brood in two stories, the upper story should be set off on the cover and the lower chamber examined first. 
Carefully remove the outside frame and lean it against the opposite side of the hive. Then quickly examine one frame after another. As each frame is removed, glance at the surface of the next comb for the queen. Examine very carefully each comb that contains eggs, for the queen will usually be on or near such a comb. If there are no eggs or young larvae in the chamber, the queen will be in the second story. Examine the frames in the second story before setting it back on the first. If the hive is jarred, or if too much smoke is used, the queen may hide, or she may run to the sides of the hive or to the bottom board, where she will be very difficult to find. As a last resort, shake the bees into a hive body and force them with smoke to run through a queen excluder into the story below. The queen then will be found on the excluder.

Handling the queen. If a queen is to be marked, clipped, or lifted from the comb, she should be picked up by the wings with the thumb and forefinger, without any pressure on her abdomen. If her wings are to be clipped, she should be transferred to the forefinger of the other hand, and at least two of her legs on one side grasped between that finger and the thumb and held firmly but not too tightly. The queen will not sting when so handled. Reports of beekeepers being stung by queens are exceedingly rare. While held in this position, the queen can be marked and her wings clipped. The beginner may well practice on drones before clipping or marking his first queen.

It is necessary to clip the queen's wings on only one side. Use a fine pair of scissors to do this. Clip the wings at about one-half their length. Do not snip too close, and do not mutilate a leg in clipping. If the left wings of the present queen are clipped one year and the right wings of a new queen the next year, it will aid in telling the year in which the queen was produced.

A queen marked with a spot of bright yellow or vermilion on the top of her thorax is much easier to find than an unmarked queen, especially if she is a dark Italian, Carniolan, or Caucasian. Use a quick-drying paint. Automobile lacquer or fingernail polish is an effective pigment to use in marking queens.

The queen can be run into a mailing cage without being caught. This is done by gradually herding her between the thumb and forefinger into the opening of the queen cage, which is placed next to the comb in front of her. When a queen has been confined to a mailing cage for some days, she is much smaller than when she is laying regularly and may fly readily if permitted.

Introducing the queen. Until you have had enough experience with bees to know how to rear your own queens, buy them from established queen breeders. Queens are generally listed as tested or untested. No reliable breeder will knowingly sell a poor or an unmated queen; his reputation would be injured. This is why most queens are satisfactory even though they may fall into the untested class.

Colonies can be requeened at any time if proper precautions are taken to meet seasonal conditions, but most beekeepers introduce queens near the close of a nectar flow or in the spring. As requeening can be combined with swarm control, usually the best time to requeen is during the spring nectar flow. If the spring season is short, with little time for the colony to build up for the main nectar flow-as in the citrus regions of southern California-queens can be introduced after the orange-nectar flow or in the fall.

Colonies should be made queenless at least a few hours before the new queen is introduced. This causes the colony to realize its condition and accept a queen more readily. It is best to introduce the queen before queen cells are started, or at least to tear down all queen cells at the time of introduction. Dequeening and requeening are often accomplished 
at the same operation. The old queen may be set aside in a nucleus or placed, without attendants, in a cage between frames of brood above an excluder of some other colony until the new queen has started to lay. If the new queen is killed at introduction, the old queen can be reintroduced in the regular way and kept until another is brought in.

Although there are several ways of in-

\section{INTRODUCING THE QUEEN}

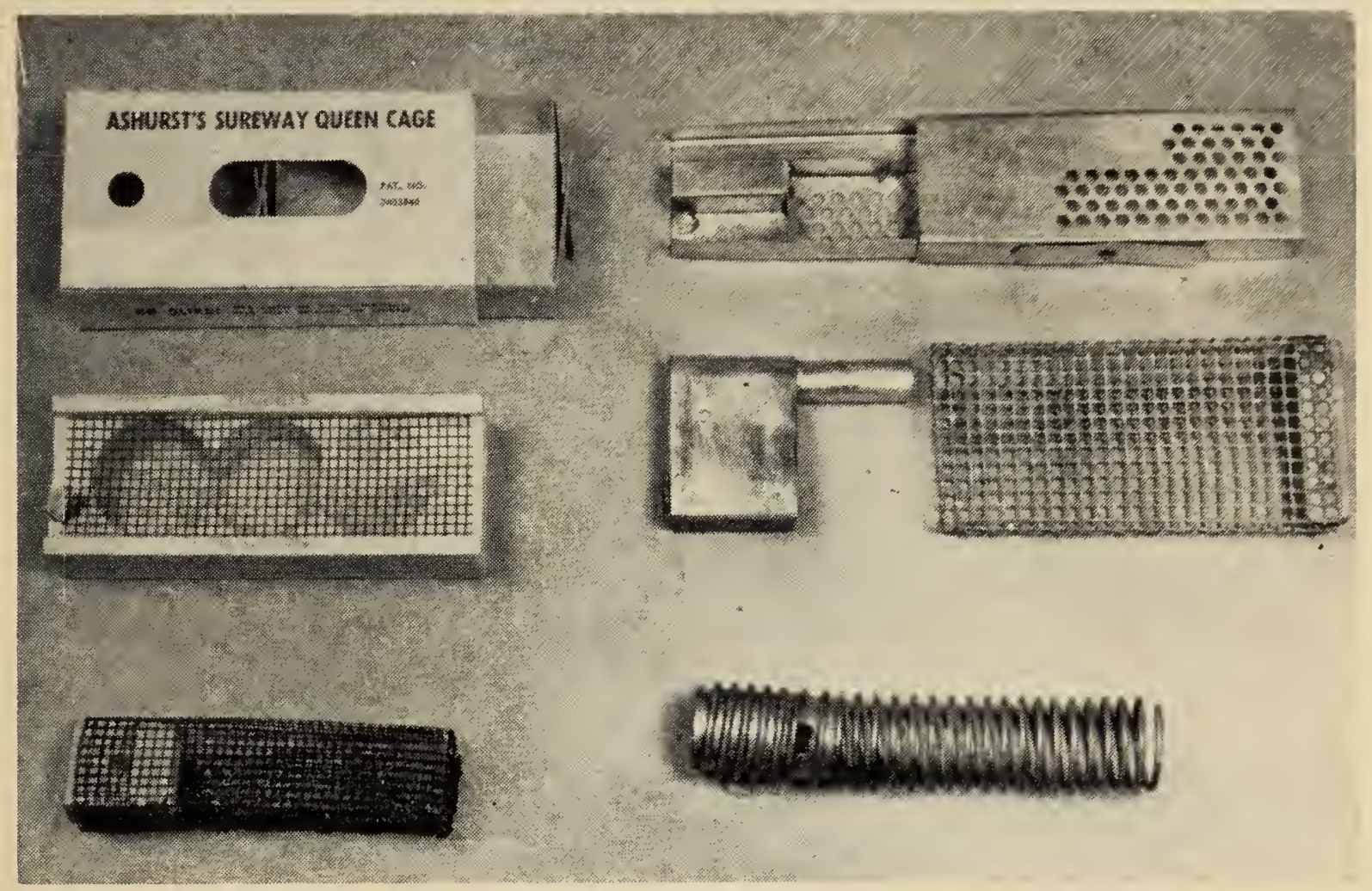

Types of cages used in the introduction of queens.

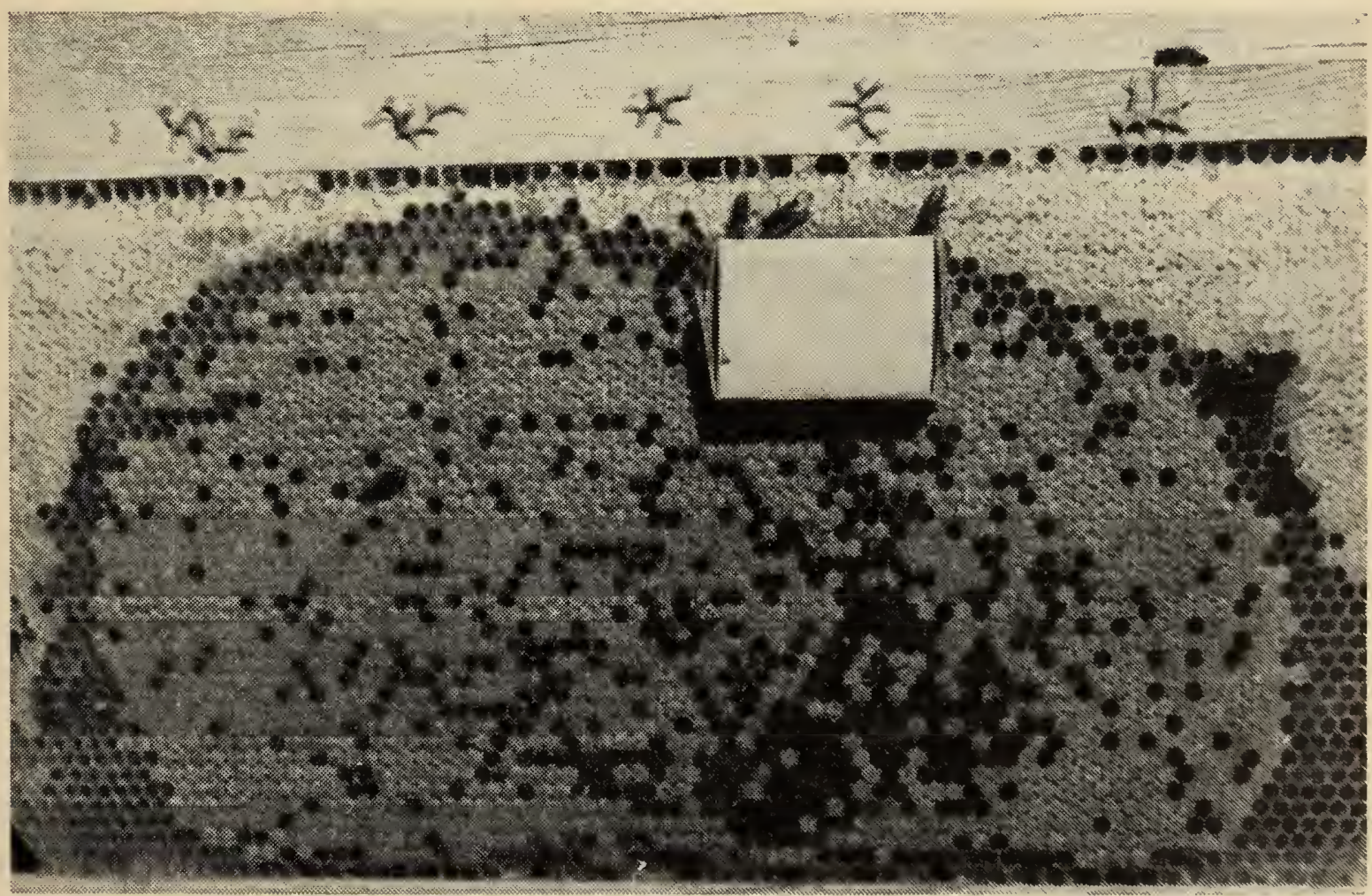

Introducing a queen by means of the paper cage. 
troducing a queen, it is most often done by means of the mailing cage. This usually has three compartments; one is filled with soft candy, which also fills a hole leading into the compartment from the outside. This hole is further covered with a small piece of pasteboard or a plug of soft paper. Take the address card from the top of the cage, but leave in place the paper that covers the opening in the candy end of the cage. If the colony is small, this paper obstruction may be safely removed.

The cage can then be placed in the queenless hive so that the bees are able to feed the queen through the wire, while other bees are eating out the candy in the end of the cage. During the 12 to 24 hours it takes the bees to remove the candy, they become accustomed to her presence in the hive and will generally accept her when she walks through the opening made by removal of the candy. The cage is usually placed on its side between two top bars or stood on its end, with the candy end up, on the bottom board between two brood combs.

Some beekeepers successfully intro- duce queens in paper introducing cages having small openings in both ends. The cage is usually partly pushed into a comb, enclosing some cells of honey, after the top shell is removed. The bees gnaw away the cage, thus releasing the queen and making it unnecessary for the beekeeper to return to the hive to remove the cage. A small paper matchbox may be modified for this purpose.

Queen-cage candy is made of powdered sugar and an invert sugar syrup called nuolomoline. Starch-free sugar is preferred because bees are unable to digest starch normally put in powdered sugar. Mix the syrup with the sugar until the mixture becomes firm enough to hold the shape of a ball. This candy is used to provision queen cages while they are being shipped through the mail. It would be a better food if the confined bees had access to water.

For home use in introducing queens, you can make the candy from honey and powdered sugar. The honey should be taken only from a colony known to be free from American foulbrood while the honey was being produced.

\section{GENERAL MANIPULATIONS . . operations that will be necessary at different times of the year ... includes honey extraction operations}

\section{Condition of the colony in the fall}

A colony which is in proper condition in the fall for wintering will have a young queen and 5 or more pounds of bees of varying ages, free of bee discases.

Each colony should have sufficient honey and pollen to last until the spring supply is available. With an early dependable spring nectar flow, 30 pounds of stores will be sufficient in most parts of California. It is good crop insurance either to leave more in the hive or to store combs of honey to give to the col- onies in the spring. The latter practice is frequently followed in outapiaries which may be molested during the winter period.

In sections of the state where fall and spring flowers are scarce, you should see that each colony has sufficient pollen for early spring brood rearing. Some hives may have more than they need, and any surplus can be distributed among the needy colonies. Colonies in 2-story hives generally accumulate pollen in the lower brood chamber. If the second story is left full of honey, they will have suffi- 
cient stores to carry them through a long building-up period in the spring, when additional stores may not be available.

Weak or queenless colonies should be united with queen-right colonies. Colonies which are below normal strength in the fall may have poor queens. If enough bees are present to cover five or six frames, and if there is a young queen, the colony is usually strong enough to winter well in valley locations and to build up to a normal strength in the spring.

Each hive should be provided with a watertight cover which must be fastened or weighed down so that it will not be blown off during the winter. Each hive should also be protected from wind. Colonies well protected from the prevailing winds during the fall, winter, and spring will use up less energy in keeping warm. Below the snowline, colonies in California need only wind protection during the winter period. Above this elevation, their strength may be conserved by wrapping the hive in one thickness of building paper, covered with a thickness of tar paper on the outside, and by making its top watertight. The hive entrance should be made small enough to suit the colony size. If necessary, it should have a wire guard against mice. A coat of paint applied to the hive every second or third year will keep it in good order. In the fall, each hive should be reduced to one or two stories, depending on the strength of the colony. Two stories are usually preferred because the second provides a food reservoir-often called a food chamber-against a failure of a nectar flow in the spring.

Last, but most important, you should know that each colony is free from disease and that each has a prolific queen. This condition must be assured by making the necessary inspections and change of queens in early fall while weather factors are still favorable.

Colonies need little or no attention in winter. It is a good policy, nevertheless, to look at the hives occasionally during the winter season-without opening them or disturbing the bees-to see that each entrance is open and no undue number of dead have accumulated at the entrance. If a colony dies during this period, the hive should be taken into the workshop immediately to forestall robbing and examined to determine the cause of death.

During the winter all equipment, including spare combs, hive bodies, and extracting equipment, should be made ready for spring and summer use. This includes repair, nailing and wiring frames, and protection of drawn combs from the wax moth.

\section{Spring management}

The first spring examination of colonies should be made on a warm spring day during the first or second cycle of brood. The condition of the brood, amount of stores, and strength of colony should be noted at that time. The queen need not be found unless her wings are to be clipped. The presence of a normal amount of eggs, larvae, and sealed brood will indicate that she is functioning properly. Colonies found queenless on first examination should be united with those having queens, unless laying queens can be introduced. During manipulations, a hive should not be kept open any longer than is absolutely necessary. Any colony found infected with either European or American foulbrood at this time should be immediately cared for according to instructions given under the subject of brood diseases and their treatment. Any additional stores needed should be supplied. If the bees start robbing, examination of the colonies should be discontinued. With favorable weather conditions, brood rearing will increase rapidly, and the colony will gain in strength soon after pollen and nectar become available. When the colony appears crowded in the brood chamber, an additional story of empty combs should be added. Frames of foundation should not be provided unless the bees are gathering nectar. 


\section{Package bees and their care}

Bees in combless packages are shipped in quantity from California to the northwestern states and Canada. Some of these packages are also sold in California, however, to increase the strength of colonies for the early nectar flow in the southern counties or to start new colonies. To secure the greatest return from these bees, proper methods must be used in their installation and care. Each package contains 2 to 4 pounds of bees and a queen. Sometimes 4-pound packages contain two queens and are divided to form two packages when installed in hives. The 3-pound package is the better size because the extra pound of bees enables the cluster to maintain a more uniform temperature during bad weather. Uniform temperature, in turn, increases brood production more rapidly.

Best time to receive package bees. To strengthen colonies, the package bees should be ordered so they can be added just before the nectar flow, for nearly all the bees will become fielders within a few days. There is also considerable advantage in strengthening weak colonies 3 to 4 weeks before the start of a long nectar flow. This practice helps to build up a desirable amount of brood to maintain colony strength during that period. Where the packages must produce

\section{Packages of bees ready for shipment by railway express.}

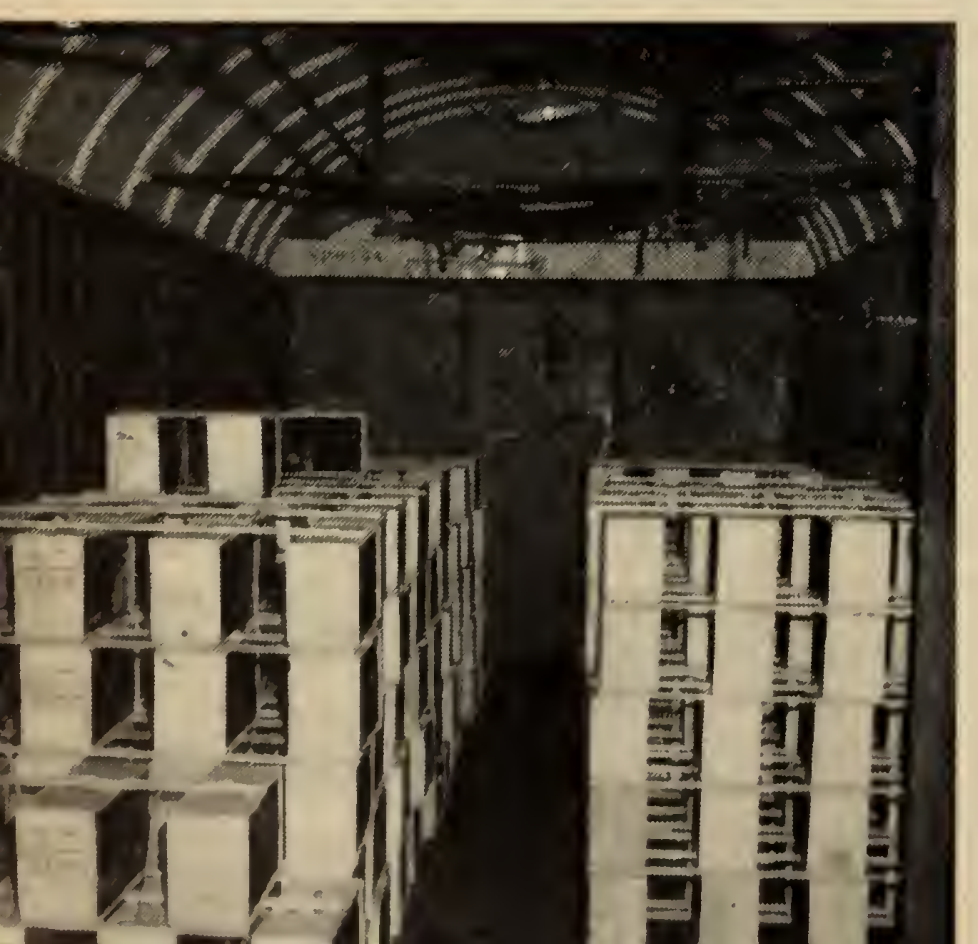

colonies for honey production or for pollination service, they should be received 6 to 8 weeks before the major plants come into bloom.

Pollen essential for package bees. Since abundant pollen is essential to the rearing of brood, the newly established bees either must be given combs that have already been filled with pollen by bees, or must be located where they are able to secure pollen from flowers. If the bees are to be established on comb foundation, they should not be installed until weather and floral conditions are favorable for the gathering of pollen.

Installing the bees. Before the bees arrive, the hives should be made ready and the locations prepared. For best results, each hive should contain at least two combs of pollen-even though some pollen is available in the field-and the equivalent of three full frames of honey. If combs of honey are not available, the bees should be fed a 50-50 sugar syrup until they are self-supporting. The addition of one comb of brood from an established colony will insure a much faster build-up of the small cluster into a working colony.

Soon after the packages are received, the bees should be fed all the sugar syrup they can hold. The quickest method of feeding the bees is to shake or spray thin syrup onto them through the wire sides of the cage. After they have been fed, the bees should be kept in a cool room until late in the afternoon. They will drift less if installed just before dark. If the day is cool and cloudy, the bees can be installed at any time.

The bees may be installed by several. differcnt methods, but the onc most commonly used is carried out as follows:

Three or four frames are removed from the side of the hive into which the becs are to be installed and placed at the back of the hive. The becs are then wet with a spray of warm water or thin sugar syrup, and then jarred to the bottom of the cagc. The feeder can and queen cagc are re- 
moved and the bees shaken into the space left by the removal of the frames. The queen is examined to see if she is alive and uninjured, and then she too is sprayed or wet through the screen of her cage, after which the wire covering her cage is removed and she is released directly on the pile of bees in the bottom of the hive. The frames are eased back into place and the hive is closed, care being taken not to injure the queen. If some bees still remain in the package, they can be shaken in front of the entrance or the cage placed on the ground next to the entrance so the bees can run in later.

If the hive is provided with combs of honey and pollen, it need not be fed additionally. Otherwise, a friction-top pail of syrup should be inverted on top of the combs, an empty hive body placed around, and the cover put in place. If there is a tendency for other bees to rob at the time of installation, the entrance of each newly established hive should be reduced to 3 or 4 inches.

The newly established colony should not be disturbed for several days or until after the queen has established a brood nest. The bees may injure the queen if the colony is disturbed before that time.

Another method of installing a package of bees is to remove enough combs to set the package of bees inside the hive. Remove the feeder can and the queen cage. Open the candy end of the queen cage and run a match stem through the candy. Then place the queen cage, wire side down, between two combs, shaking some of the bees over the queen cage. Place a can of feed over the combs inside a hive body and reduce the entrance. The cage can be removed the following day and the combs replaced. If the queen has left her cage, it can be removed.

For maximum safety against the introduction of American foulbrood into a newly established colony by the use of drawn combs or a swarm of unknown origin, $1 / 2$ gram of sodium sulfathiazole should be added to each gallon of sugar syrup or honey syrup fed (see pages 6568).

Adding package bees to weak colonies. When package bees are used to strengthen weak queen-right colonies, they can be ordered without queens-if the queens in the colonies are satisfactory. If the colony is to be requeened, kill the old queen a day before installing the package containing the new queen. Wet the bees in the packages with sugar syrup, as described above, and sprinkle sugar syrup liberally over the combs of the colony to which the bees are to be added. Shake the wet bees from the packages directly on top of the frames, or preferably into a space made by removing three or four combs; then replace the frames and cover the hive. If the hive is to be requeened at the same time, the queen should be introduced by the usual cage method. If the queen comes with the package and is in a cage provisioned with candy, the opening into the candy end of the cage should be uncovered by removing the cork or metal plug. If the queen is in an unprovisioned cage, she can be wet thoroughly with syrup and released directly among the bees shaken from the cage. When the bees are added to a queenless colony, however, it is safer to introduce a queen by the cage method.

One method of installing a package of bees. The queen cage has been placed on top of the frames and the cage of bees set in the space from which five combs were removed.

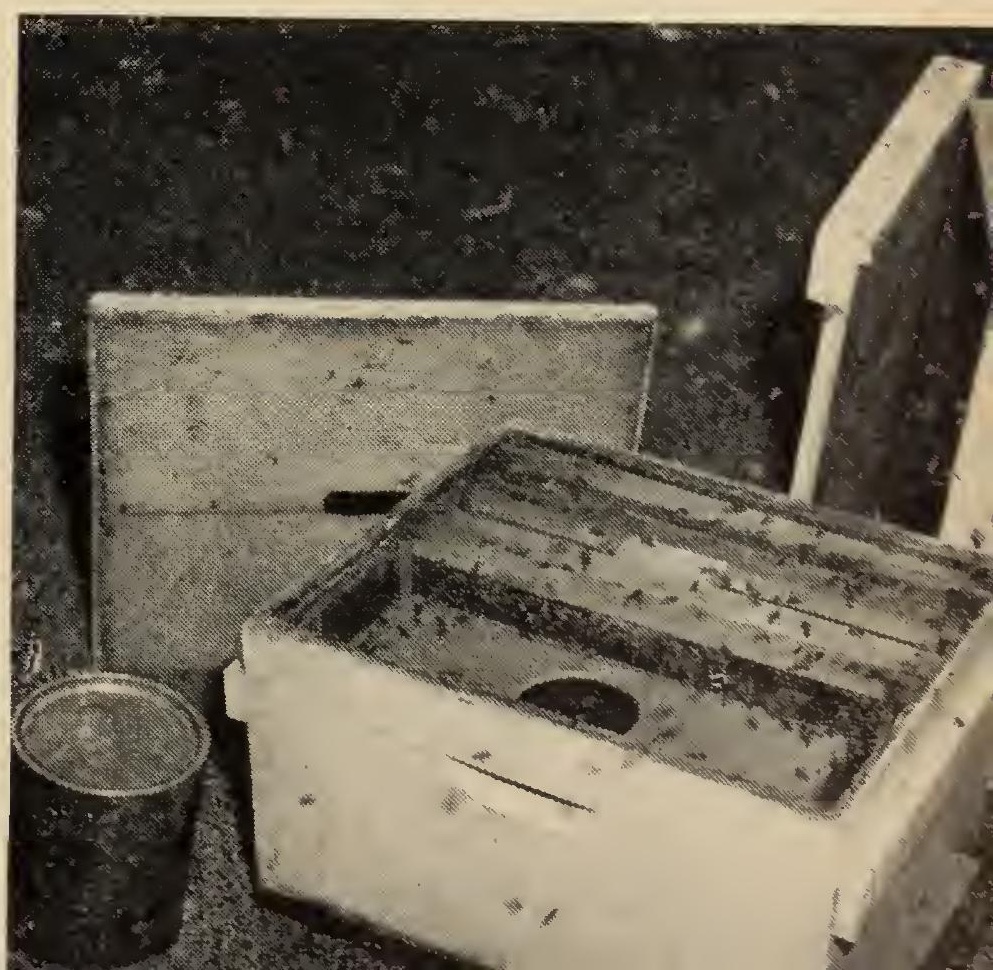




\section{Swarm prevention and increase}

Swarming, an inherited instinct of the honeybee, is a means of preserving and propagating the species. This instinct is stronger in some races - even within certain strains of the same race-than in others. The tendency to swarm, therefore, can be reduced to a certain extent by a careful selection of breeding stock. Chief among the many factors which contribute to swarming are overcrowding in the brood nest, lack of storage space, presence of old queens, lack of ventilation in the hive, and confinement of the colony to the hive during a nectar flow by cold or rainy days during a normal swarming period. Swarming seems to be more persistent in some regions than in others, being more prevalent in areas where there is a great abundance of pollen. The swarming tendency usually declines during a major nectar flow if the colony is given ample comb space in which to rear brood and to store honey.

Bees build numerous queen cells in preparation for swarming and often "hang out" on the front of the hive for some days. Such symptoms are advance notice that conditions in the hive must be made more favorable or a majority of the bees will leave for a new home previously located by scout bees. Some beekeepers depend on cutting out all queen cells every 10 days to control swarming, but this method is very seldom used in commercial apiaries in California.

One method of swarm control which can be coupled with the making of new colonies is as follows: When a hive contains brood in both stories and will soon need additional comb space, lift the top story off, place a queen excluder on top of the lower chamber, then a super of combs, and then the former second brood chamber on top. Destroy any queen cells prescnt. Nine or ten days later, examine the hive again and find the queen. If she is in the top story, set this chamber aside on a new bottom board and supply a cover. If she is in the lower chamber, set this aside, and put the top story in its place. If the queen has laid in the combs added 10 days previously, place the combs containing eggs and larvae in the chamber set aside with the queen. Exchange the frames of sealed brood for empty combs if necessary. The two hive bodies on the original stand should contain mainly sealed brood. All queen cells must be destroyed. Transfer the bees with the combs. If the queen is of good stock, one of the queen cells can be left to requeen the colony; but it is best to introduce a young laying queen into the queenless portion, since the colony will then go ahead faster. The new queen can be introduced safely by the cage method within a few hours after the division has been made. If time permits, a ripe queen cell can be given to the division, instead of a laying queen. As a rule, this manipulation settles the swarming problem for the remainder of the season and provides one increase in the number of colonies. The two colonies can be united at the beginning of the nectar flow in summer or later if the beekeeper desires.

A second method of increase is to make one or two nuclei from each colony strong enough to occupy two brood chambers with ten or more frames of brood. A nucleus is simply a small colony; its size is generally denoted by the number of frames of which it is composed. To make a 3 -frame nucleus, two frames with brood and bees and one of honey are taken from a strong colony and placed in another hive; one or more frames of bees are shaken into this hive for good measure. The nucleus is then moved to another apiary, and a queen is introduced by the cage method or by providing a ripe queen cell. The entrance of the nucleus hive may be reduccd in size to 1 or 2 inches. Many of the field bees will return to the original hive if the nuclcus is left in the same apiary, but enough young bees usually remain in the new hive to care for the brood, the majority of which should be sealcd. 


\section{Extracted honey production}

Supering. Experienced beekeepers secure a maximum amount of honey by giving storage room just ahead of the requirements of the colony. An examination of the combs is the best way to determine when additional storage space is needed. This examination may be simply a glance at the top bars of the frames under the cover or, at most, the removal of one or two outside combs. If the combs are being whitened along the top bars by the addition of new wax, this means that the comb builders are lengthening the cells in which to store new honey and that more room may soon be needed.

Some experienced beekeepers make a practice of weighing a few hives in different parts of an apiary by lifting the back of each hive just off the ground by the hook of a spring scale. If the hives have not increased in weight since the last visit, the colonies in the apiary are not disturbed. The daily weight records of a colony on platform scales often prove valuable. They determine the periodic yields of the more important honey plants in any given area and indicate when supers may be required.

The amount of super room to give at any time depends on the strength of the colony and on the duration and intensity of the nectar flow. Supers of foundation should not be given unless the colony is so crowded that it requires more room for expansion. Then they are provided only if the nectar flow is intense enough and lasts long enough to enable the bees to draw the foundation into comb. Best results are obtained if frames of foundation are interspersed with drawn combs. If the nights are cool, too much room in a hive is detrimental. It may cause more bees to remain in during the daytime to keep the hive warm.

When you super a colony for extracted honey, it is generally good practice to place in the center of the super the two outside combs of the brood chamberprovided these contain honey and no brood-and to furnish two empty combs in their place. In hives without a queen excluder these combs, if filled with honey, will discourage the queen from coming up into the super. When the bees have started to whiten the combs near the top bars of the first super, a second super can be placed beneath or on top of it. If supers are added near the close of the nectar flow, they should always be placed on top.

Many beekeepers favor a shallow or half-depth super because the amount of super space can be controlled better than with a full-depth super. A shallow super may also be used as a chamber in which the bees can store a reserve supply of honey.

Some large-scale beekeepers in California use only 3- or 4-story hives throughout the year and visit each colony often enough to remove the frames of surplus honey and add combs. It is good crop insurance, however, to have enough equipment to keep a little storage space ahead of the bees at all times, especially in years of heavy nectar production.

The simplest method of producing extracted honey is to provide each colony with a 2-story brood chamber, a queen excluder, and at least two full-depth supers, each containing nine combs. Bees will store as much honey in nine combs, evenly separated, as in ten placed closer together; and combs with cells extending beyond the wood of the frame are easier to uncap. Colonies should be requeened annually with vigorous queens to reduce swarming and to insure strong colonies. Requeening may take place in the fall or during the nectar flow in the spring. If colonies are wintered in 1-story hives, the second brood chamber should be added when the bees cover eight or nine combs. When the combs of the second brood chamber are being whitened around the top bars with new wax, the queen can be placed in the lower brood chamber, below an excluder, with two or three frames of sealed brood. A super of 


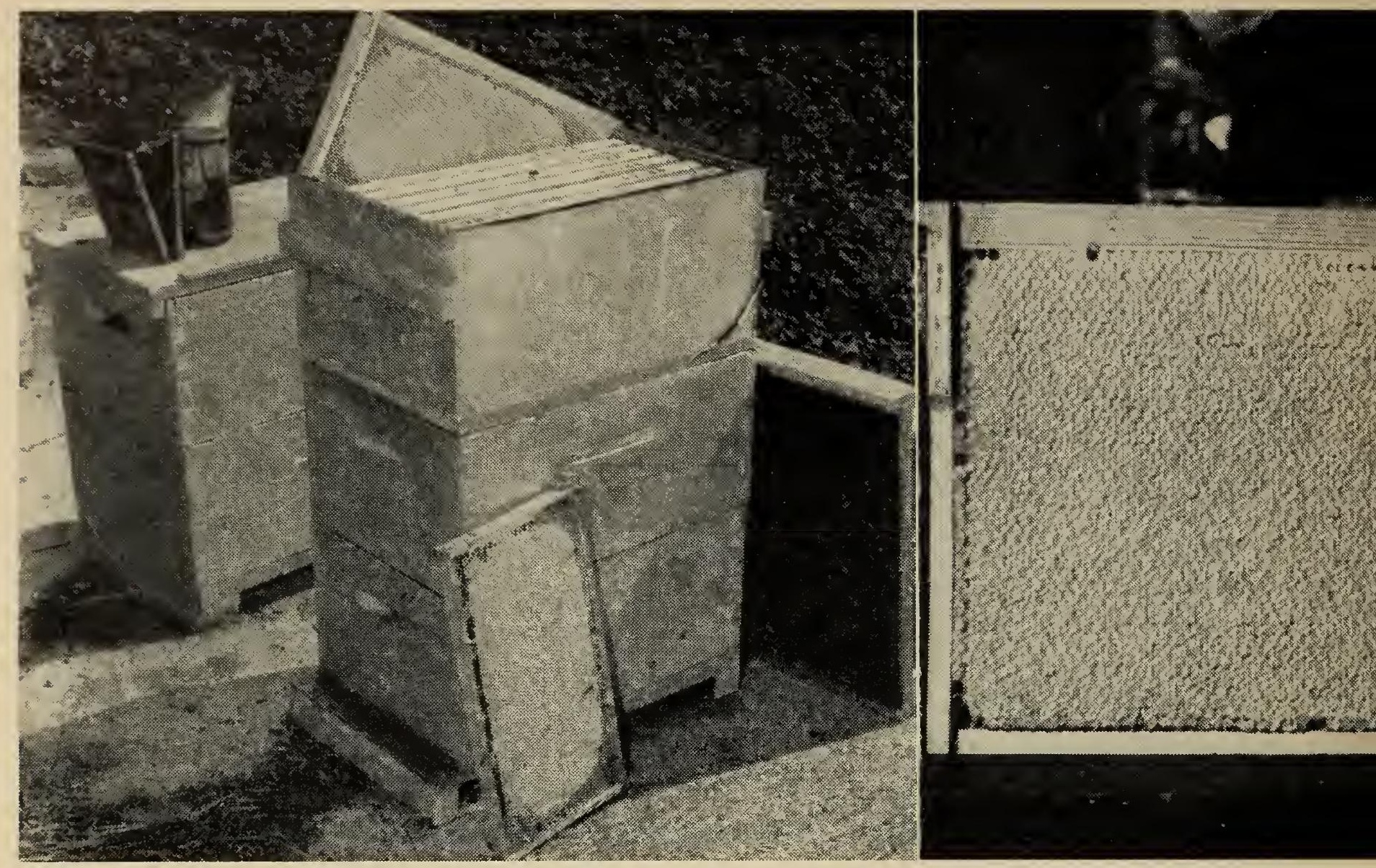

Left. A super of honey ready for extracting. The bees were removed from the combs by the bee-escape board still on the hive. Center. An almost perfect extracting comb of honey. Right. An

combs should be added on top of the second brood chamber which contains most of the unsealed brood.

This manipulation will greatly reduce swarming and may give the colony ample room for a period of 2 or 3 weeks. Under favorable eonditions, all of the worker brood above the queen excluder will emerge and the cells will be filled with honey within 3 or 4 weeks. The colonies may build queen cells in this super. These ean be destroyed 10 days after putting on the excluder, or the virgin queens ean be left to die on the excluder. If these virgin queens ean get out of the hive through a crack, they may fly, mate, and return to start a second brood nest above the queen excluder.

Unless enough supers are available for the entire honey erop, each super can be extracted when the combs are one-half to three-fourths eapped over. Then the combs can be replaced for storing additional surplus. During early spring or late fall, unless most of the cells are sealed, there is some danger that the uneapped honey will be unripened.

Removal of the honey crop. In the days of box hives and immovable combs, colonies were either driven out or killed with fumes of burning sulfur before the honey was removed; but with the movable frame hive, these practices are no longer necessary. The bees may be freed from the combs of honey by shaking and brushing, by use of the bee eseape, or by use of earbolized boards. Most eommercial beekeepers use the first or last methods, for the bee-escape board is not practical in most outapiaries beeause an extra trip is necessary to take off the honey. The bec-eseape board is useful for the back-lot beekeepers.

The majority of bees ean be shaken from an extracting comb with a quick downward and upward movement, and the remainder brushed off with the bee brush. This method may not be praetical when bees are robbing. Honey should not be taken off by this-or by any other- 

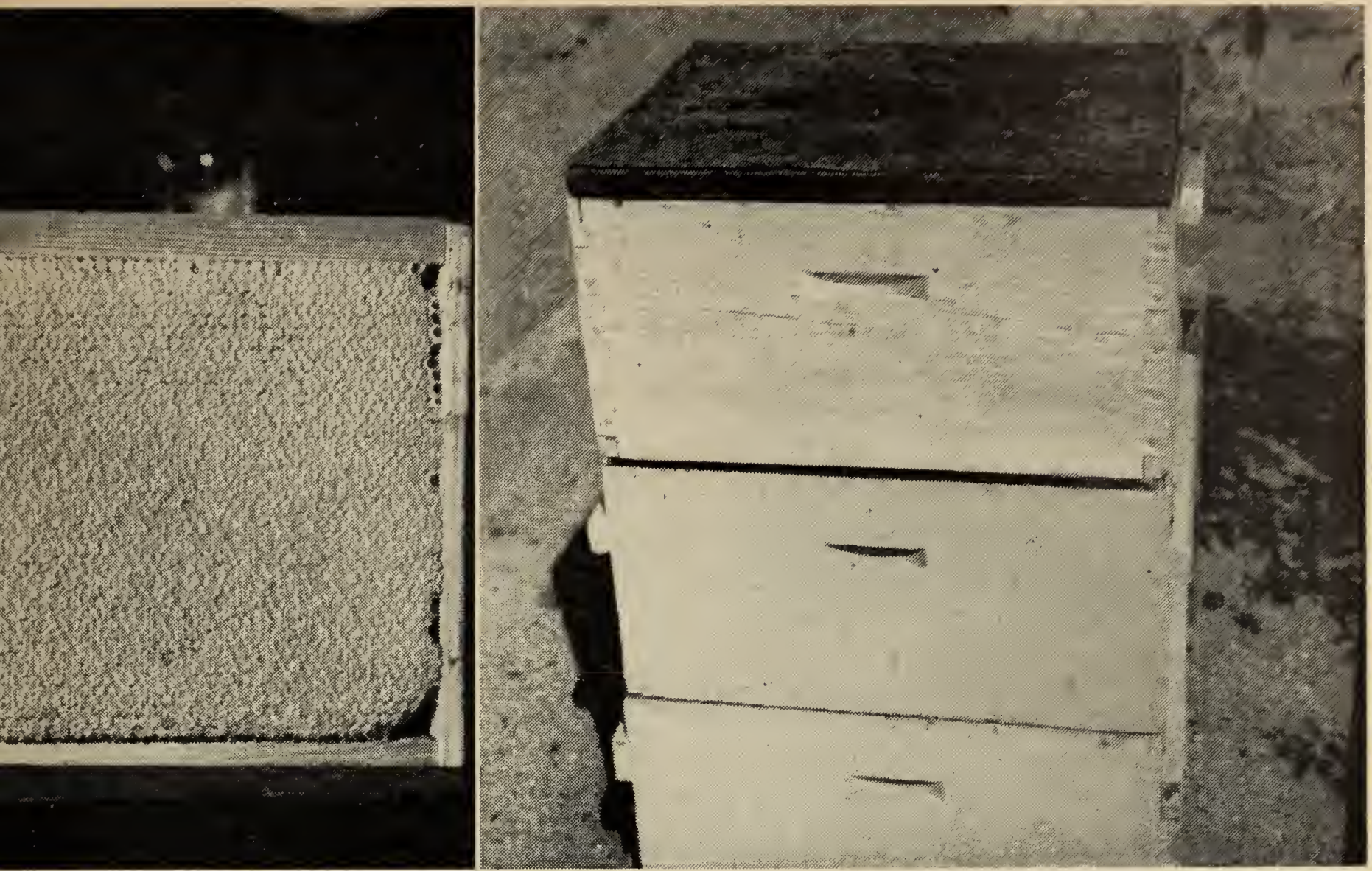

acid board placed on top of a super of honey that is ready for removal. (It is best to remove the queen excluder beneath the super before putting on the acid board.)

method when it is so thin that it can be shaken readily from the combs. It should be left on the hive to ripen. Sealed honey is usually well-ripened and ready to be extracted. When removing individual frames of honey, you should use an empty hive body to hold the combs as fast as they are freed of bees.

The bee escape is a device so constructed that bees may go through it one way only; they cannot return because of one or two sets of springs. When this device is placed under a super of honey in the center of an inner cover or a ventilated bee-escape board, with the entrance up, the super will generally be free of bees by the following morning. Beeescape boards are much used in removing sections or shallow-frame honey. They cause little disturbance to a colony. If a bee escape is placed in one or more corners of the escape board, with the exit to the outside of the hive, the supers will be rapidly freed of bees. Unless the super above the bee-escape board is bee-tight, the combs are likely to be robbed by other bees. The bee-escape board should not be left on during hot weather, for the combs may melt down.

The fumes of carbolic acid are repellent to bees and may be used to drive them from supers of honey that are to be taken off. Special covers, called acid boards, are used for this purpose. This board is made with the same dimensions as the top of the hive body and about 1 inch deep. Across the top of the framework is tacked a piece of hardware cloth, then several thicknesses of cheesecloth; over all is placed a piece of tar paper and a cover of tin. The cheesecloth is sprinkled with a 50 per cent solution of pure carbolic acid. To prevent the odor from getting into the honey, care must be used to keep the acid cloth from touching any part of the frames. Remember, too, that carbolic acid is highly corrosive to the skin.

When honey is removed by this method, the acid board is left on a hive 


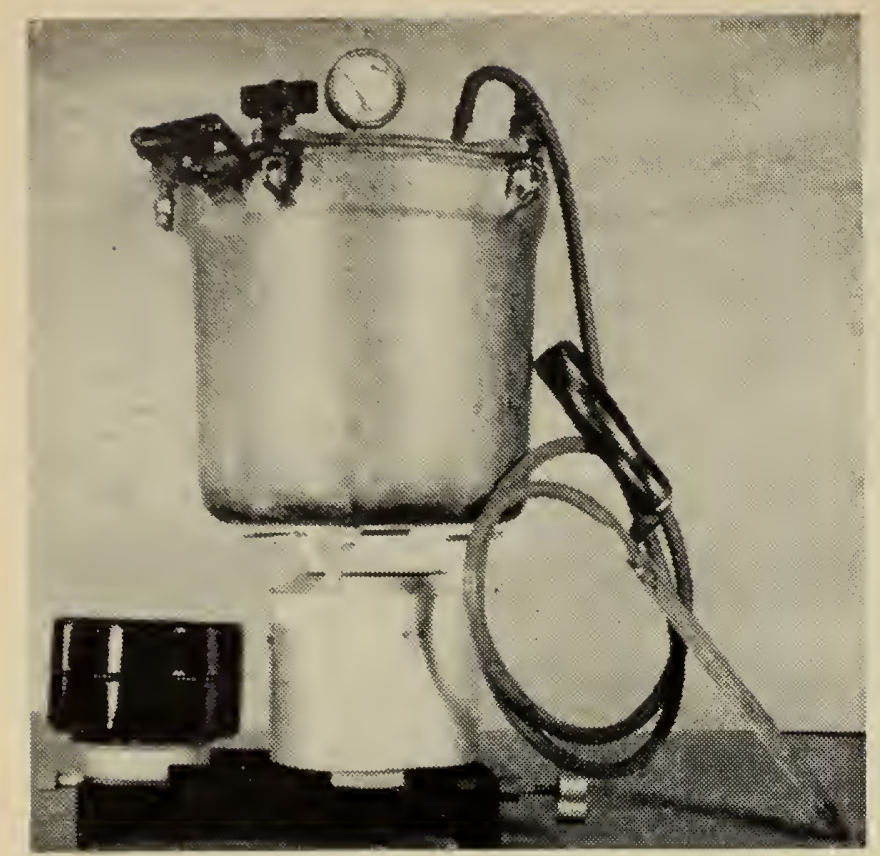

A handy source of steam for a single uncapping knife.

only a few minutes or just long enough to free the top super of bees. Such boards work best on hot days when the heat of the sun will drive the fumes down into the hive. If the covers are left on too long, the bzes will cluster on the outside of the hive, and the colony will remain disorganized for a considerable length of time.

Before the combs are extracted, the supers of honey should be placed crosswise in stacks in the honey house and left until the fumes of the carbolic acid have evaporated. If the work is carefully done, the honey will not absorb any of the odor. An electric fan to circulate air through the combs hastens the removai of the fumes from the supers. In hot weather, supers of honey can be removed faster by this method than by any other. When bees are prone to rob, honey cain be taken off with the acid board with less disturbance in the apiary than by shaking and brushing.

Process of extracting. The honey extractor is a machine which removes honey from the comb by centrifugal force. These extractors are manufactured with a capacity of 2 to 50 or more frames. A 2-frame extractor, with baskets that

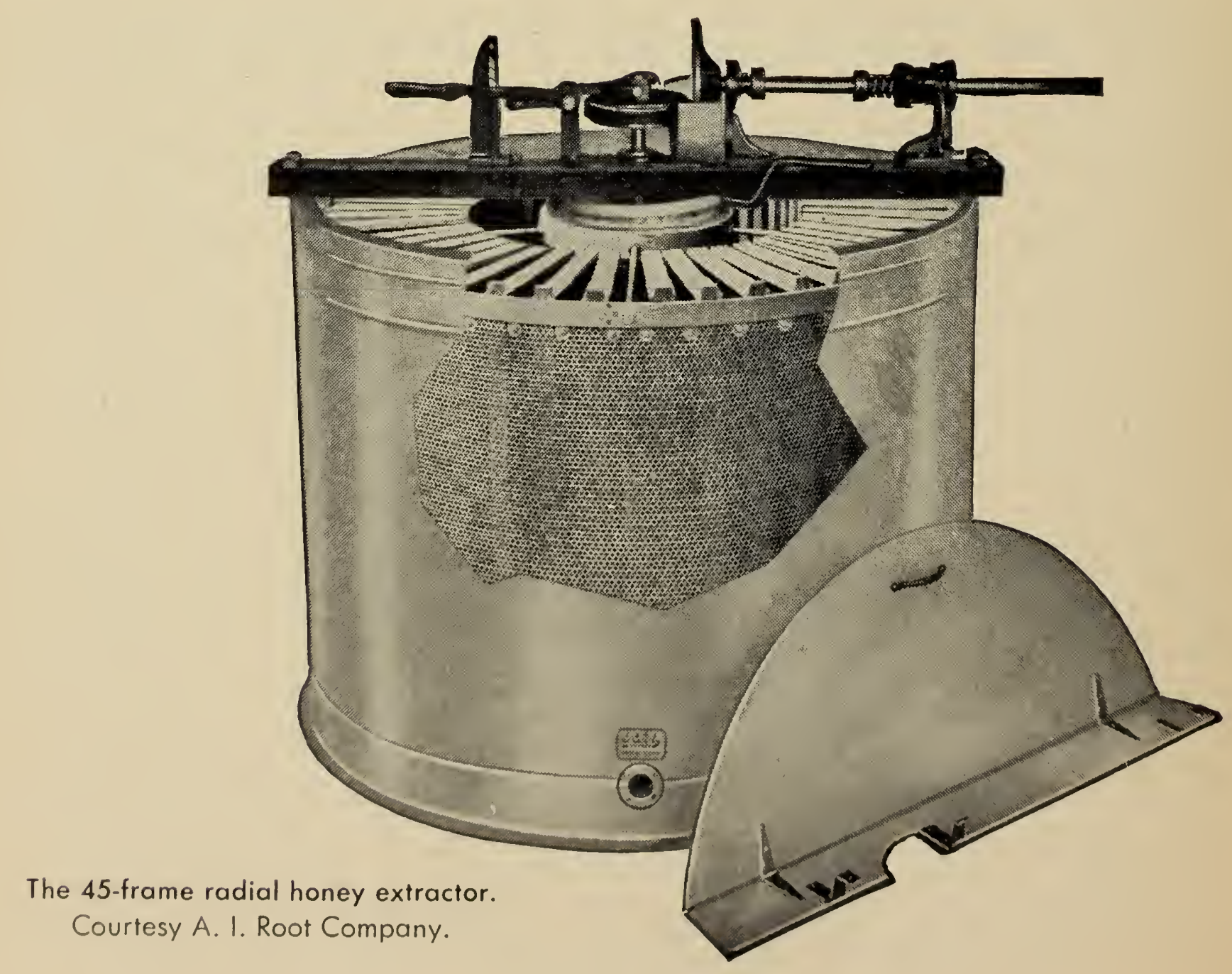


can be reversed without removing the combs, is large enough to take care of at least 20 colonies. The combs are first uncapped on both sides with an uncapping knife, which is heated by steam, electricity, or hot water, and then are placed in the baskets of the extractor. At first the baskets are turned slowly until part of the honey is removed on one side; then they are reversed and the process is repeated. To get all the honey out, the speed must be increased, but not to such an extent that it breaks the combs. New combs are easily broken. The 8-frame Lifetime extractor and the 45-frame Radial extractor are most commonly used by commercial beekeepers. Honey is easiest to extract before it loses the warmth of the hive. The extracted honey runs from the extractor into a sump, which allows the larger particles of comb to be separated from the honey before it goes through the honey pump or into the storage tanks. Sometimes the honey is run through a coarse strainer to remove these particles when a pump is not used. To avoid getting air bubbles into the honey through pump action, the honey should flow into the pump in a manner to keep the pump full of honey. The pump should operate slowly at all times, making no more than 50 r.p.m. In cool weather or with heavy honey, the liquid honey must be heated in a water-jacketed tank to facilitate straining. The most suitable cloth for this purpose is 86-mesh bolting cloth or nylon. Double thickness of cheesecloth will remove most but not all of the foreign particles. If heated to $110^{\circ} \mathrm{F}$, the honey will strain readily.

Most of the bubbles introduced during extracting and straining will rise to the top if the warm honey is allowed to stand in a tank overnight; then the honey should be poured into suitable containers. If honey is canned or bottled immediately after being extracted, the small bubbles will form a white, unsightly scum on the surface. Honey will discolor if kept hot for too long a period.

The Lifetime 8-frame honey extractor. Courtesy Superior Honey Company, Los Angeles.

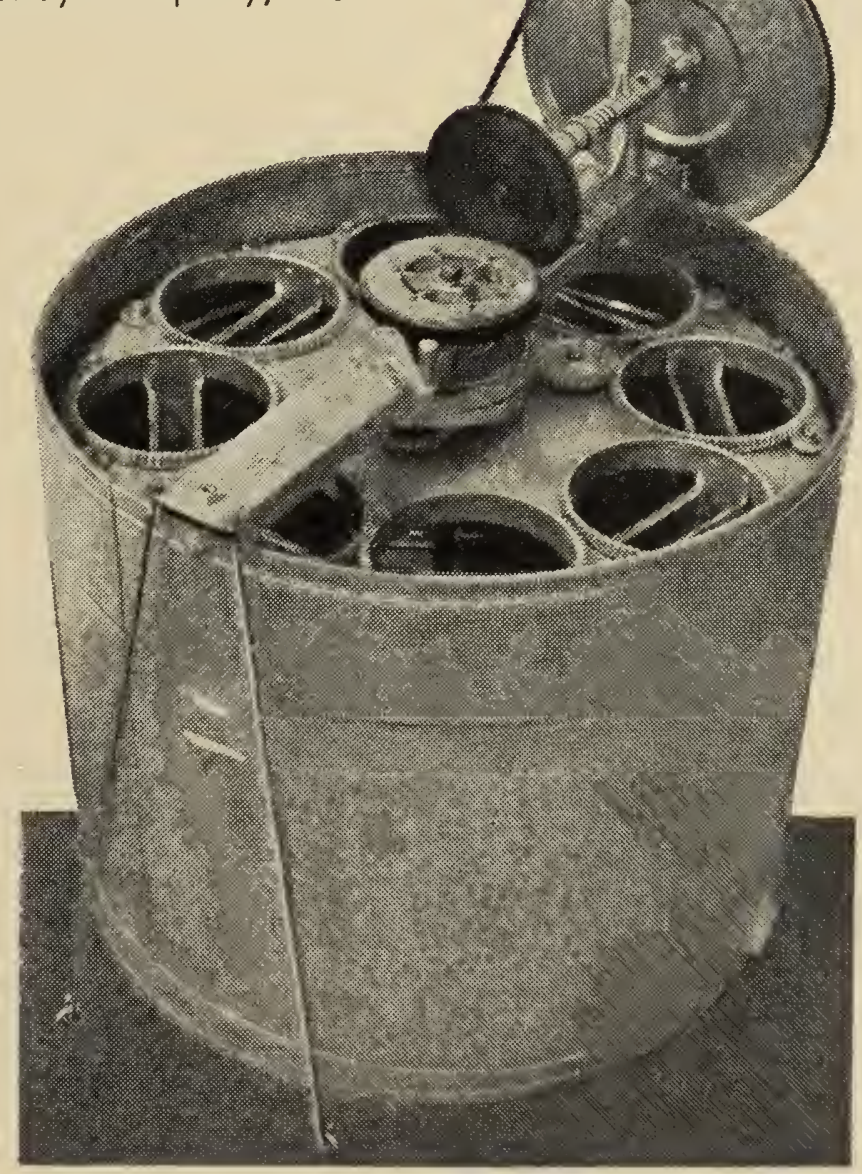




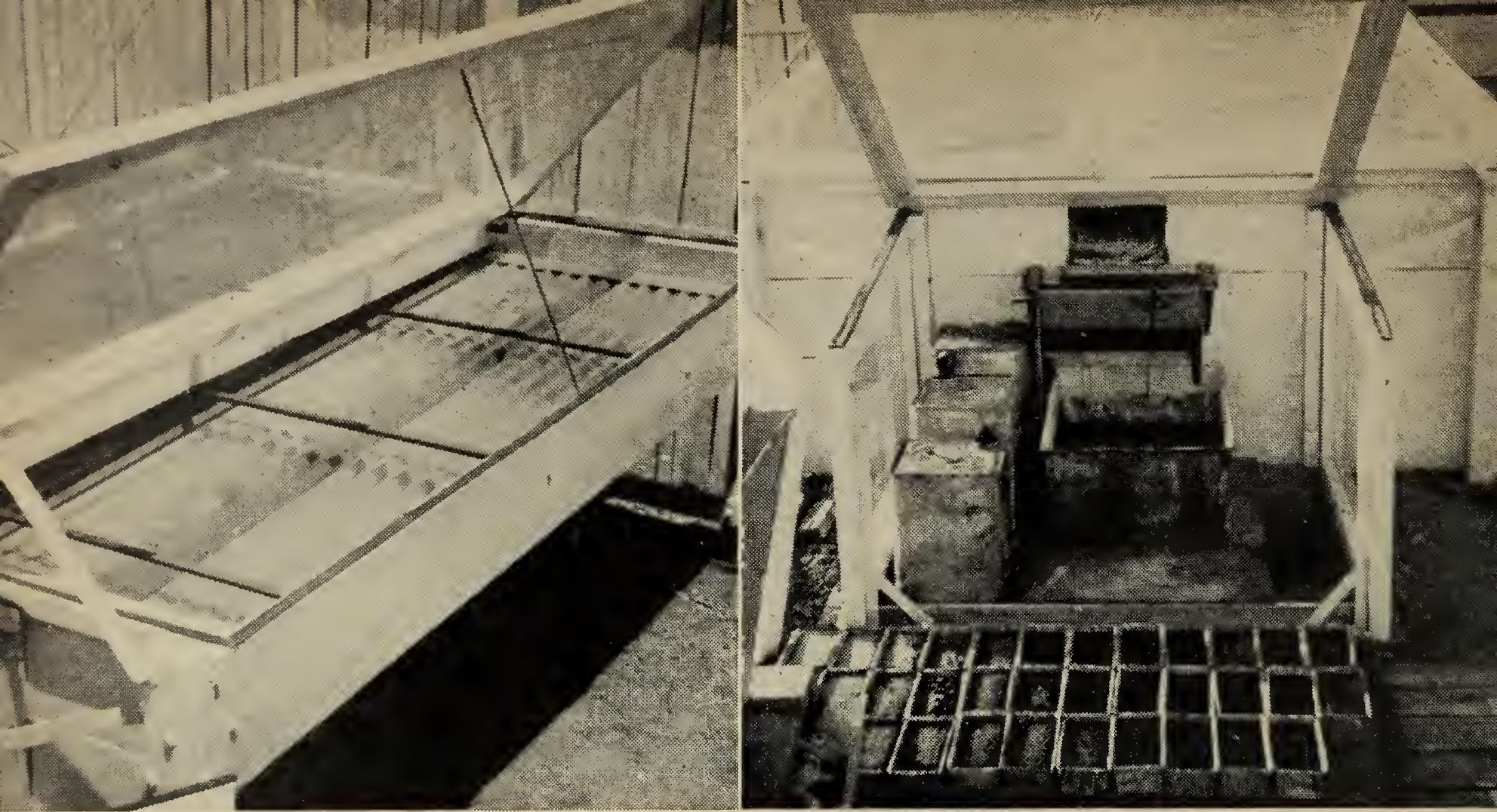

A good type of solar wax extractor for melting cappings. Left, corrugated aluminum bottom drains into a honey and wax separator placed in a glass box (right) in front of the melter. The honey runs into the tins, and the wax into a large mold from which it can be dipped, if desired, into wooden molds.

Cleaning the combs. If the nectar flow is still in progress, the combs can be placed back in the hives to be refilled; but if it is at an end, the combs can either be stored as they are removed from the extractor or given to some colonies to be cleaned. If there is danger of robbing, the wet combs should be put on the hives in late afternoon, left for a few days, and then removed with bee-escape boards or

A compact arrangement for extracting honey in which the Brand cappings melter rests on a honey clarifier. The whirl-around holds the uncapped combs of honey before they go into the extractor. The honey runs from the clarifier into tanks located on the floor below.

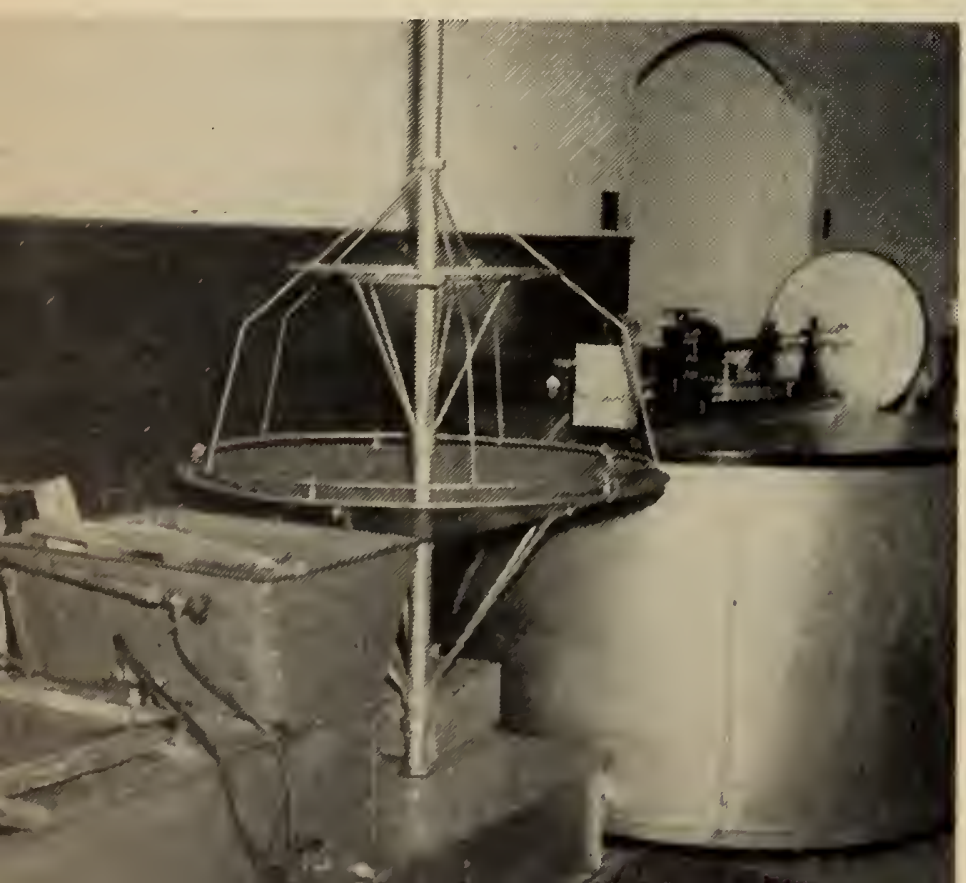

in the cool of early morning when few bees are in the supers. Three or four supers can be stacked on each hive.

Care of the cappings. The cappings cut from the combs should be drained of honey, then melted and molded into solid blocks for sale. Cappings are often melted in a solar wax extractor - a glass-covered, metal-lined box heated by the sun's rays. The melted wax and honey can be separated as they run from the solar extractor. After the cakes of wax are scraped free of foreign materials on the bottom, they are ready for sale to bee supply firms. Cappings may also be melted in a copper boiler or tank, the remaining honey separated from the wax. and the liquid wax run into molds. The wax should not be melted in an iron receptacle since contact with iron darkens the wax. The inside of the wax molds should be wet with soapy water to prcvent the wax cakes from sticking. The wax will not crack if it is pourcd into the molds at only a few degrees above the melting point-around $143^{\circ}$ to $145^{\circ} \mathrm{F}$ and then allowed to cool slowly.

Many beekecpers extract the honey from their cappings by means of a whirl- 
dry extractor. Special wire baskets to hold the cappings can be made to fit this extractor. If the whirl-dry is operated for an hour or so, practically all of the honey will be thrown out and can be added to the general supply. Honey that comes from the solar extractor or from melted cappings is generally dark and off-flavor. It should be kept in separate cans.

There are also various devices on the market, heated by hot water or steam, that melt the cappings during the uncapping process. In each method the melted wax and hot honey may be separated by gravity. One make of cappings melter operates on the principle of applying the heat to melt the cappings above the general level of the honey. As the cappings from the combs fall into the melter, they float on top of the honey and are melted as they come in contact with the steam-heated coils. The honey and melted wax drain off at different levels into separate receptacles.

\section{Comb honey production}

The production of comb honey is considered to be more difficult and exacting than the production of extracted honey because the colonies have to be crowded almost to the swarming point, and the nectar flow has to be more constant and of sufficient intensity to produce combs of good quality. Further, all combs have to be completely sealed in order to be marketable. The initial cost in sections, equipment, and labor is also greater than for the production of extracted honey. (Consult bee supply catalogs for the equipment required to produce section comb honey.)

In preparing the sections, you can use the split sections and avoid the need of equipment with which the sheets of comb foundation would otherwise have to be fastened to the sections. The sheets of foundation should not be placed in the split sections much before they are needed because the foundation frequently

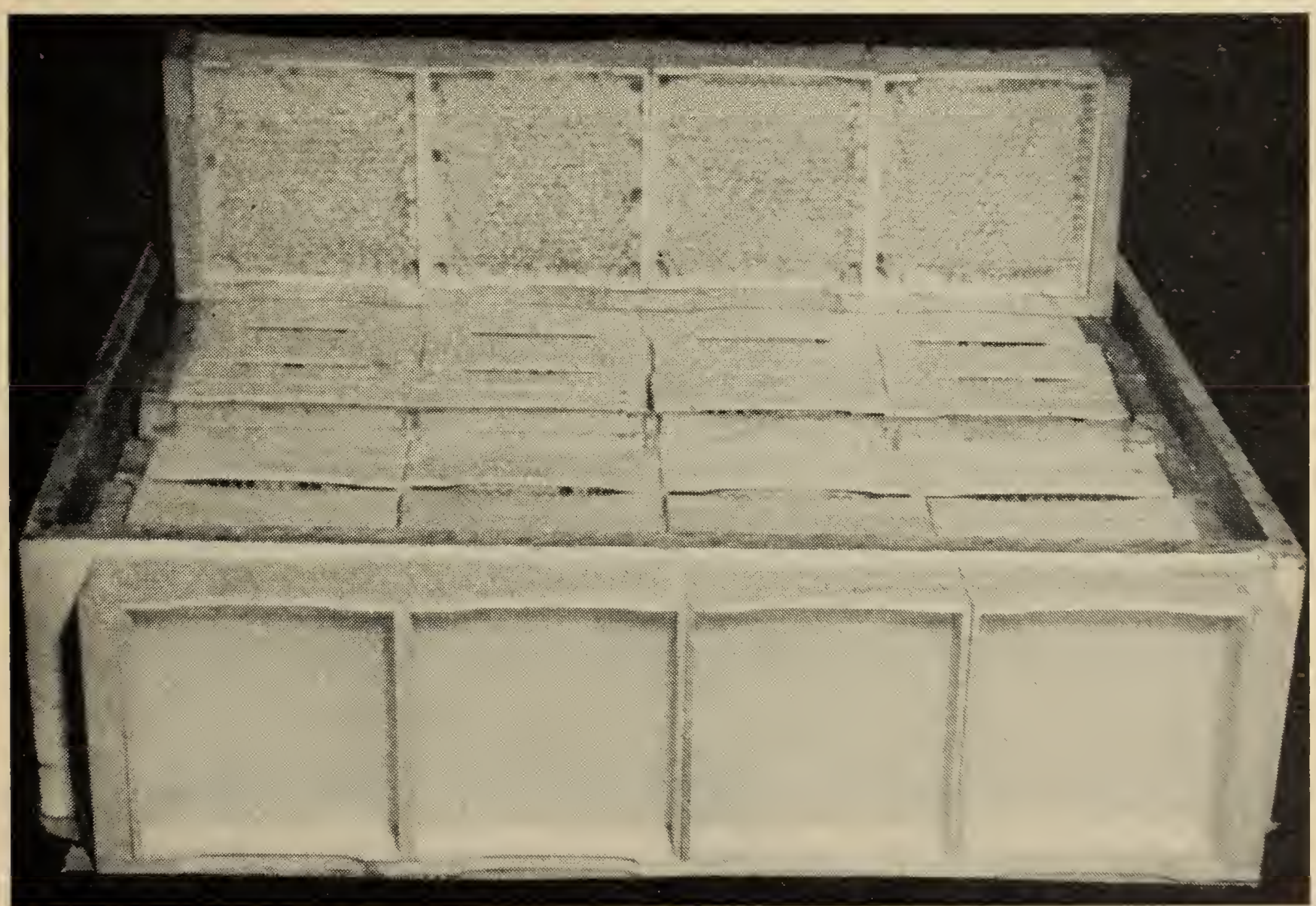

A super filled with section honey, with four split sections filled with this super foundation in the foreground. 
buckles when exposed to changes in temperature. The tops of the sections should be painted with hot paraffin after they have been placed in the supers in order to prevent the bees from staining the wood with propolis.

\section{Colony management for comb} honey. Only the strongest colonies should be used for the production of section honey, and supers should not be placed on the hives until after the nectar flow from a major source has started. For best results, the colony should be strong enough in numbers to occupy not less than two full-depth hive bodies. Some beekeepers unite two colonies to insure greater strength in their comb honey builders, later contracting the brood chamber to a single story and using the extra brood to make up for the colony lost through uniting.

The colony is reduced to one story at the time the section supers are to be added, thus forcing the bees into the section supers. The brood chamber is filled with combs of sealed brood which will provide adequate space for the queen as the bees emerge from their cells. If queen cells are present, they are cut down. If the colony persists in building queen cells, it may be necessary to kill the queen

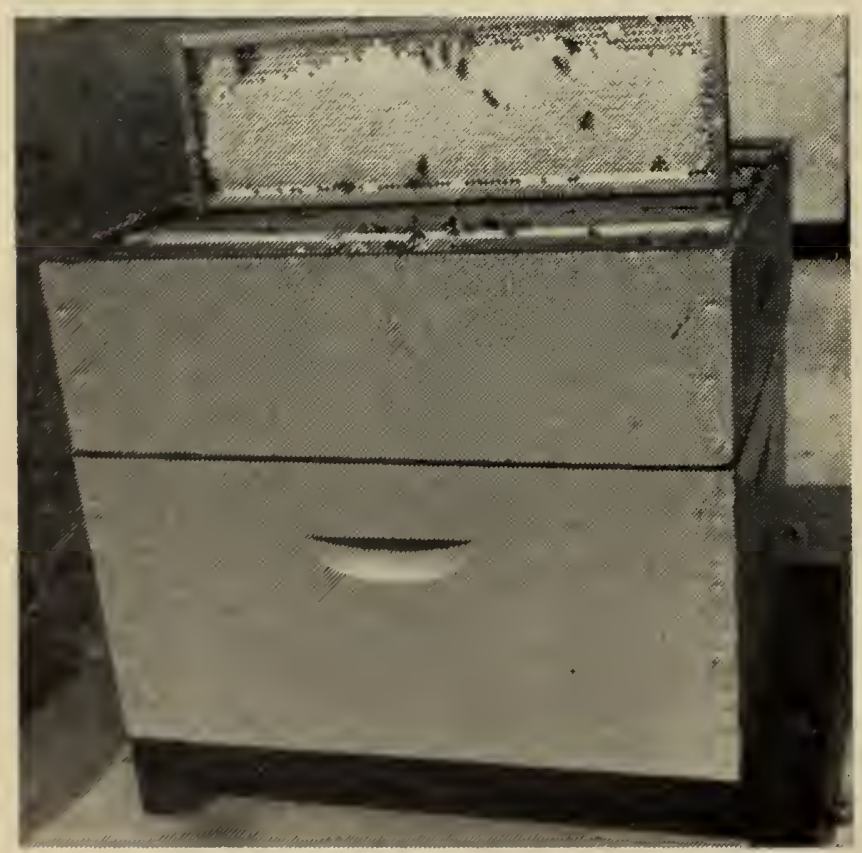

A $1 \frac{1}{2}$-story hive with the shallow super filled with honey. Shallow supers of honey are easier to handle than full-depth supers. and to introduce a young laying queen 5 to 7 days later, at which time all remaining queen cells are broken down. One or two section supers can be added at the first manipulation, depending on the strength of the colony and the intensity and duration of nectar flow.

After the bees have started to build combs in the first super, the second super can be added on top. When the first super is about half filled with honey, the two supers can be reversed so the bees will continue to finish the sections in the first super but will have the added space in which to work. This system can be repeated as long as the nectar flow continues and as often as needed to give the bees more room in which to work without providing more sections than the nectar flow warrants. The idea is to get all sections completely filled with marketable honey before the end of the nectar flow. The supers of sections should be removed as soon as the sections are completely filled and sealed in order to prevent travel stain. Comb honey supers can be removed with the acid board or by the bee-escape method previously described.

Near the close of the nectar flow, the second story should be returned to the hive, after the section supers are removed, in time to permit the colony to store enough honey for the winter period. Where several colonies are used in comb honey production, the second stories, with combs of extra brood, are stacked on a few colonies to secure winter stores for the section-producing colonies.

Queen excluders are not required when comb honey is produced in sections but are nceded when honey is produced in shallow frames or in sections larger than the "pound" boxes. Supers of brood combs should not be placed above section supers or shallow frames in which comb honey is being produced, as the bees store some cells of pollen in the comb supers and the amount of travcl stain on the surfaces of the combs will be greater. 


\section{The honey house}

Honey should be produced and handled in a sanitary manner at all times. The honey house should contain certain fundamental features designed to eliminate unsanitary conditions and to save unnecessary labor in handling honey, supers, and general beekeeping equipment.

If the contour of the land permits, the honey house can be built with upper and lower ground-floor levels. This arrangement will make possible the extraction of honey on the upper floor and its transfer by gravity to tanks on the floor below. If the honey house is built on one level, honey pumps must be used to transfer the honey from the extractor to the storage tanks.

It is desirable to unload supers of honey and to load empty supers of combs inside an enclosure away from robbing bees. This can be accomplished efficiently by including in the back of the honey house a sunken driveway into which the truck can be backed to unload or to load. The comb receiving room can be located on one side of this driveway, the extracting room at the end, and the honey room, workshop, and office on the other side. A loading space at the end of the driveway should connect all rooms, with the floor level even with the truck bed. Sturdy drip trays under the supers of honey will permit the use of a warehouse truck in handling the supers for unloading or loading and prevent honey from dripping on the floor or truck bed. Supers of honey can be unloaded in the comb room and left there until free of all bees. The circu-

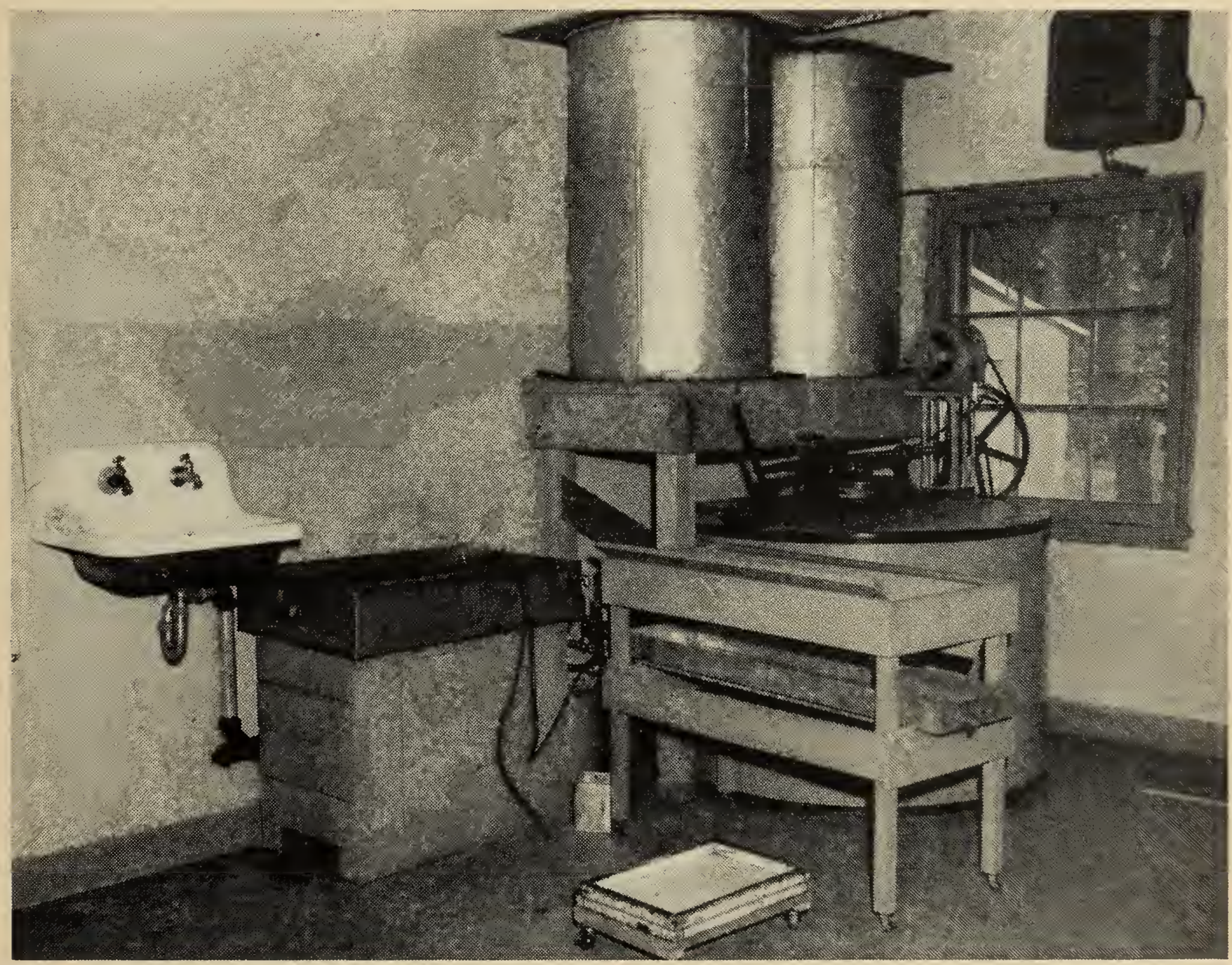

A compact arrangement of honey extracting equipment. The cappings are melted in the steamjacketed cappings melter and the honey and wax separated as they run out. The uncapped frames are stacked in the comb table while the honey extractor is operating. The honey is pumped from a sump to the tanks. Steam comes from a boiler in the small building seen through the window. 
lation of warm, dry air in this room will remove excess moisture from the honey, especially if the supers are crisscrossed in the stacks. The floors should be made of concrete and provided with drains to facilitate frequent cleaning. The comb receiving room and the honey extracting room should be fitted with screens having bee escapes to permit the escape of any bees that might be carried in with the combs.

While beekeepers try to remove all bees from the combs before hauling them to the comb receiving room, a considerable number of bees may still cling to the combs. They generally fly to the windows of the receiving room and are attracted to any hive which may be located at window level to catch them as they escape through bee escapes placed in the screens.

The comb room can be divided and used for fumigation as well as temporary storage purposes. All windows and doors should be thoroughly screened. For greatest convenience, the extracting room should be provided with water, electricity, and steam. In some extracting rooms a small steam generator is located near the uncapping box; in others the steam is piped in from a larger boiler located in another room where the boiler may also serve the wax-rendering or honeyprocessing equipment. The extracting room need be no larger than is adequate to house the extractor, the uncapping equipment, and a few stacks of supers.

The honey is generally pumped or run by gravity to settling tanks. The tanks should be of sufficient capacity to allow the honey to stand for several days before it is drawn off into wholesale containers. As honey comes from the extractor, some beckeepers heat it sufficiently to permit straining through a fine 60- or 86-mesh wire strainer. The honey need not be heated to more than $110^{\circ} \mathrm{F}$ for this purpose. A honey sump located between the extraclor and the honey pump or gravity outlet is desirable for every extracting setup. This permits the coarse particles of comb to be separated from the honey by baffle plates before the honey is run or pumped into the tanks.

Some beekeepers have constructed efficient portable extracting outfits to extract honey at each apiary; they then transfer it to clarifying tanks at a central plant at night. Generally, however, most beekeepers prefer to haul their honey supers to a central extracting plant where they can have access to greater conveniences.

If you operate less than 100 colonies you should make suitable arrangements to include as many of the standards for honey house sanitation in smaller quarters as are needed by a commercial operator. You may need to take greater care to remove all bees from the supers of honey before they are taken to the honey extracting room. However, this room should have well-screened windows, clean walls, and a washable floor which should be kept clean. Honey tanks should be located in clean rooms with screened windows and kept covered with a finely porous cloth or a solid cover.

The hobbyist or small beekeeper might find it convenient to coöperate with a large beekeeper, having suitable extracting equipment, for the extraction of his honey.

Fire hazards in the honey house. When a honey house and general workshop for a beekeeping enterprise is built, the possibility of eliminating all fire hazards should be one of the first considerations. Beeswax, super combs, and dry hives are highly combustible, and frequently the results of years of labor have been destroyed within a few minutes by an "unexpected" fire. Careful attention should be given to all wiring and electrical devices, gas outlets, flues, and sparks from furnaces or steam and heating plants. Wax-rendering and steam plants should be separate from the main honey house and workshop.

Lighted bee smokers have caused many fires in trucks as well as in warehouses. 
They should be emptied into a can of water kept in each apiary for that purpose, or smothered by closing the funnel opening and then carried in a fireproof metal box. A lighted or smoldering smoker should never be carried into a building.
Bottles, which magnify the heat of the sun's rays, may cause fires if adjacent to dry grass. It is, therefore, desirable to keep dried grass and weeds cleaned away from the outside of buildings in which beekeeping equipment is stored. This practice also aids in ant control.

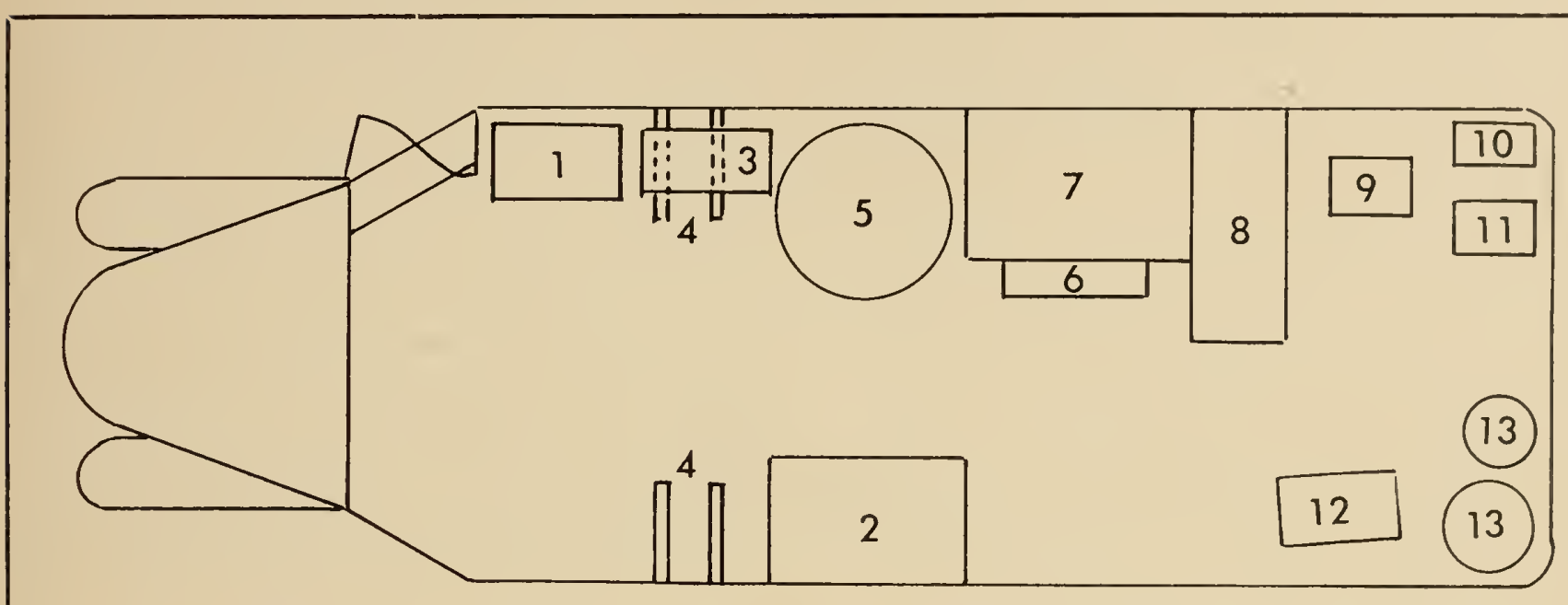

\section{A PORTABLE HONEY EXTRACTING PLANT}

Passenger bus modified into a portable extracting plant. This outfit is complete enough for a 5-man crew to extract 150 60-lb. tins of honey in a 7-hour day. Above, floor plan showing capping press $(1,2)$, comb table (3), super entry (4), 8-frame extractor (5), gravity clarifier (6), air blower (7), 21ㄴ2-h.p. gasoline engine (8), honey pump (9), tools (10), gas tank (11), wash water tank (12), butane tanks (13). Courtesy W. C. Miles, San Bernardino, California.

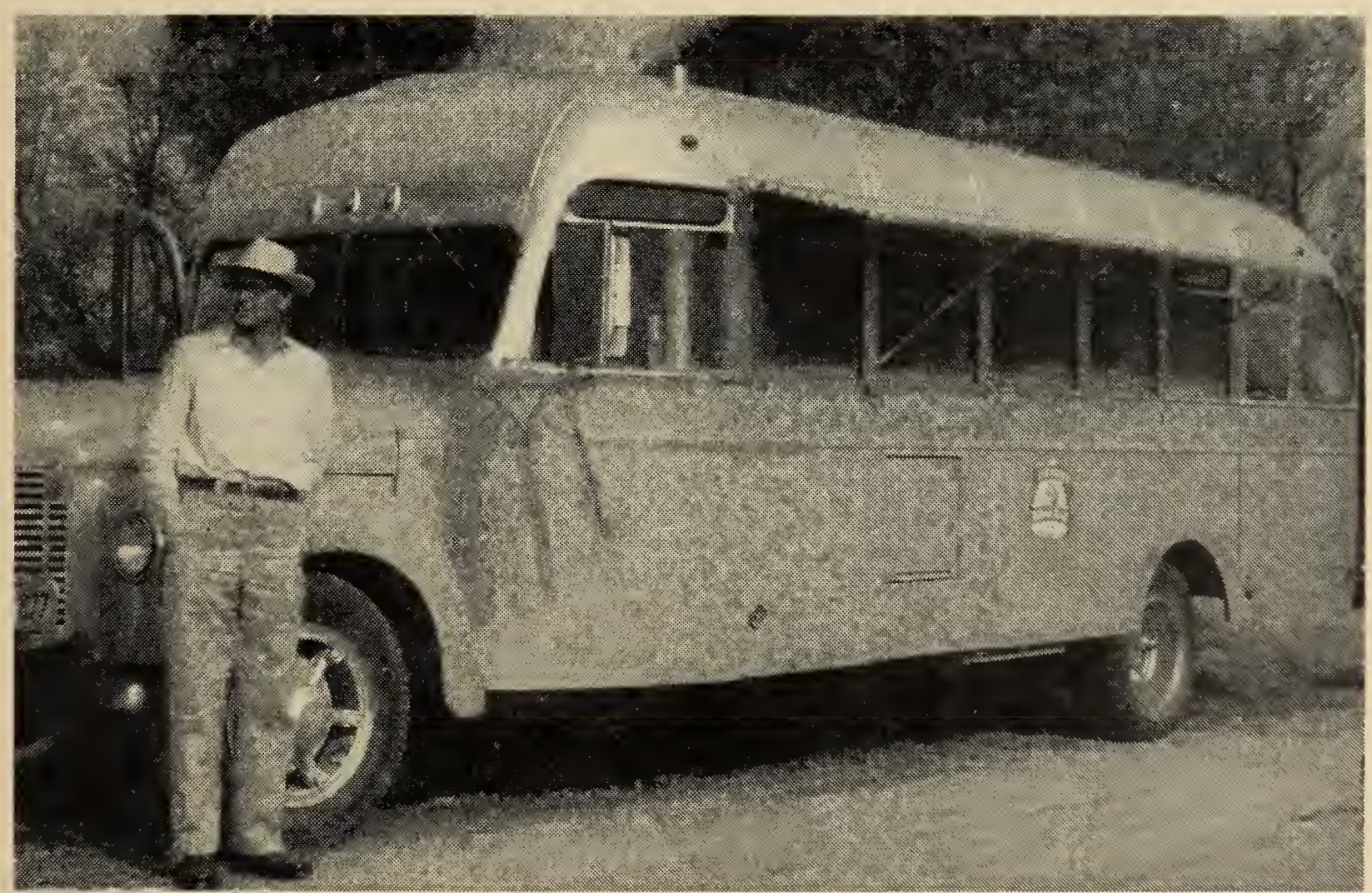




\section{MISCELLANEOUS OPERATIONS ... Ones that may or may not be necessary during any given year but will occasionally become quite important}

\section{Moving hives of bees}

Migratory beekeeping is an established practice in California. This practice is made necessary by the short duration of the average nectar flow from any one source and the long season when bees can fly actively. This practice is also an essential part of providing colonies of honeybees for the pollination of various farm and orchard crops. This type of beekeeping has been well adapted to the many nectar sources available in various parts of the state. Excellent roads and fast motor equipment make it possible for a beekeeper to pick up 200 or more colonies at nightfall and move them many miles within a short time. Migratory beekeeping is not simple, however; it is hard work and, in large-scale operations, requires expensive equipment.

When colonies are to be moved from one apiary to another, the different parts

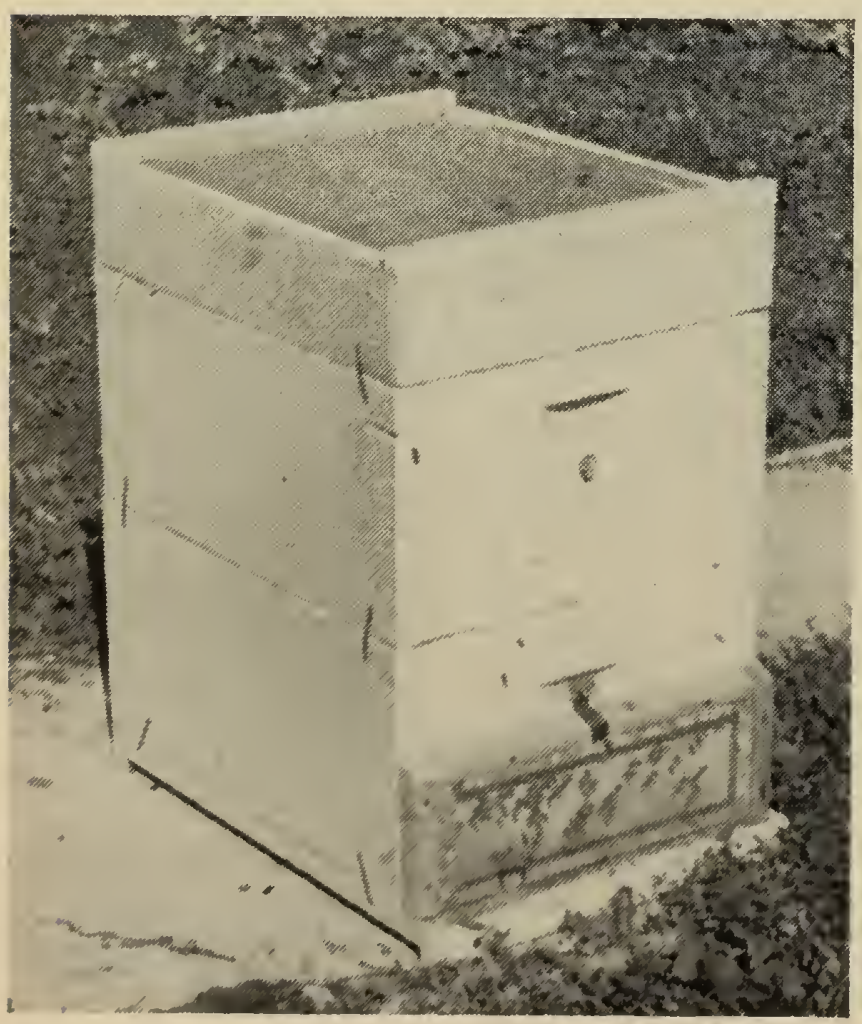

A 2-story hive with screens on top and over the entrance. of the hive may be securely fastened together with hive staples or lath. The bees may be confined by top and entrance screens. The top screens can be nailed on the hives while the bees are still flying, but the entrance screens should be put on at the close of the day when the bees are all in from the field. The top screen should be deep enough to provide ample clustering space during hot weather. The entrance screen should permit bees to cluster between the screen and the front of the hive above the entrance. Because of the traffic on main-traveled roads and the fear of the average motorist that a bee will get into his car, bees should be securely confined during transport over the highway or should be hauled at night. Some beekeepers enclose the truck bed with screened panels or even with plastic cloth. Despite precautions in fastening up bees and in loading, some strays will cling to the outside of the hives. Since these bees will be attracted to street lights, it is advisable to avoid stopping for fuel. It is better, in general, to detour around congested city streets.

Since it is often necessary to move colonies in hot summer weather, many commercial beekeepers in California move their bees without screens. While this practice is not recommended for the careless beekeeper, it is essential to migratory beekeeping in this state. When colonies are to be moved without screens, loading should start just in time to complete the operation before dark. Each colony is smoked at the entrance as it is loaded. Some hives are left in each row to catch the returning bees. When all bees are in, these few hives are loaded, all securely roped on, then the truck is kept moving until it reaches its destination. 
Wind pressure and the vibration of the truck apparently keep the bees from flying out of their hives, although they may cluster on the outside between the hives on hot nights. If the weather is warm, a fine spray of water over the hives will cool the bees and make them more content to remain in their hives.

\section{Mechanical hive hoists}

Mechanical hoists for loading hives and supers of honey are being perfected by various beekeepers, and their use greatly facilitates the loading and unloading of hives without the heavy work needed when only manpower is used. Lights are also attached to the hoists so that loading and unloading can be, done at night. By their use, one man can do the work of two and thus reduce the cost of production as well as make the work easier.

Unloading of the hives is frequently delayed until daylight by which time the bees have quieted considerably from the disturbances of moving. This delay is avoided when mechanical hoists are used because they can also provide a source of light, and the bees on the outside of hives are no problem. The hives are usually smoked at their entrances before they are unloaded.

\section{Bees orient to new surroundings}

Though bees orient themselves to their surroundings, they will return to their former location unless taken entirely out of the area where they have been accustomed to work. Colonies which are to be moved only a few yards should be changed a few feet at a time on successive days. If these bees are anesthetized with nitrous oxide and then moved, few will return to the old location. The nitrous oxide can be made by adding one or two tablespoons of ammonium nitrate fertilizer to well-lighted smoker fuel in the smoker.

Sometimes many bees will return to their old location when moved a mile or so in the same general territory. Many field bees may also be lost at the time of their first flight in new surroundings. When they leave for the field the day after they are moved, many apparently fail to note the landmarks of their new location. Such losses can be minimized if the hive entrances are partially impeded by brush or weeds to prevent uninterrupted flight.

\section{Uniting colonies}

When two colonies are to be united, the easiest method is to kill the poorer of the two queens and to set the queenless colony on a single thickness of newspaper over the colony with which it is to be united. In hot weather the colonies should be united late in the afternoon. One or two small holes should be punched through the paper. The bees will gnaw the paper into bits and carry it out of the hive. When this method is used, the bees become acquainted with one another without fighting, and few will return to their former location.

\section{Transferring bees from trees or walls}

Many people ask how to kill or to transfer bees that have become established in trees or in the walls of buildings. They may be killed readily by spraying or dusting into their entrances such poisons as chlordane, lindane, and dieldrin. These poisons are much safer to use than Cyanogas which has previously been recommended. Two applications of these poisons at intervals of 10 days may be necessary to effect a complete kill. The entrances should then be closed to prevent other swarms from entering later. The chlordane has a long residual action.

An inexperienced person should not try to transfer a colony of bees from the walls of a house or from a box or a tree because the danger of being seriously stung is too great. A person experienced in removing bees from such inaccessible places can control the bees while ex- 
A mechanical hive hoist used in loading hives.

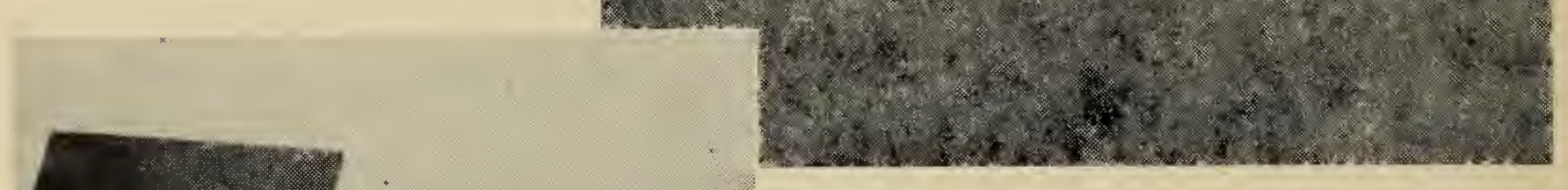

Close-up of the power unit of hoist shown above.

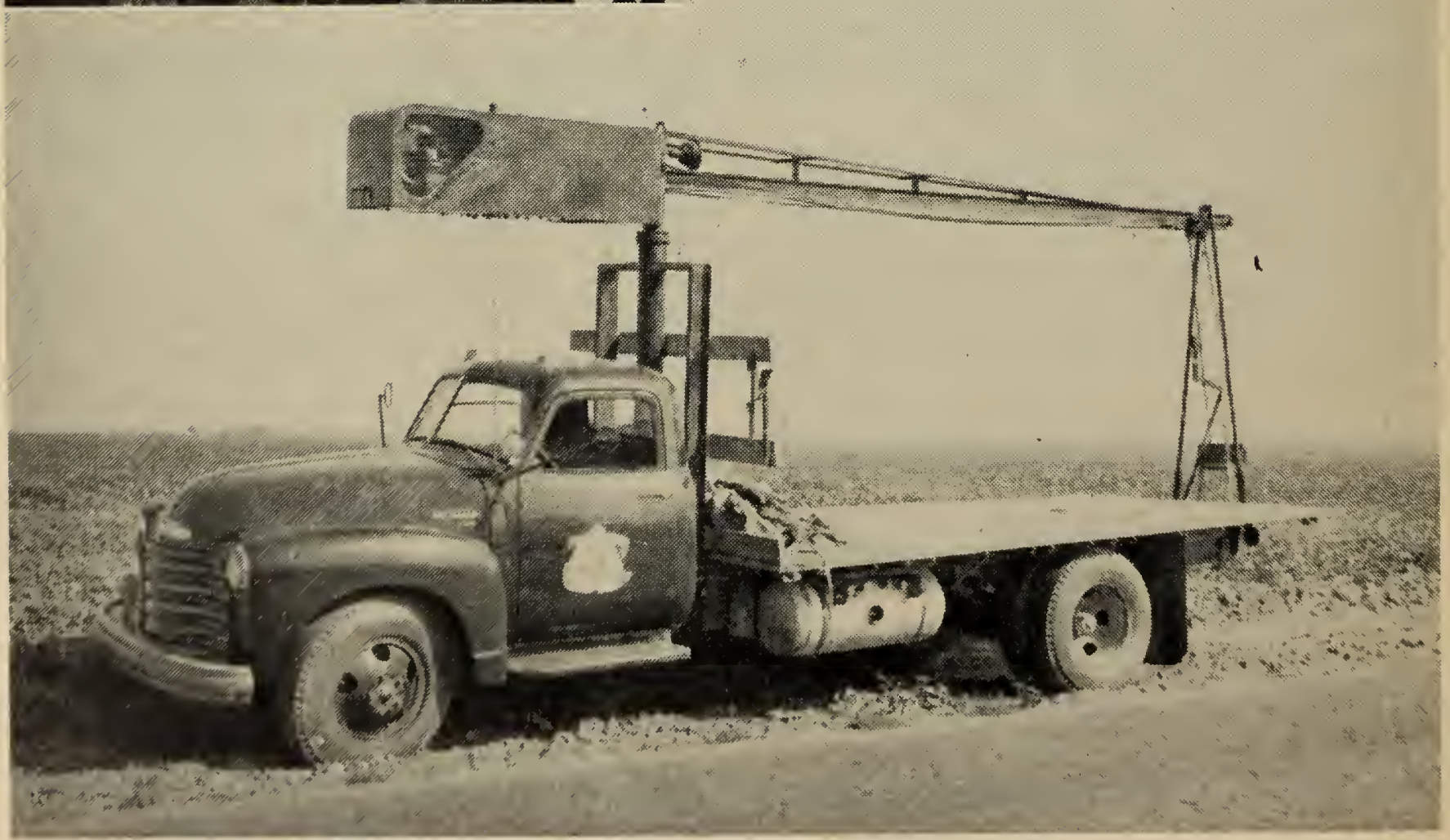

A heavier type of hive hoist that includes an auxiliary gasoline generator and two electric motors. 
posing their nest; then the combs can be cut away, the portions containing brood fastened into frames with cotton string, and the bees enticed into a hive. Usually the hive must remain near the entrance to the wall or tree for a day or two. This is done even though all traces of the combs have been removed from the cavity and the opening has been closed against the re-entrance of the same bees or others. With the necessary equipment and with patience, bees can be trapped from a wall or tree by means of a bee escape so arranged that they can leave but cannot re-enter their old abode. A frame of brood placed in a hive in front of their old entrance is generally necessary to induce the bees to accept the hive as their own. A queen should be introduced after a few days and the hive left in position until most of the brood in the combs has emerged. Then the remainder of the bees in the cavity should be killed, the entrance closed permanently, and the hive taken away. In such instances, wax moths will destroy the combs left in the walls and thus release any honey stored in them. Some reports have indicated the presence of enough honey to seep through the plastering of the walls. This can be avoided by leaving the entrance into the walls open for a few days, or until robber bees can carry out the honey.

\section{Apiary records}

Most successful beekeepers keep sufficient records to indicate their profit and loss from beekeeping operations, and such records are necessary to satisfy income tax returns. If production records kept over a period of years include data on temperature and rainfall, forecasts can be made with greater certainty of the possibilities of honey production some weeks or months ahead of the producing seasons.

In addition, it is important to keep hive records of the origin and age of the queen of each colony as well as of the outstanding colonies if you are interested in improving your stock. Beekeepers frequently keep records on the hives or in notebooks, using abbreviations to save time.

A periodic record of the variations in weight of a hive, together with the blooming dates of the various flowering plants yielding nectar and pollen, will reveal many factors which influence the behavior and production of colonies in the area. These records will enable the beekeeper to plan his work ahead during the winter months.

\section{Food requirements}

Bees must be fed when they lack sufficient stores for their own maintenance. Colonies may be robbed too closely of their surplus stores; and when, for an unexpected or extended period, no nectar is available, artificial stores must be supplied if their natural stores are insufficient. Colonies sometimes obtain a quality of honey that will cause dysentery during long periods of winter confinement; then artificial food must be supplied in the fall to offset this. Under California conditions, bees are not confined for long periods by cold or inclement weather. Colonies in high mountain locations can be moved to the valleys or foothills for the winter and spring.

Some beekeepers feed their colonies for extended periods between nectar flows in order to maintain brood rearing and colony strength. As long as bees have sufficient pollen in their combs, or are bringing in fresh pollen from the field, they may rear brood under the stimulus of such feeding, but they cannot rear brood on sugar syrup alone. Most apiarists now prefer to leave an abundance of honey in the hives, 30 to 60 pounds-enough for the most prolonged dearth of nectarand thus avoid the expensive and troublesome practice of feeding.

Honey supplements. If feeding is necessary, the best substitute for honey is a heavy syrup made of white granulated sugar and water. For winter stores. 


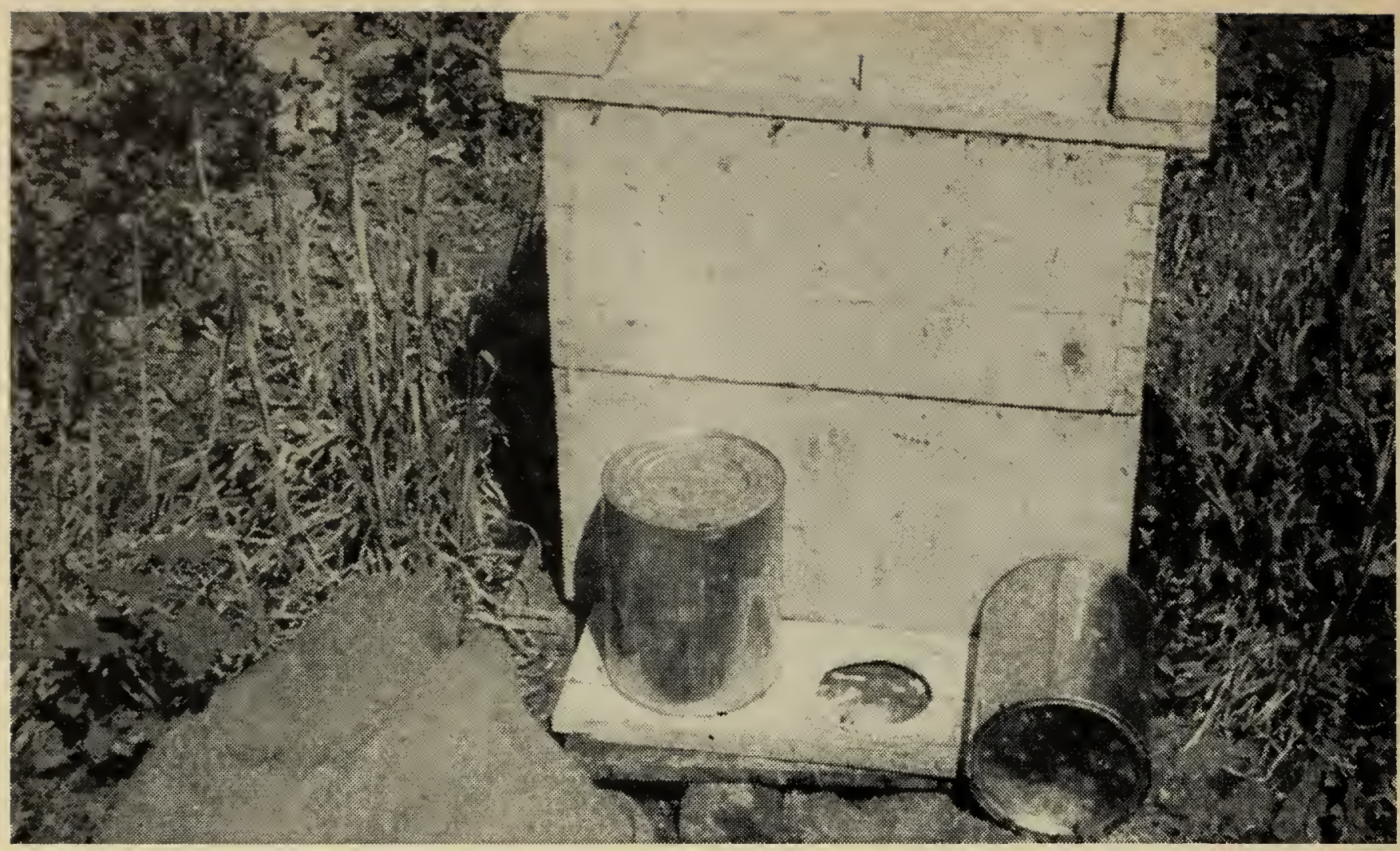

Side feeder for a cell-building colony. The bees enter the tunnel from the hive.

the syrup should be made by dissolving 2 parts of sugar in 1 part of water. In feeding the colonies in cold weather, increase the ratio of sugar to $2 \frac{1}{2}$ parts to 1 part of water, adding 1 teaspoon of cream of tartar to every 20 pounds of sugar to keep the syrup from granulating. In making this heavy syrup, use boiling water to dissolve the sugar, and add the cream of tartar to the boiling syrup. Stir constantly until all sugar is dissolved. Sugar syrup that has fermented, especially in tin or iron containers, should not be fed to bees, for it is often poisonous to them.

If a beekeeper desires to feed his colonies extracted honey instead of sugar syrup, it is advisable to dilute the honey from one-fourth to one-half with water. Honey syrup incites robbing more quickly than sugar syrup. For the greatest safety in feeding honey of an unknown origin, it is desirable to add $1 / 2$ gram of sodium sulfathiazole to each gallon of syrup (see American foulbrood, page 64).

Some beckeepers prefer to feed their colonies candy instead of syrup because it does not stimulate robbing and requires less equipment. The following recipe makes a satisfactory candy for bee feed: 50 pounds of sugar, 4 quarts of water, $1 / 8$ cup of vinegar, $1 / 2$ teaspoonful cream of tartar, and 6 pounds of honey. Bring the liquids to a boil and add the sugar slowly, stirring constantly to prevent burning. Boil to $239^{\circ}$ on a candy thermometer and cool in tubs of water, stirring until the mixture begins to show a creamy color. Then pour into molds, using shallow or deep frames, or lath, lined with waxed paper. If the candy is creased as it cools, it can be broken into blocks of suitable size when cold. A colony can be fed by inserting a frame containing this candy in place of a comb.

Method and time of feeding. There are many systems of feeding colonies on sugar syrup, some of which are: entrance feeders, open-pan feeders, division-board feeders, filling the combs direct with heavy syrup, and open-air floats. The type of container most often use in recent years is the 5- or 10-pound friction-top pail. The lid is punctured with a number of holes made by a threepenny wire nail; the number of holes, as well as the strength of the colony, determines the speed with which the pail is 
emptied by the bees. For slow feeding only one or two holes are needed; but for winter feeding there should be 20 to 30 holes. The pails are filled with the syrup and inverted over the bee-escape hole of the inner cover or placed directly on top of the frames or on a special board leading into the hive from the back or side. If the pail is inverted directly on top of the frames in cool weather, the frames should be covered with canvas to preserve heat. A still better method in cool weather is to cut a hole in a piece of heavy tar paper, place it over the frames, and invert the pail over the hole. In all such methods, an empty hive body should be placed around the feeder; but if this is impossible, the feeder may be inverted over a $3 / 4$-inch hole bored through the outer cover.

If apiaries are so isolated that openair feeders can be used, the feeders should be located a short distance from the apiary to reduce robbing. Syrup can be poured into open pans, trays, or troughs, all of which should be provided with suitable floats to prevent drowning. The stronger colonies will, of course, secure the most syrup. A simple system for quickly feeding many colonies of bees is to plow a trench, line it with tar paper, fill it partially with straw, and pour in the syrup. This is obviously a "charitable" method of feeding if other colonies are within flying distance.

To avoid robbing in an apiary, colonies should be fed late in the afternoon so that by morning the bees will have lost much of the excitement aroused by acquiring the syrup. The best results from stimulative feeding are secured if the colony feeds on a small amount of syrup continuously over a long period. Frictiontop pails can be used for this purpose if the lids are perforated with only two to four holes; the lids will not leak if the pail is level. Colonies being fed for winter stores should receive the syrup soon after the close of the fall nectar flow. If this is done, the bees may have time to
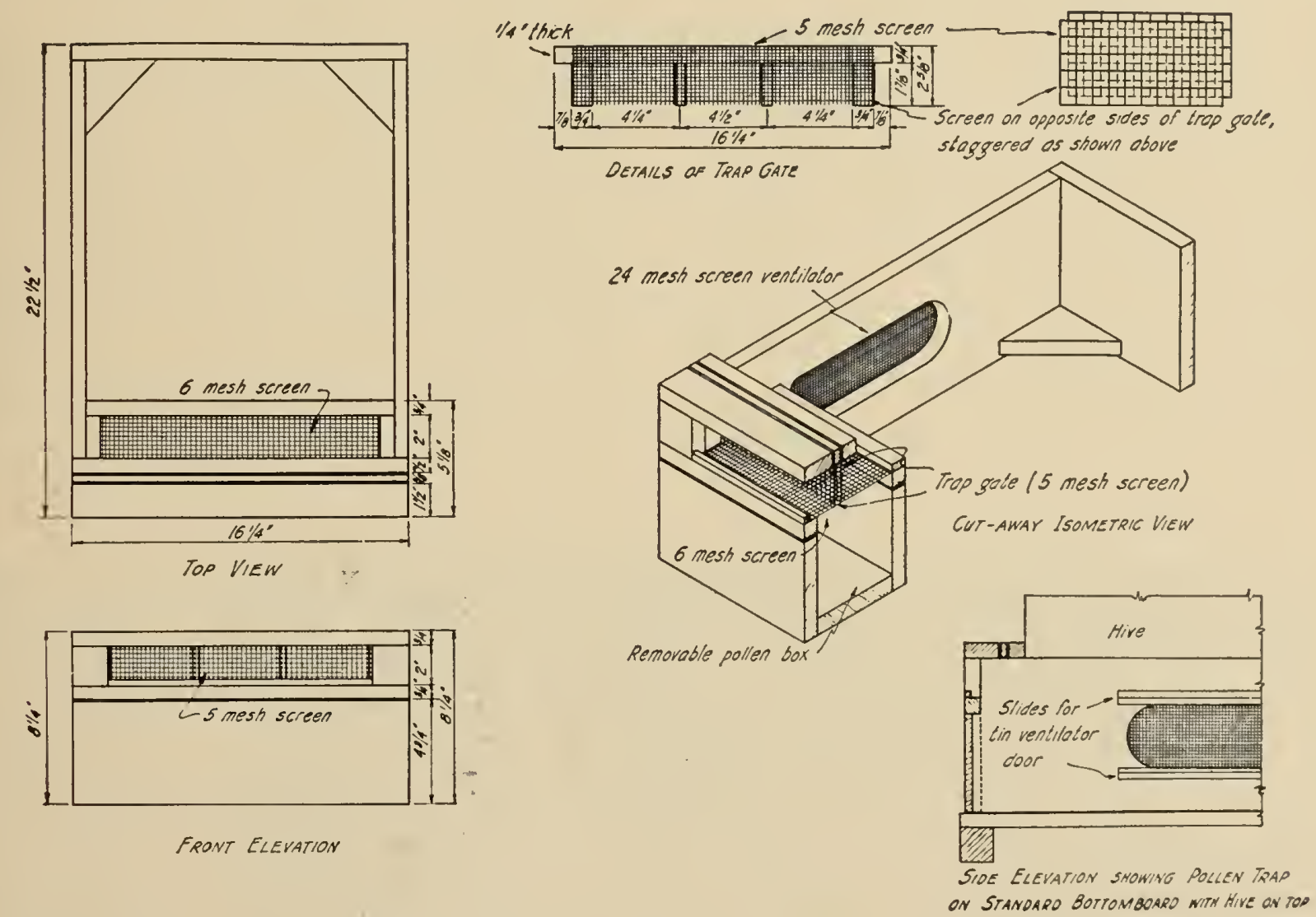

Detail of a pollen trap for collecting pollen from the legs of returning fielders. Courtesy Bureau of Entomology and Plant Quarantine, U.S.D.A. Bee Culture Investigation, Davis. 


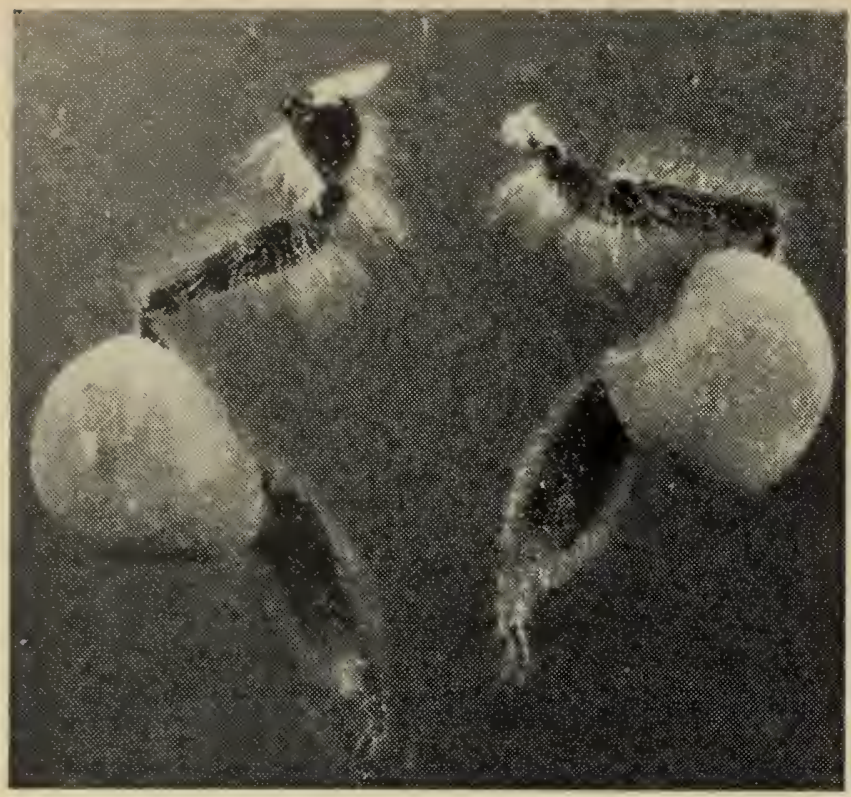

Heavy loads of pollen in the pollen baskets on the hind legs of worker bees.

invert the sugar syrup before cool weather sets in. In this way, they avoid unnecessary labor in generating heat to evaporate the excess moisture.

Pollen supplements. There is no substitute for pollen in the diet of the colony. In regions where there are occasional shortages of pollen, needy colonies should be moved to new locations where pollen is available, or combs of pollen should be stored for just such emergencies and given in time of need.

Pollen traps have been devised to scrape pollen pellets from the legs of bees as they go through a screen grid on entering their hives. This pollen can be dried and stored for use during a pollen scarcity. When the dried pollen is mixed with soybean flour-produced by the extraction process to contain only a low per- centage of fat-and made into a soft cake by the addition of a heavy sugar syrup, the bees will consume it readily and increase the amount of brood. Less efficient pollen supplements, in the absence of pollen, are soybean flour in combination with brewers' yeast, or soybean flour alone, mixed with heavy sugar syrup and made into cakes. Each of these pollen supplements should be placed on top of the frames, immediately over the brood nest, and covered with paper to prevent drying out. The material should be just thick enough not to run down between the frames.

In securing pollen, take care to place the traps only on disease-free colonies.

In making up the mixtures, the following formulas can be used:

Pollen and soybean flour: 3 pounds of pollen, mixed with just enough warm water to loosen the pollen grains thoroughly from the pellets, 12 pounds of soybean flour, 20 pounds of granulated sugar, and 10 pounds of water. A strong colony will use a pound or more of the pollen-soybean mixture within a week or 10 days.

Soybean flour and brewers' yeast: 2 pounds of powdered yeast, 18 pounds of soybean flour, 30 pounds of sugar, and 15 pounds of water. The yeast can be mixed in the water to insure thorough blending. The debittered brewers' yeast is the most satisfactory, while the active and nondebittered yeasts are less acceptable to the bees.

Cake of pollen paste placed on top of the combs and space left for division board feeder.

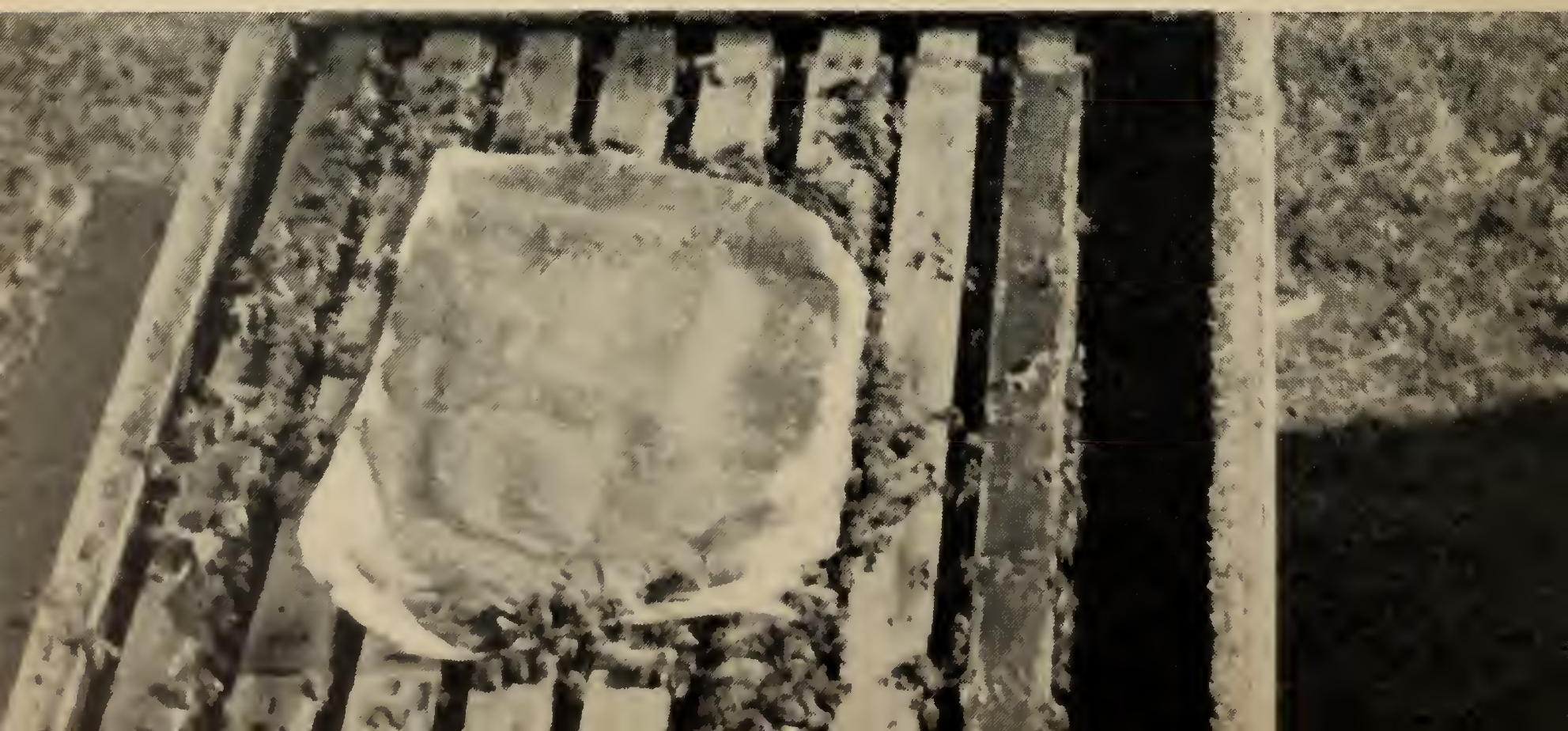




\section{THE REARING OF QUEENS . . . is a highly technical and extremely important operation that requires special equipment and experience}

The importance of good queens cannot be overemphasized. In order to appreciate the amount of work involved in rearing them, every beekeeper should requeen some of his colonies with queens he himself has reared. To rear queens successfully on a commercial scale takes a considerable amount of equipment, special environmental conditions, and years of experience.

During the swarming season, under natural conditions, the queen will deposit an egg in one or more queen-cell cups; also the bees will build queen cells around young worker larvae, from which queens will be produced. These naturally built queen cells can be cut off and transferred to combs in other colonies or to queenless nuclei where they will produce queens. This method is desirable only when the original queen is purely mated and is fully satisfactory. Such cells are seldom produced except during the swarming season, and the practice of rearing queens from a swarming colony is questionable because the tendency to swarm may be increased by such selections.

\section{The use of artificial queen cell cups}

Instead of using naturally built cell cups, the commercial queen raiser makes his own by dipping molds into melted beeswax. The artificially formed cell cups are then fastened to a bar with melted wax, or are placed in small wooden cups, which in turn are fastened to a bar with wax or with a small tack. A modified Hoffman frame can be made to hold three bars, on each of which are fastened about 15 cell cups. A small drop of royal jelly, taken from natural queen cells, about 3 days old, diluted half with warm water, may be placed in the bottom of each cell cup; then a young worker larva, 12 to 24 hours old, is transferred into each cup by means of a transfer needle. The transferring should be done in a warm, humid room free from drafts. The cell bars are then placed in the frame with the cells inverted, and the frame is given to a strong queenless colony previously prepared. Experienced queen breeders can transfer larvae to dry cell cups and secure as good acceptance as when diluted royal jelly is used as a cushion and food for the young larvae.

\section{The cell-building colony}

To get a few cells built, a strong colony can be made queenless 24, hours before the larvae are transferred; the colony should be strong enough to occupy two stories. It should be fed sugar syrup continuously for 3 days before it is made queenless and during the time it is building the cells. One story, containing the queen and two or three frames of brood and bees, should be placed on a stand beside the old location. Its entrance should be turned in the opposite direction from the original hive so that most of the bees will return to their former location. Place the rest of the brood and bees in the queenless part, where enough space should be left for the frame holding the cell bars. This colony will accept a majority of the cells given if the larvae were not injured when transferred. Twenty-four hours after the cells are placed in this hive, the hive body containing the queen can be placed on its original stand, a queen excluder put on, and the body containing the queen cells placed over the excluder. Ten days after 


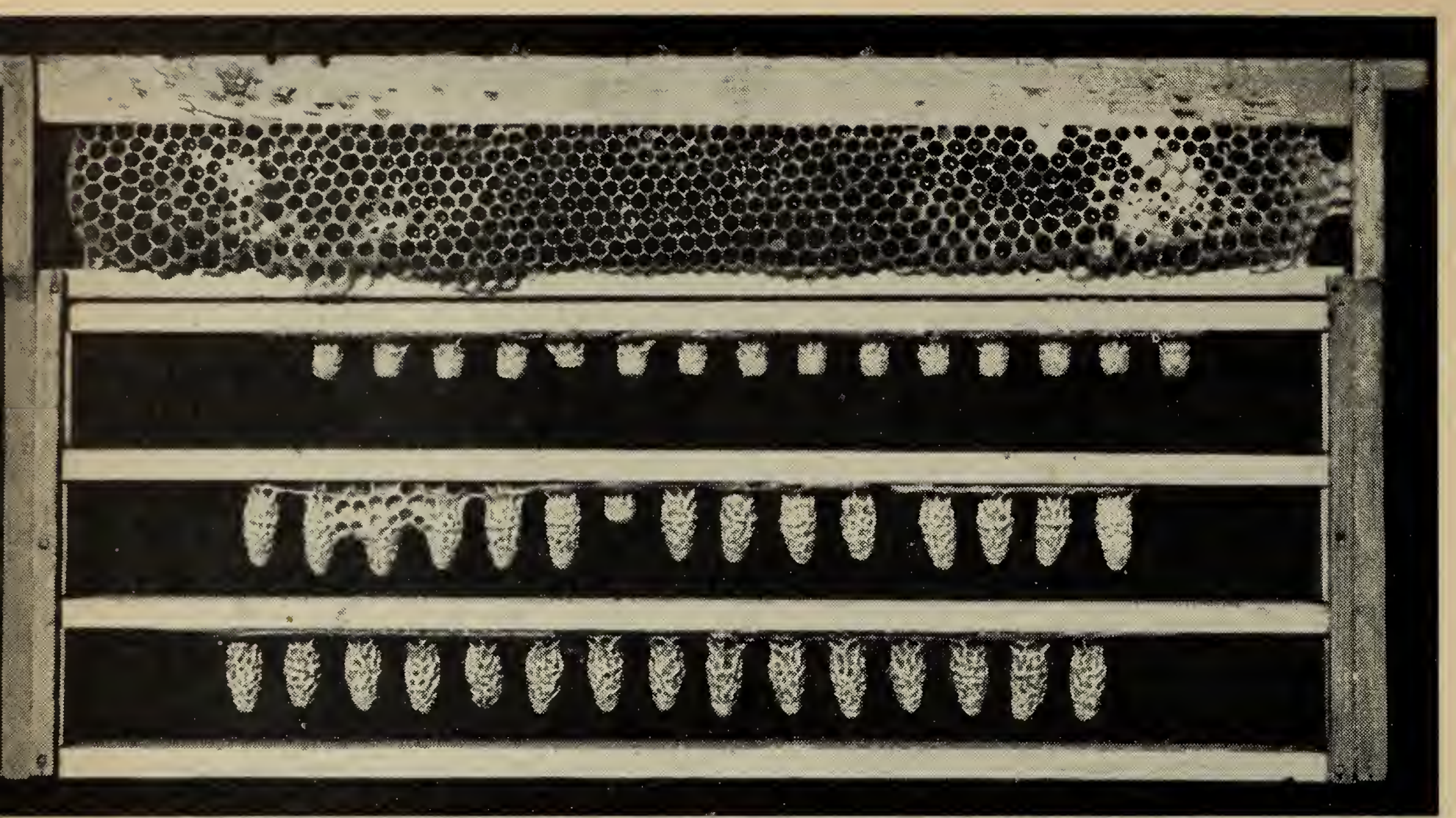

A frame holding three bars of queen cells; the top bar has cells only 24 hours old, while the other cells are sealed.

the larvae are transferred, the cells should be removed and placed separately in nuclei or colonies that have been queenless for at least one day. The young queens will emerge on about the twelfth day after grafting if the larvae transferred to the cell cups were 24 hours old.

\section{A stock improvement program}

While many beekeepers rear some or all of their own queens, others prefer to get their queens from commercial queen raisers. In either case, you should requeen often enough to keep prolific queens of a good strain of honey producers at the head of each colony. Avoid inbreeding by rearing queens from unrelated queen mothers in alternate years.

In testing queens for prospective breeders, it is desirable to rear several queens from a number of purebred queens selected for their desirable qualities and to keep records on the colonies of the daughter queens to determine which queen mother produces the best queens. If you do not have a number of colonies of well-bred bees from which to select prospective breeders, it is best to get a number of untested queens from a queen raiser and rear queens from each for testing purposes.

The commercial queen raiser is better equipped to do this testing then the average commercial honey producer, but any beekeeper who raises queens for his own colonies should practice this selective rearing of queens in order to maintain colonies of good temper, disease resistance, and productivity. If you requeen your colonies with queens from the same queen mother for two successive seasons, a large proportion of the young queens the second season will mate with their sisters' drones.

Handle the ripe queen cells carefully, because injury to the developing bees will produce deformed queens. The bees that adhere to the frame containing the cells should be brushed off-never shaken off. Not more than 45 cells should be given to a strong cell-building colony at a time, but after the first transfer additional bars of cells can be given every 4 days. To insure proper development of 


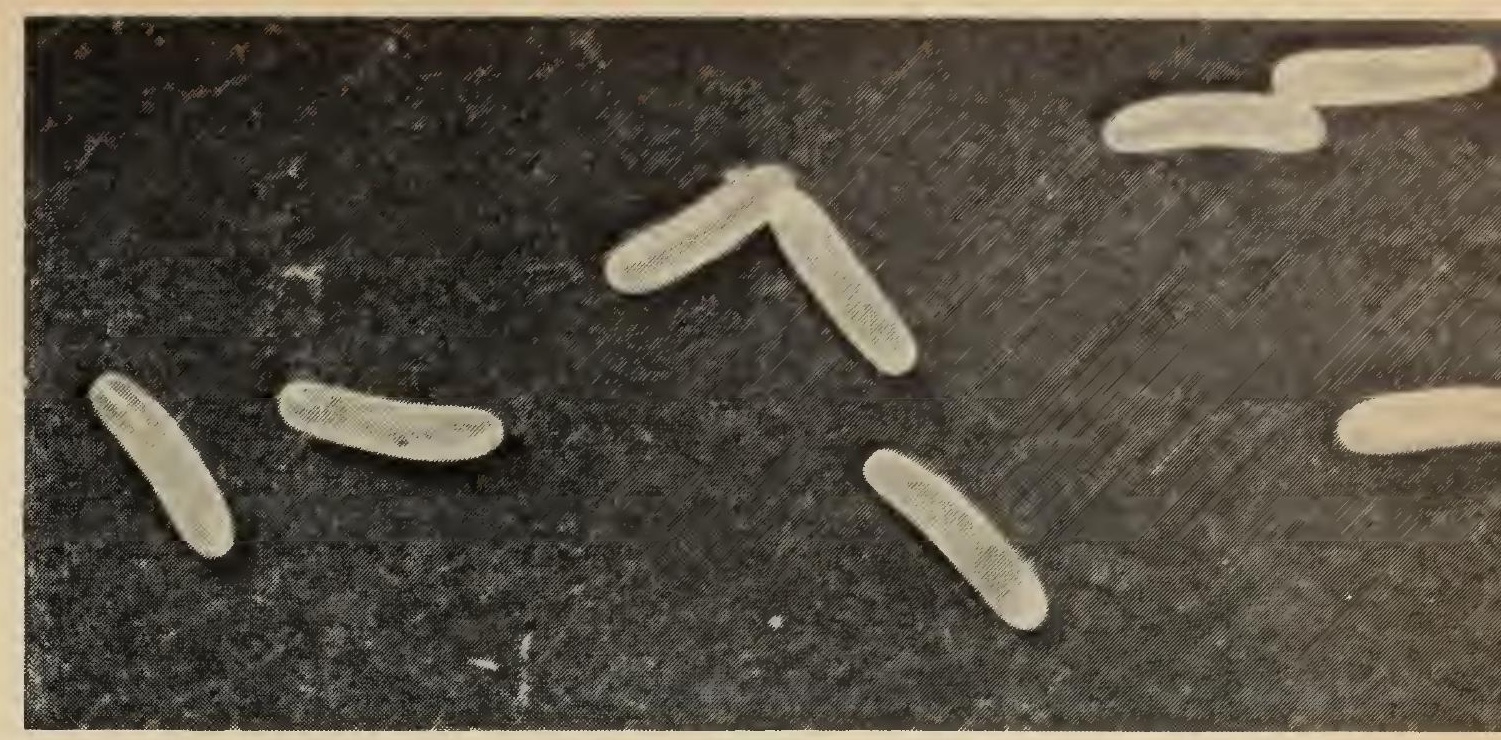

Top. Eggs of the queen honeybee, much enlarged. Left. Queen. cells cut open to show young queen pupa. Right. Opened queen cell with larva at the spinning stage, showing the silk fibers and the surplus food at the bottom of the cell. Bottom. Queen cells from which queens have emerged.
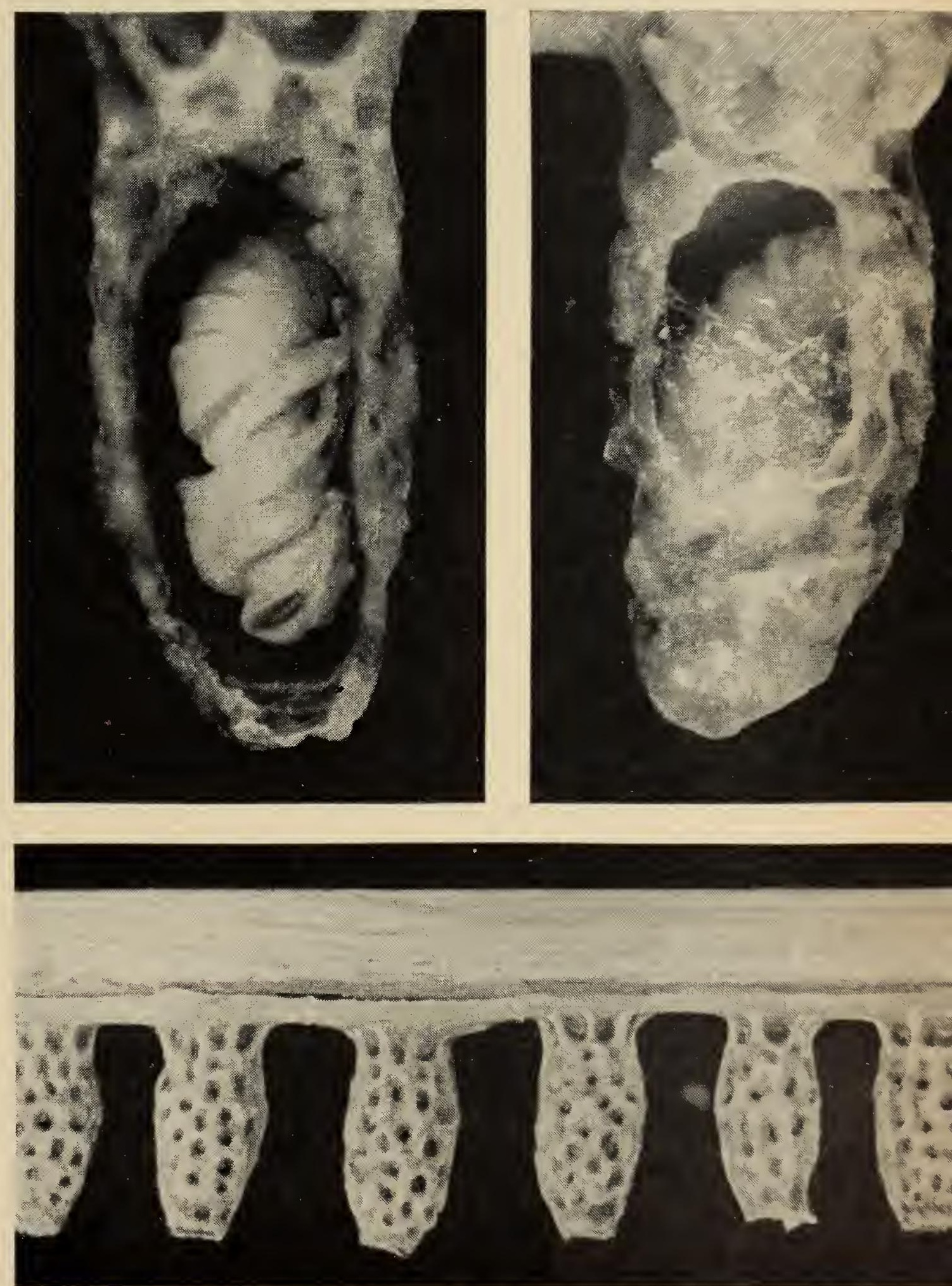


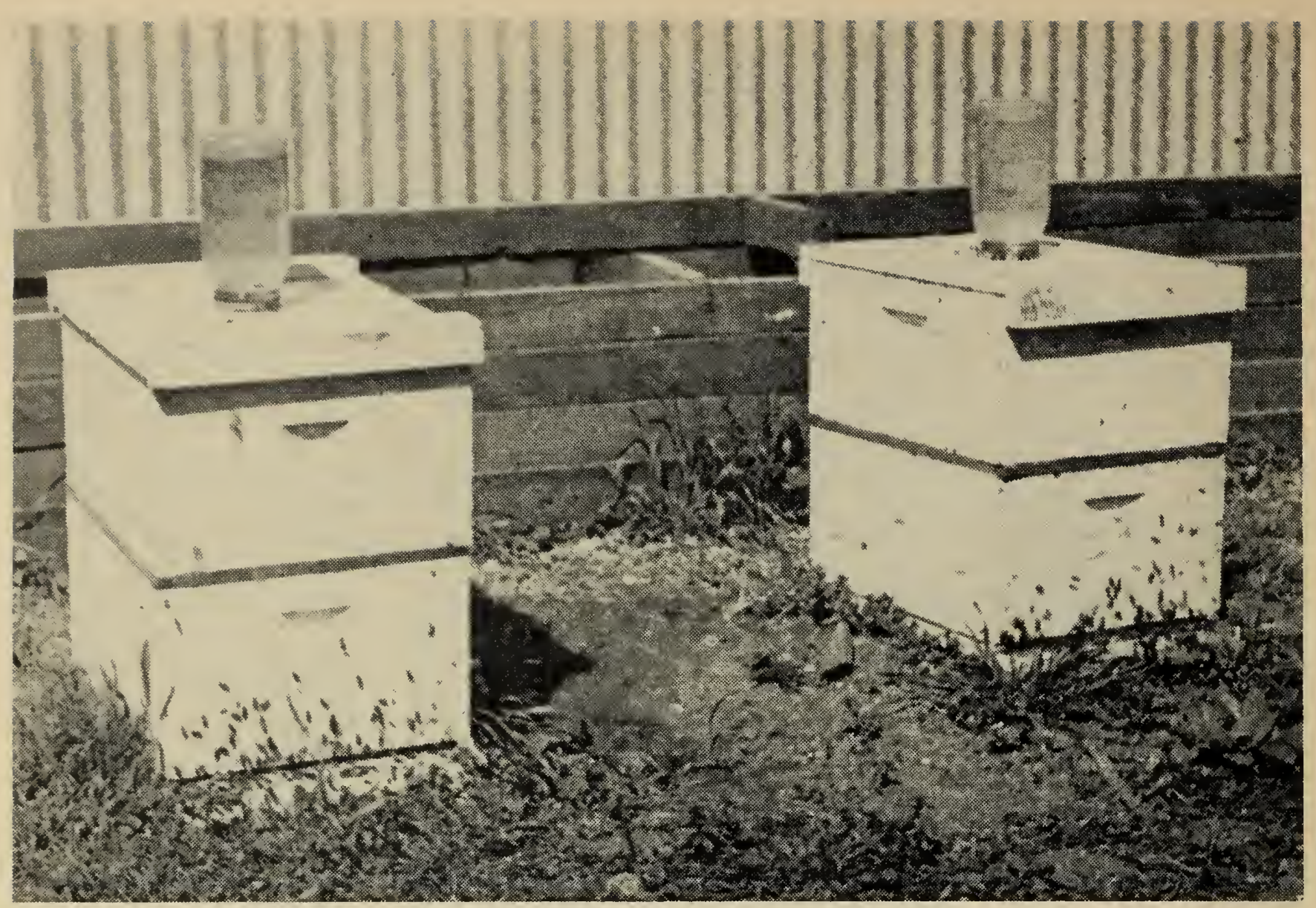

Queen-right cell-building colonies with the feeder jars inverted over holes in the lids. A queen excluder separates the hive body containing the queen cells from the queen-right brood chamber.

the young queen larvae, the cell-building colony should be overflowing with bees, should have an ample supply of pollen, and should be fed, slowly but constantly, a heavy sugar syrup. Young bees or combs of emerging brood should be added every 7 to 10 days.

The young queens will generally mate within 10 days after their emergence and can be caged or introduced into colonies a few days after they have started to lay. Sometimes young queens are unable to mate because of physical injury or because unfavorable weather conditions prevent it. Under such circumstances unmated queens may begin to lay. They are then called drone-layers because their eggs can produce only drones. This seldom occurs naturally until the unmated queen is 3 weeks old.

\section{Federal laws regulate importation of bees}

In 1922 a federal law was passed prohibiting the importation of honeybees and queens into the United States except under the supervision of the United States Department of Agriculture, Washington, D.C., in order to forestall the introduction of certain bee diseases that have proved destructive in various European countries. This law was revoked, effective August 27, 1947. Another federal law was substituted which now prevents all importations of honeybees from European countries except such as may be brought in by the United States Department of Agriculture for its own experimental or scientific purposes or by a special permit issued by the Department. Under this system queen bees are received and examined by the U.S.D.A. before they are released to a beekeeper. Queens and bees may be shipped either way across the Canadian border. (Inquiries concerning these regulations should be directed to United States Department of Agriculture, Division of Bee Culture, Agricultural Research Center, Beltsville, Maryland.) 


\section{DISEASES AND ENEMIES OF BEES . . . how to reduce losses from these sources to a minimum, by remedial and/or preventive methods}

The honeybee, like most other insects, is subject to diseases and enemies which continually menace its survival. In territories with no organized methods of control, brood diseases in particular may make beekeeping uncertain or impossible. Fortunately, this condition is decreasing in the more important beekeeping regions of California when county inspection of apiaries is carried out in an efficient manner. The destructiveness of the different diseases, however, and the uncertainty of entirely eradicating them from any particular area compel every beekeeper to study the more important diseases, their methods of spread, and their control.

The diseases may be divided into two classes: those affecting the brood and those attacking the adults. Brood diseases are generally more serious and more difficult to control than diseases of the adults, except, possibly, the Isle of Wight disease, which has not so far occurred in this country. Brood diseases are usually specific in character and can be distinguished by their gross and microscopic symptoms. Some cause offensive odors and are therefore generally called foulbrood; but this term more rightly applies to two of world-wide distributionAmerican and European foulbrood. A summary of symptoms of brood diseases is given in table 3 .

\section{To prevent and control bee diseases}

Apiary inspection laws. Beekeepers can do much to eradicate bee diseases by frequently inspecting their own colonies and by obeying the regulatory measures on registration, used equipment, and moving of hives.
Apiary laws are subject to change, and the latest regulations on beekeeping should be obtained from the State Department of Agriculture, Sacramento.

The California Apiary Inspection Act of 1927, with its subsequent amendments, deals with the control and eradication of bee diseases in California. It pertains particularly to foulbrood diseases. Its enforcement is directed by the California State Department of Agriculture through the county agricultural commissioners, and their deputies. Almost every county in California in which beekeeping is recognized as an important agricultural industry has some apiary-inspection service. In the remaining counties, beekeepers may secure apiary inspection by applying to the State Department of Agriculture, Sacramento.

To facilitate the inspection of apiaries and to be notified if poisons are to be applied in the vicinity of your colonies, the location of each apiary must be reg. istered with the County Agricultural Commissioner before November 1 of each year. The present law requires that each apiary must be registered and must have its identifying number or letter in some conspicuous place-on a sign near the apiary, on the front of a hive, or on a hive cover. The brand number or an identifying letter must be obtained from the State Department of Agriculture.

When an apiary is moved within the state, the county agricultural commis. sioners of the counties involved must be notified of the change in location within 5 days. The description of the apiary location must be specific. It is unlawful to move colonies infected with American foulbrood without the written permission of the county apiary inspector. 


\begin{tabular}{|c|c|c|c|c|c|c|c|c|}
\hline \multirow{5}{*}{ 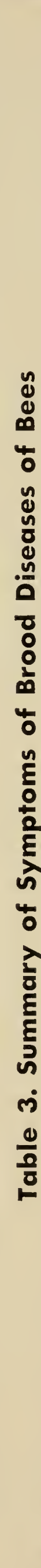 } & 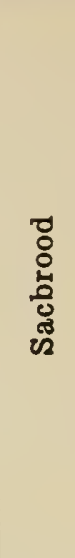 & 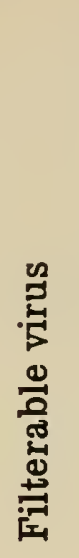 & 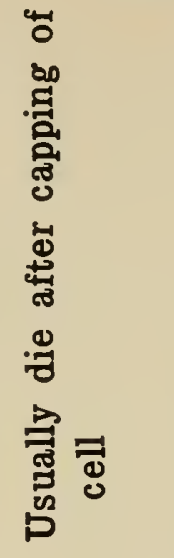 & 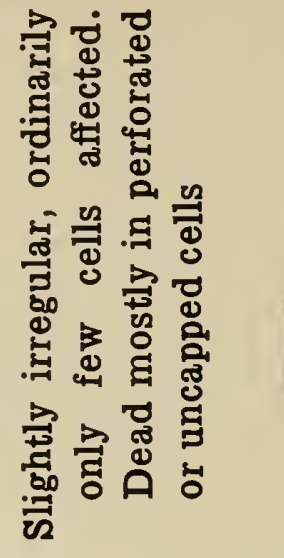 & 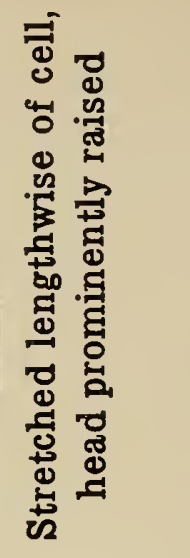 & 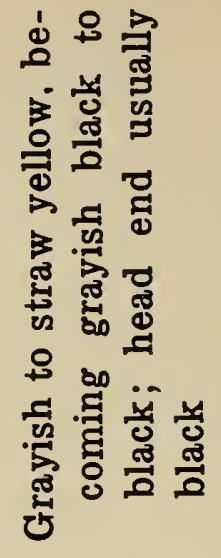 & 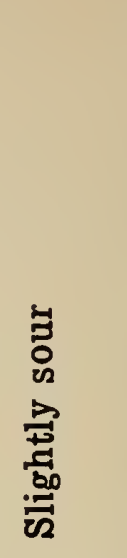 & 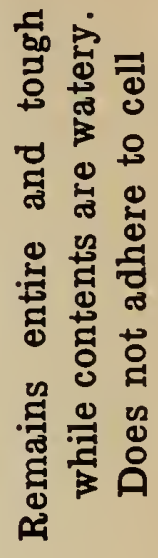 \\
\hline & 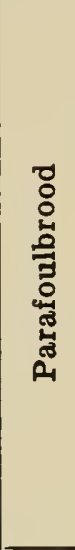 & 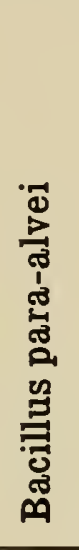 & 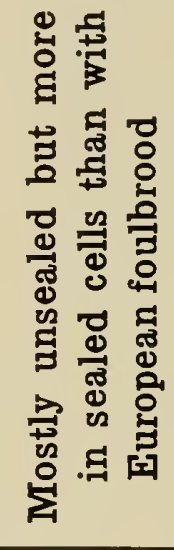 & 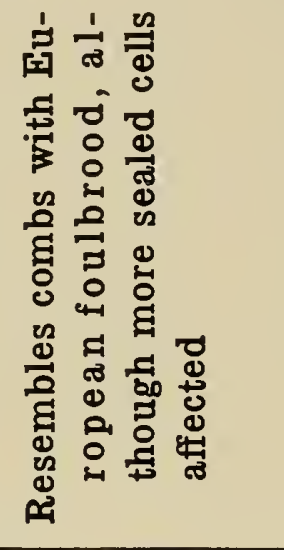 & 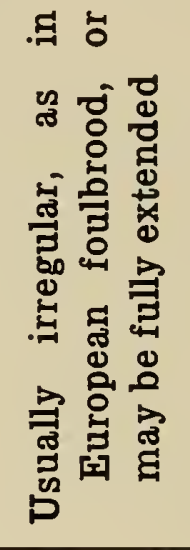 & 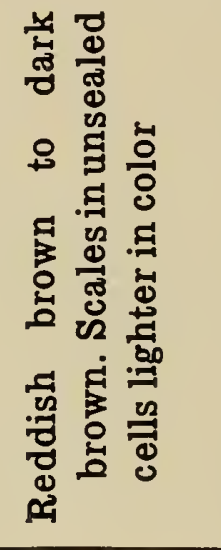 & 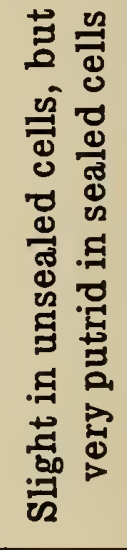 & 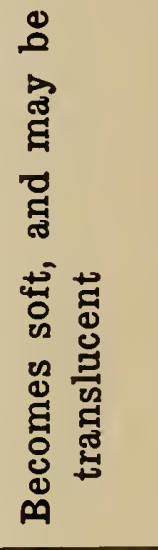 \\
\hline & 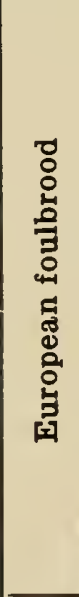 & 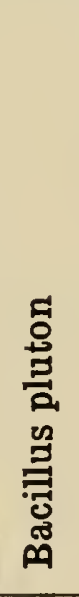 & 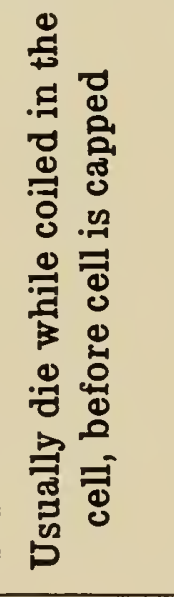 & 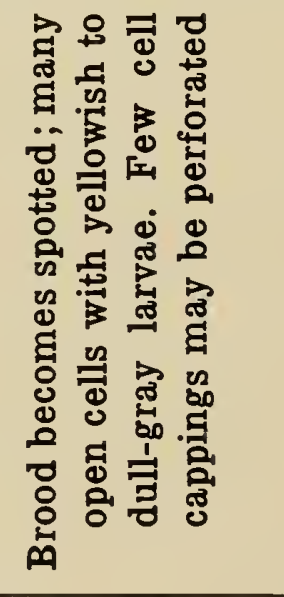 & 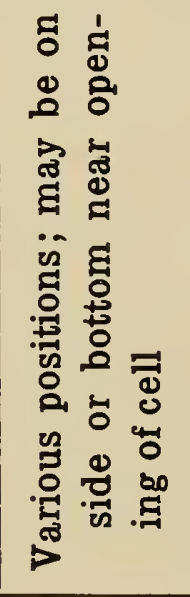 & 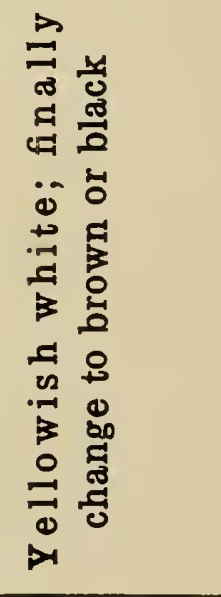 & 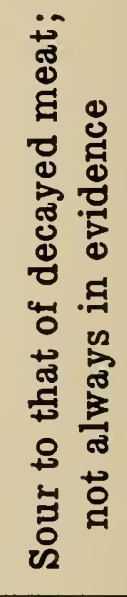 & 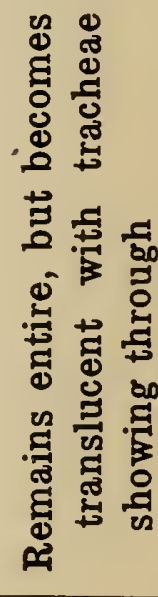 \\
\hline & 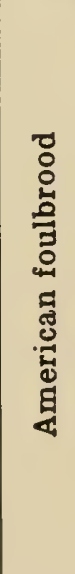 & 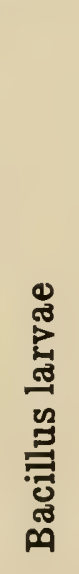 & 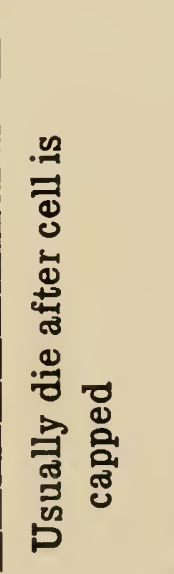 & 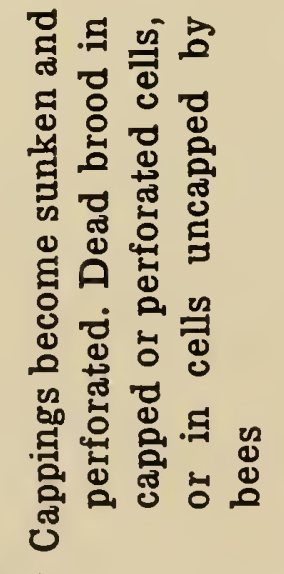 & 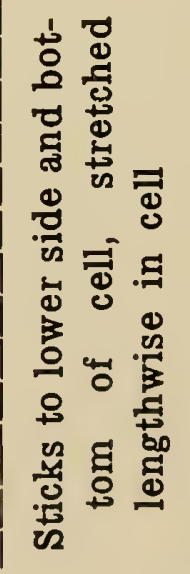 & 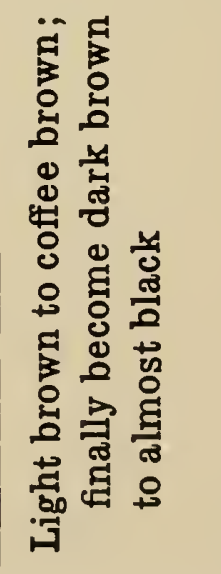 & 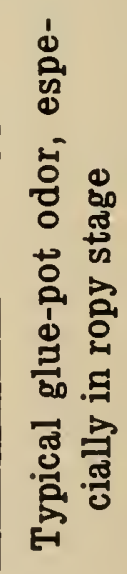 & 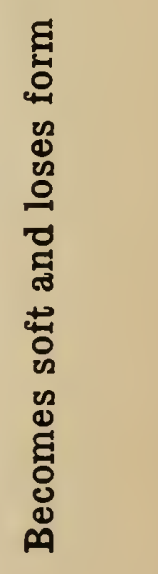 \\
\hline & 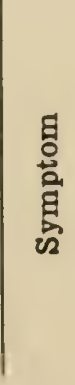 & 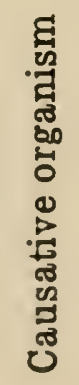 & 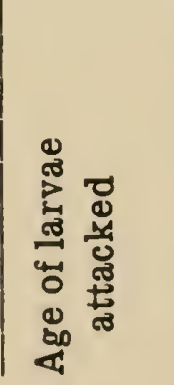 & 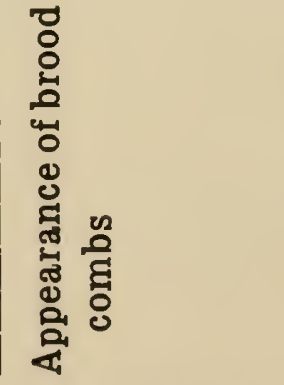 & 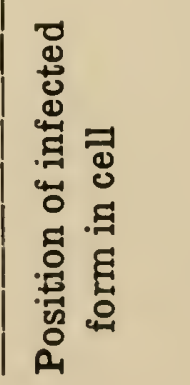 & 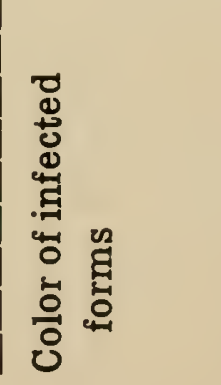 & סृ & 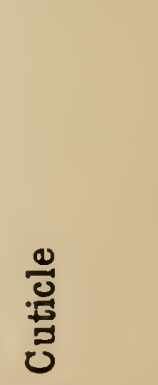 \\
\hline
\end{tabular}




\begin{tabular}{|c|c|c|c|}
\hline 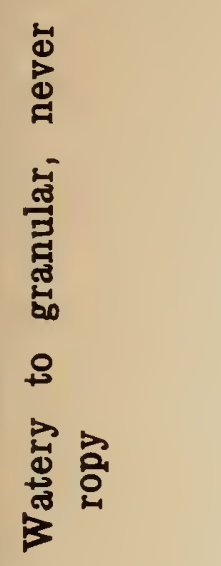 & 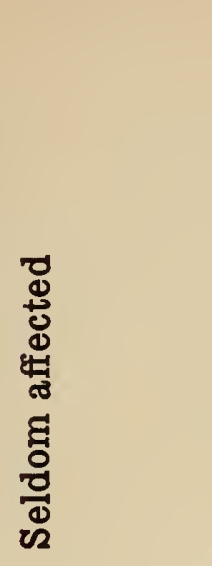 & 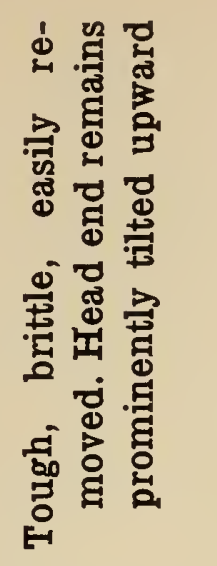 & 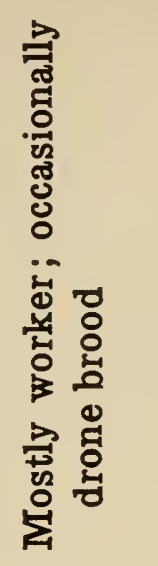 \\
\hline 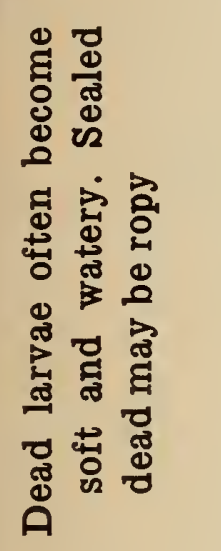 & 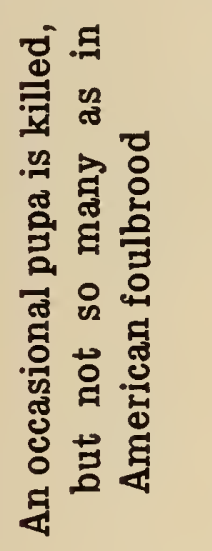 & 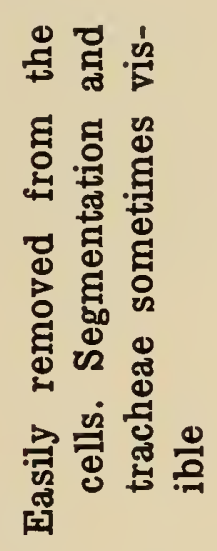 & 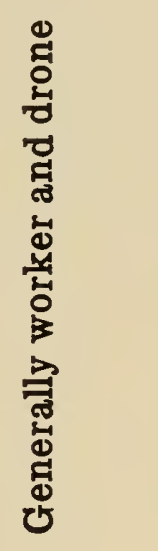 \\
\hline 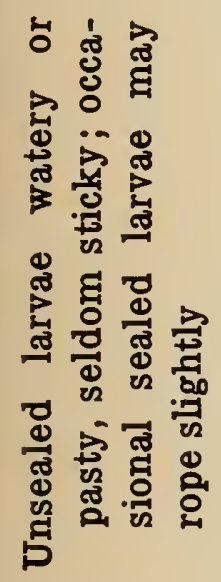 & 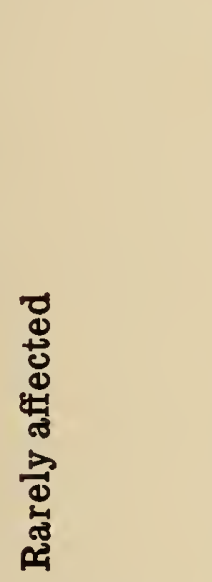 & 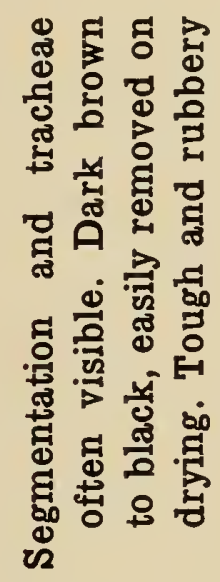 & 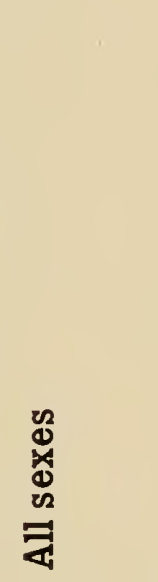 \\
\hline 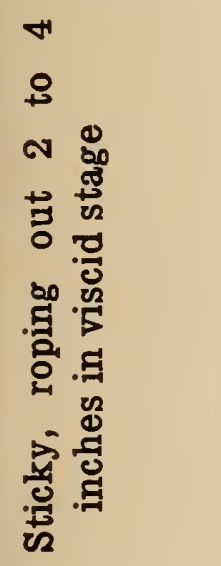 & 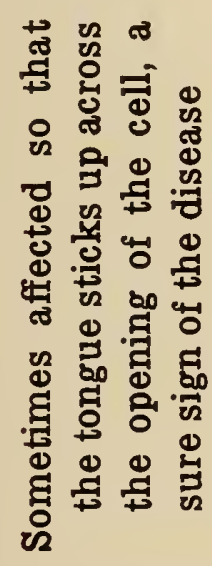 & 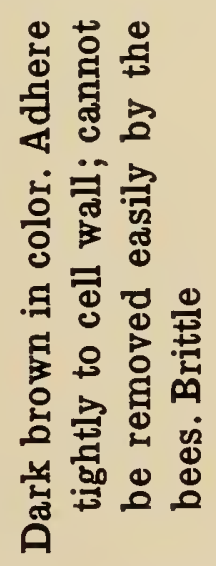 & 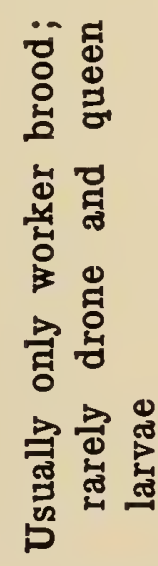 \\
\hline 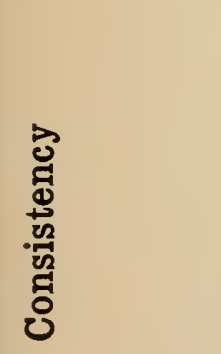 & 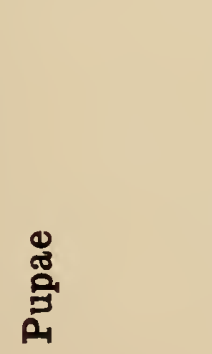 & 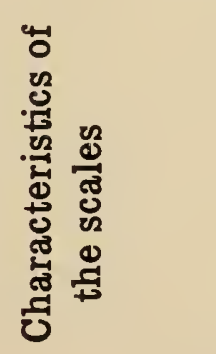 & 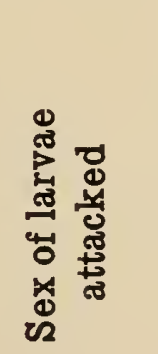 \\
\hline
\end{tabular}


Before moving hives of bees or used equipment across state borders, inquire about the regulations governing such traffic. Some states prohibit the importation of used bee equipment, while others require each shipment to be accompanied by an inspection certificate indicating that the colonies were inspected and found free of disease.

The state or county inspectors are always ready to aid the beekeeper in disease control. If you have any doubt concerning the gross symptoms of any disease, consult the county inspector or send a sample of the diseased brood to the State Department of Agriculture in Sacramento or to the Apiculturist, University of California, Davis, for diagnosis. The sample can be a smear of a diseased larva on a piece of paper or on a toothpick enclosed with a letter.

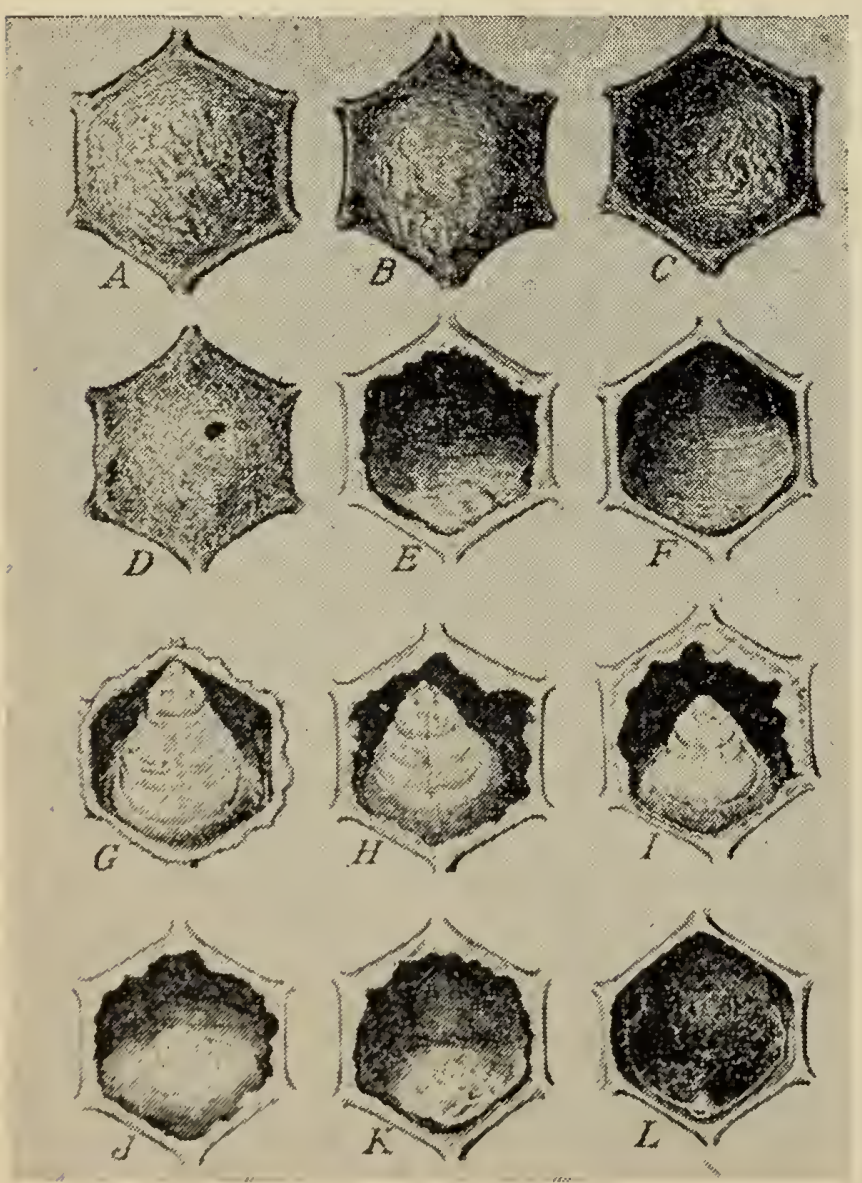

Symptoms of brood infected with American foulbrood: A, normal capping over healthy larva; $B$ to $F$, stages in the discoloration and removal of cappings; $G$, capping removed to show healthy larva; $H$ to $L$, stages in the decay and drying of larvae killed by American foulbrood, front view. From U.S.D.A. Cir. 392.

\section{Diseases affecting the brood of bees}

American foulbrood. This disease is by far the most destructive and most generally distributed brood disease. Once attacked, a colony seldom recovers if it is left alone. The disease is persistent. It is caused by a spore-forming bacterium, Bacillus larvae, which kills the larvae shortly after the cells are sealed. For this reason the beekeeper seldom discovers the disease until occasional cells of sealed brood have sunken, greasylooking cappings, often with irregular perforations. The dead larvae vary from brownish yellow to coffee brown, according to the degree of putrefaction; they are always stretched lengthwise of the cell and retain their shape for only a short time after death. In the final stages of decay, they lose all traces of segmentation and become a flattened mass, the contents of which are tenacious or ropy. If, at this stage, a match stem is used to stir the contents of a diseased cell and then slowly withdrawn, the decayed material will rope for a distance of 1 to 4 inches before breaking. The offensive odor is similar to that of heated glue. The final remains, or scale of the larva, usually adhere tightly to the lower side and bottom of the cell. In advanced cases, pupae are also killed; remains will be found with the pupal tongue extending upward, sometimes attached to the top of the cell. Most cells containing these scales are uncapped entirely by the bees. The disease attacks the worker brood primarily - but in rare instances drone and queen larvae become infected.

The spores of $B$. larvae can survive in honey for an indefinite period. For this reason, the disease is spread primarily by bees robbing honey from diseased combs and by the use and interchange of infected equipment. Swarms that emerge from diseased colonies may transmit the disease, especially if they are hived on drawn combs.

Various methods to control American 


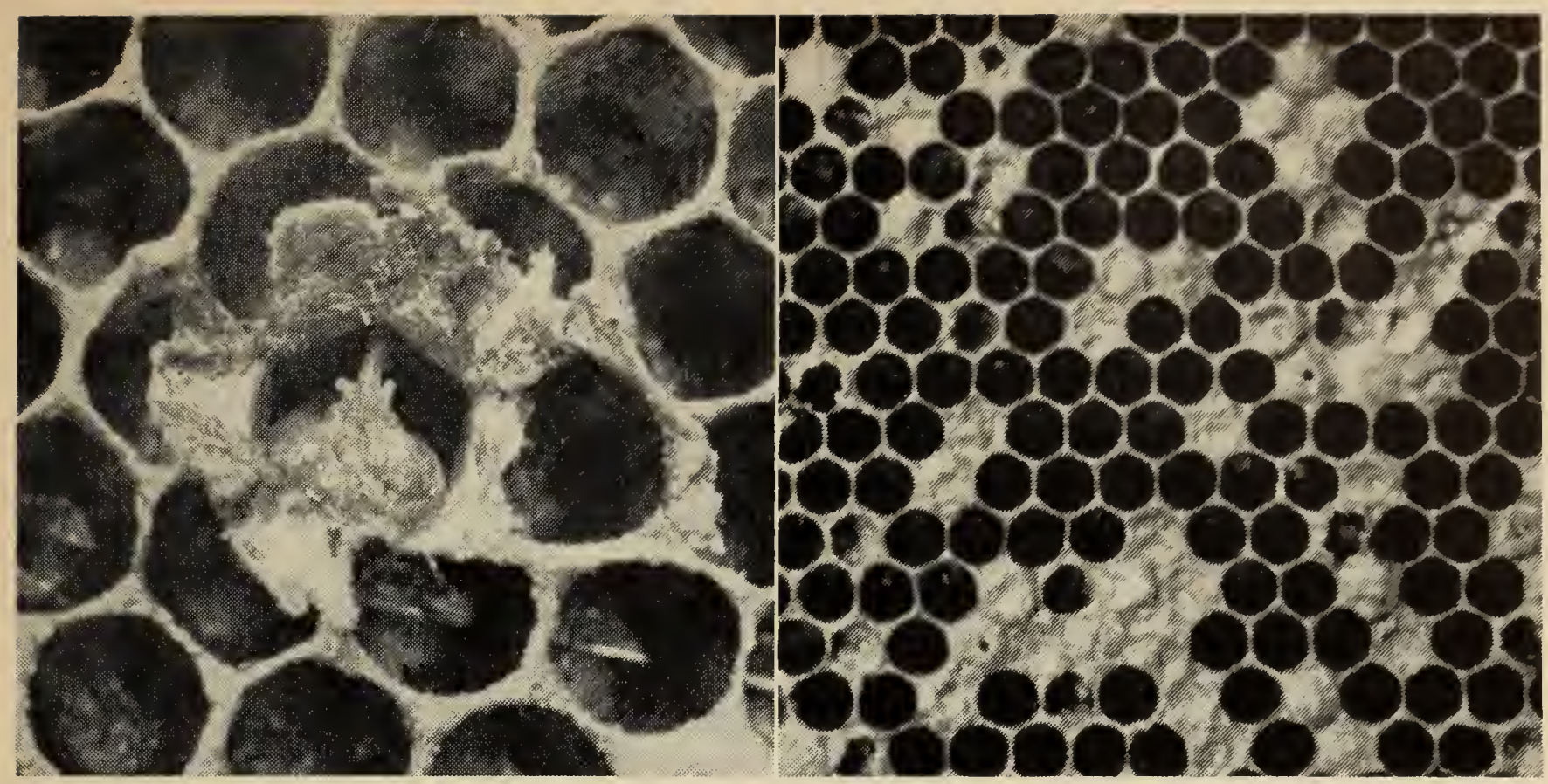

Left. Pupa infected with American foulbrood frequently dies with the tongue extended upward across the cell opening. Right. A comb of brood showing typical symptoms of American foulbrood.

foulbrood have been based on the fact that the disease can be transmitted by honey from infected colonies. The bacillus causing the disease is also highly resistant to drying. Attempts have been made to save the bees by shaking them from an infected hive onto frames containing sheets of foundation; but this practice often causes the disease to be spread by robbing bees and by bees drifting from the infected colony during the procedure. Consequently, the quickest effective treatment is to kill the colony and thoroughly destroy all bees and infected combs by burning.

During the past few years, some strains of bees resistant to American foulbrood have been produced by private, federal, and state agencies. Evidence has been established that this resistance is an inherited character and that the great destructiveness of the disease may be reduced or controlled through the breeding of strains selected for this factor. Since the mating of the queen cannot be controlled on a practical basis, the introduction of this disease-resistant character into all California strains could not be an accomplished fact for many years even if it were attempted.

The most practical method of killing the colony is to place a tablespoon of powdered calcium cyanide (Cyanogas) on a piece of paper and slip it on the bottom board 2 or 3 inches behind the entrance.

This deadly poison should be handled with extreme care so that the fumes will not be inhaled by the operator.

After killing the bees, carry the hive to one side of the apiary. Any field bees which later return will drift into adjoining hives without any danger of spreading this disease. The present (1954) California regulations require that all frames, combs, and bees be burned in a hole deep enough to keep any honey or wax from running out on the ground. After the fire has burned out, the remains must be covered with soil to a depth of 24 inches. Save the bottom board, hive bodies, and covers, but scrape them clean and scrub all parts thoroughly with a strong soap solution to remove all comb and traces of honey.

Sulfathiazole and American foulbrood. The potential value of sulfathiazole in the control of American foul. brood was first explored by Haseman 
and Childers in 1942 and the results published in 1944. Since then numerous articles have appeared in scientific journals and beekeeping literature for and against its use. Investigations with sulfathiazole in the treatment of colonies infected with American foulbrood were started at the University of California in 1945, and results have since been recorded on approximately 100 colonies infected with American foulbrood. The following comments are designed to answer some of the questions regarding the use of sulfathiazole but do not constitute a recommendation of its general use.*

In line with the results of other research workers, it has been found that when sulfathiazole is present in sufficient concentration in the food fed by nurse bees to bee larvae, the sulfathiazole inhibits the growth of $B$. larvae and thus prevents the development of the disease. It also stimulates or enables the bees in some manner to clean the scales of American foulbrood from the cells when they prepare the cells for additional brood. The sulfathiazole does not act as an antiseptic.

It is well known that the spores of $B$. larvae can live indefinitely in honey, although no other organism can sustain itself in this way. American foulbrood is spread from colony to colony, frequently by the bees of one securing infected honey from another. In the interchange of combs between the brood nest and supers in the normal management of colonies, cells containing scales of larvae dead of American foulbrood may be covered up with honey or pollen in any part of the hive. These hidden scales or the spores in the honey are not affected by the sulfathiazole unless the honey and pollen are used for brood rearing while the nurse bees have access to the sulfathiazole. For these reasons, it was found desirable to include two fundamental manipulations in the use of sulfathiazole in the treatment of colonies infected with American foulbrood: (1) all the honey and pollen in the combs should either be removed or used by the bees while they have access to sulfa-syrup; and (2) the combs and bees should be so manipulated as to cause the bees to clean out every cell for the production of brood while the bees are feeding on the sulfa-syrup.

This thorough treatment involves removing the honey from all the combs in each infected hive, $\uparrow$ diluting the honey one-third to one-half with water, and adding $1 / 2$ gram or $1 / 4$ teaspoon of sodium sulfathiazole dissolved in warm water and mixed thoroughly in each gallon of the syrup before it is fed back to the bees. Sugar syrup can be used instead of honey. During the feeding process the combs have to be manipulated at intervals from the sides of the brood chamber toward the center of the brood nest so that brood will be reared in each cell. It was found that the bees in treated colonies would not clean out the diseased material from cells unless the cells were in the immediate brood area. To hasten the cleaning-up process, 2- and 3-story colonies were divided and laying queens were introduced into each division even when bees had to be added to increase the strength of each division. Feeding was continued, at intervals, until all the disease had disappeared when brood had been reared in all the combs.

As a precaution against the spread of the disease, the colonies under treatment were isolated and kept under quarantine

* Sulfadiazine has been found to be equally effective and can be substituted where sulfathiazole is mentioned in this discussion.

$\dagger$ The extractor should be washed thoroughly afterwards with hot water or kept solcly for this purpose.

Under the 1954 provisions of the Agricultural Code of California, it is held illegal for a bcekceper to maintain colonies diseased with $\Lambda$ merican foulbrood or to cxtract honey from any combs in a discased hive. The $\Lambda$ gricultural Code directs that the bces in a diseased colony be killed and burned and the combs with their contents either burned in a prescribed manner or melted in an approved wax-salvage plant and the equipment sterilized. 
for the balance of the first year. During the second year, the colonies were again induced to rear brood in all their combs but were not fed sulfa-syrup. Colonies that went through the second season without the aid of sulfa-syrup and without showing any evidence of AFB were considered cured of the disease and put into production.

Each comb that had originally contained diseased brood was marked with an " $\mathrm{A}$ " on the top bar and also painted with a spot of blue paint so each could be recognized later. It was considered un- wise to extract any honey for sale from a colony that had any sulfathiazole in its combs. The honey they produced was used to feed other colonies. Colonies treated in the above manner have since shown no evidence of AFB after two to eight years.

Many beekeepers throughout the country have advocated using sulfathiazole as a preventive to the spread of the disease by feeding a gallon of sulfa-syrup in the fall and early spring when bees do most of their robbing, and then burning all colonies found infected with AFB.

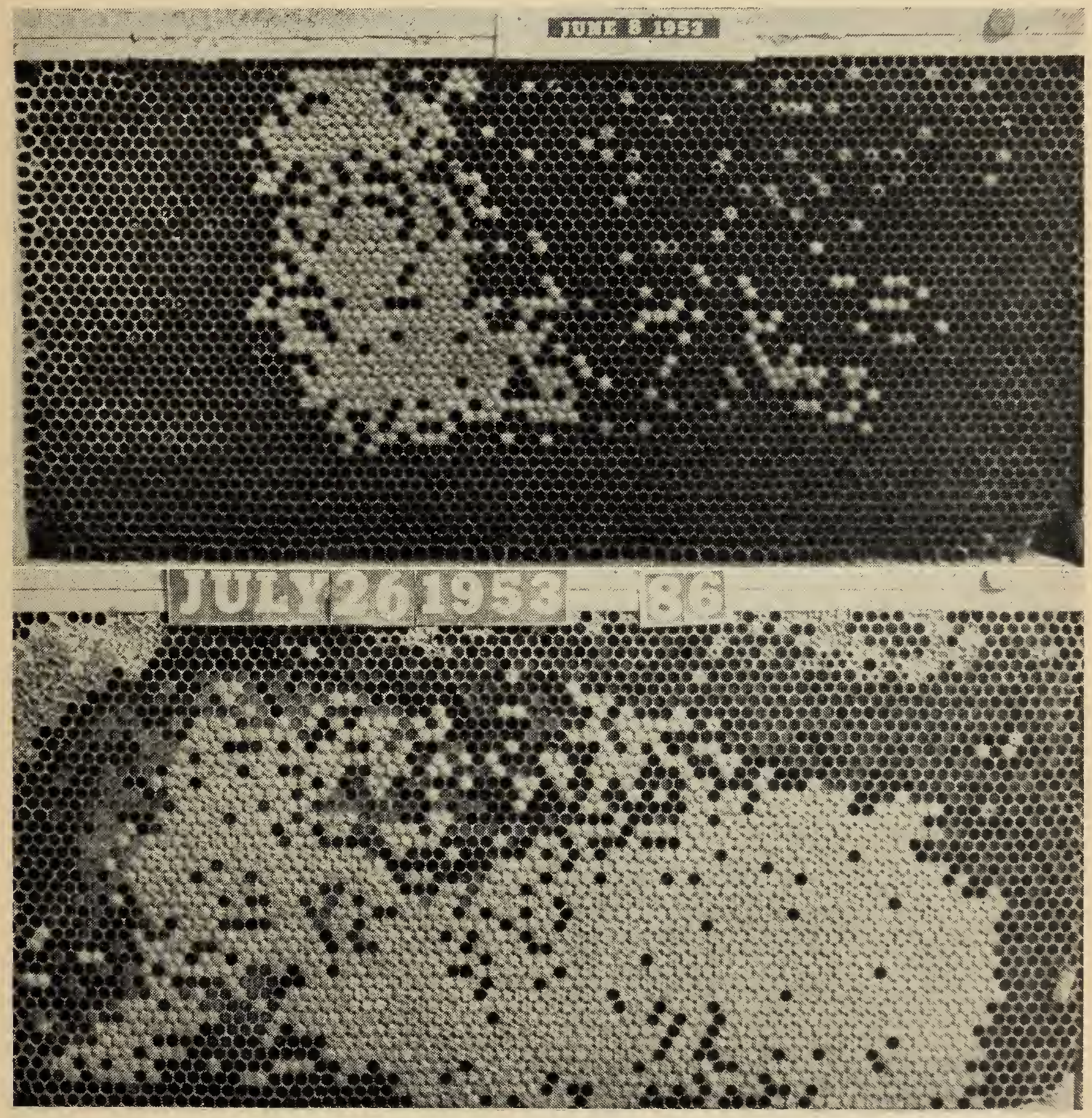

Combs of brood showing (top) the symptoms of American foulbrood and (bottom) the results obtained by proper treatment with sodium sulfathiazole. 


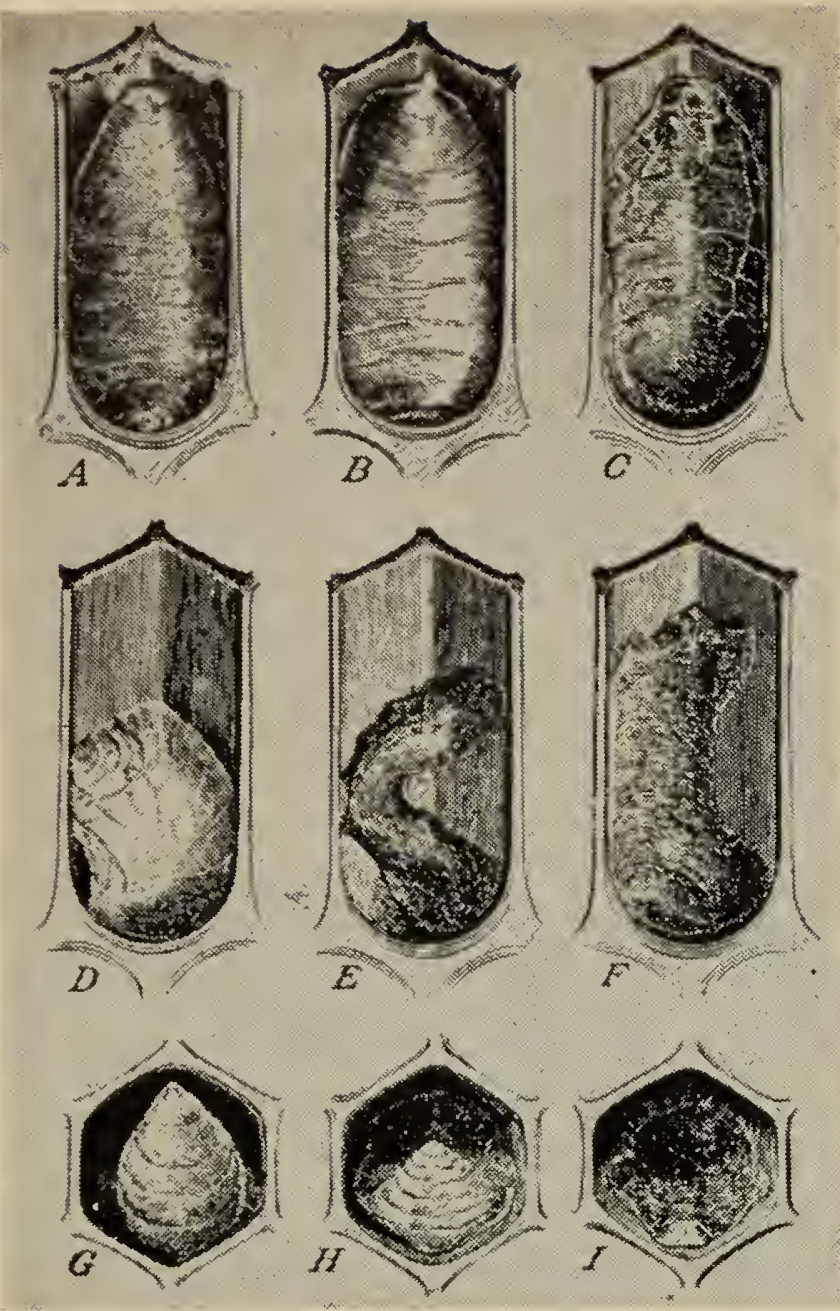

The typical symptoms of brood infected with European foulbrood: A, ventral view of extended larva recently dead of European foulbrood; B, extended larva partly decayed; C, scale of extended larva; $D$, another recently dead larva; $E$ and $F$, scales of dead larvae irregularly twisted; $G, H$, and I, front view of $A, B$, and $C$, respectively. From U.S.D.A. Cir. 392.

When this practice is followed, no more sulfa-syrup should be fed than the bees can use in brood rearing in order to eliminate the possibility of contaminating marketable honey. We have not experimented with this procedure because it is inexact for experimental purposes. Our results have indicated, however, that the bees will mix the sulfa-syrup with any incoming nectar and store it with the honey in both the brood and super combs. The danger of adulterating honey with sulfathiazole is ever present when sulfathiazole is used during or just before a nectar flow, and great care should be exercised to avoid this possibility.

The antibiotics. The general effect of other antibiotics on the prevention or con- trol of brood diseases is being investigated in various states and Canada with the aim of reducing losses from bee diseases. Space will not permit a discussion of these drugs, some of which appear to have considerable promise in the prevention and control of both American and European foulbrood. The results of such experiments are carried in the bee journals.

European foulbrood. This form of brood disease attacks the larvae still coiled in the bottom of the cell, usually at a very early stage. The infected larva generally turns a light yellow; it loses its well-rounded form and becomes so translucent that the tracheae can be seen through the body wall. In some instances the diseased larvae become light brown to dark brown. As the disease progresses in the colony, older larvae are attacked, and a small percentage of the diseased larvae then occur in sealed cells. The dead larvae are generally found in almost any position in the cell-on the sides, on the bottom, or near the front. The final scale formed is removable from the cell by the bees. The ropiness of the decayed larval remains is less noticeable than in American foulbrood; often no ropiness can be found. Both ventral and longitudinal views disclose extended, recently dead larvae and scales of dead larvae which are twisted irregularly.

European foulbrood seems to be caused by a mixed bacterial infection of the brood of bees rather than by a single organism. Bacillus alvei, B. pluton, Streptococcus apis, B. orpheus, and Bacterium eurydice have all been associated with this disease by various investigators. For these reasons, the gross symptoms of European foulbrood may vary considerably with the type of bacteria present, and sometimes are confused with certain stages of American foulbrood and para foulbrood.

This disease does not occur in all sections of California. Apparently it is associated in some sections with the ab- 
sence of an early spring nectar flow. Many experienced beekeepers believe there is some correlation between the incidence of the disease and the kind of pollen the bees gather in summer. Usually the disease does not occur in either strong or weak colonies until the second or third cycle of brood in the spring; then it gradually weakens the colony until there are not enough bees to store a maximum amount of honey. The disease may disappear with the beginning of a nectar flow, it may continue in somewhat abated form throughout the season, or it may result in the death of the colony.

Before the introduction of Italian bees into the United States, European foulbrood was very destructive to the German blacks commonly used. Strong colonies of Italian bees are generally immune; but under adverse circumstances, even they are sometimes reduced by its inroads. Beekeepers, in fact, state that this disease does not "play fair," but appears when least expected.

Since the bees are able to remove the diseased material, treatment is based on at least four fundamentals: 1) strengthening the infected colonies by the addition of more bees; 2) dequeening for a time to break the brood-rearing cycle, in order to give the bees time to clean diseased material from the cells; 3) requeening with a resistant strain; and 4) treating the infected colony with an antibiotic to hasten its cure or to prevent the disease from becoming established in spring. There has been no positive prevention of European foulbrood, except in some instances with resistant strains, until the discovery that terramycin or streptomycin could be used for this purpose. The use of antibiotics in Colorado and elsewhere has been made necessary by the failure of the other methods mentioned here to prevent the disease from developing to a point where the infected colonies either die or become nonproductive. Since the research is still in progress, the reader should consult current bee literature for recommendations. If the colony is strong, the queen should be killed and a ripe queen cell given, or a virgin queen from a resistant strain of bees can be introduced as soon as the colony has discovered that it is queenless. If a nectar flow is in progress, this treatment will generally be effective. If no nectar is available, it may be necessary to allow a queenless period of 10 days, after which the colony can be given a young queen from a resistant strain. Feed. ing during this queenless period to increase colony morale and to stimulate brood rearing aids in the control of this disease. Sulfathiazole has no beneficial effect in the treatment of European foulbrood, but such antibiotics as terramycin, aureomycin, and streptomycin, have been found to be of considerable value.

Parafoulbrood. In 1930 a brood disease was discovered in Georgia and Florida which had some symptoms that differed from those of other known diseases. Subsequently, the disease was found in North and South Carolina and occasionally in other states. It was dis.

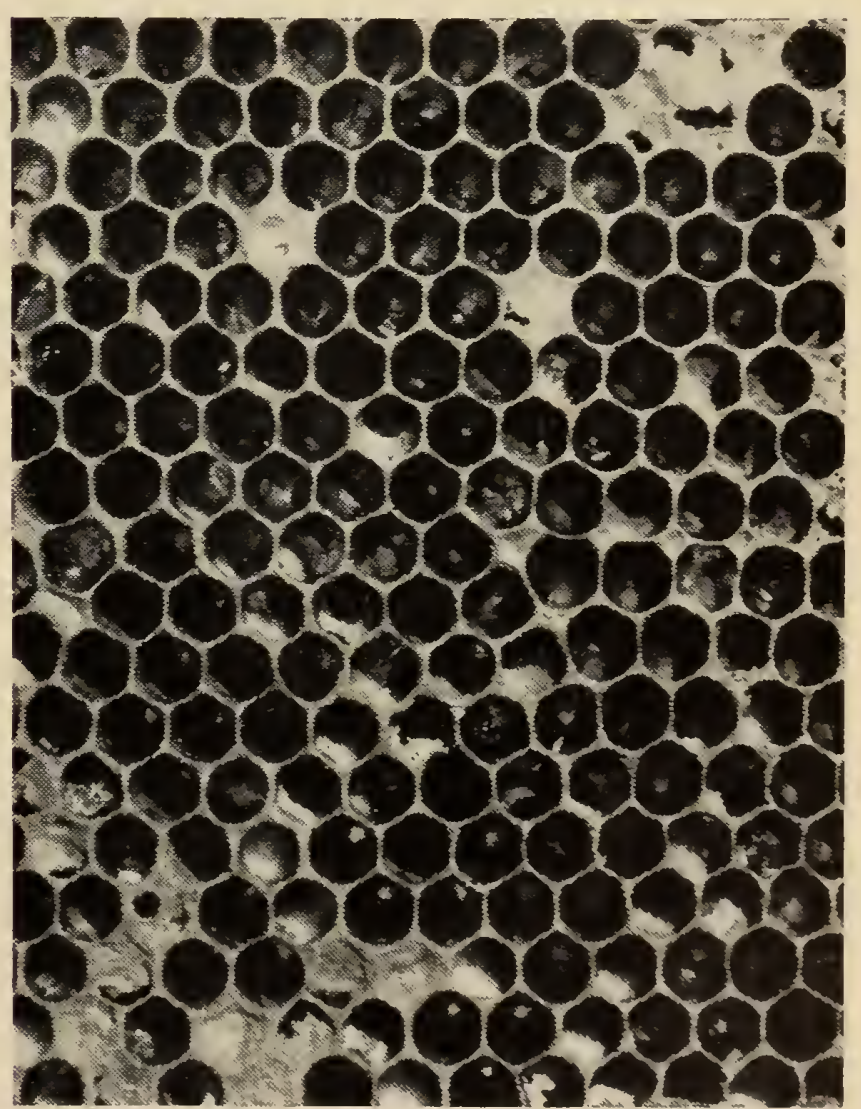

A section of a brood comb almost 100-per-cent infected with parafoulbrood. 
covered in a single colony for the first time in California by Eckert in 1948. One additional colony and two nuclei were found infected with the disease in 1951, two colonies in 1952, and two more in 1953. It seems probable that the disease might have been present previously and the symptoms confused with those of European foulbrood.

This disease generally attacks the larvae before the cells are sealed, but occasionally it kills late larvae in sealed cells and also young pupae. The color of the dead brood is first grayish white, then becomes light brown, brown, reddish brown, or dark brown. Scales are easily removed from the cells, as in European foulbrood.

If there is any doubt as to the actual type of disease found, it is advisable to send a sample of the dead larvae to the Apiculturist, University of California, Davis, for microscopic diagnosis. While the symptoms of parafoulbrood may be confused in the hive with either American or European foulbrood, they can be differentiated under the microscope. The present recommended control is the same as that for colonies infected with European foulbrood although nothing is known at this time as to its reaction to the antibiotics. Sulfathiazole was ineffec-

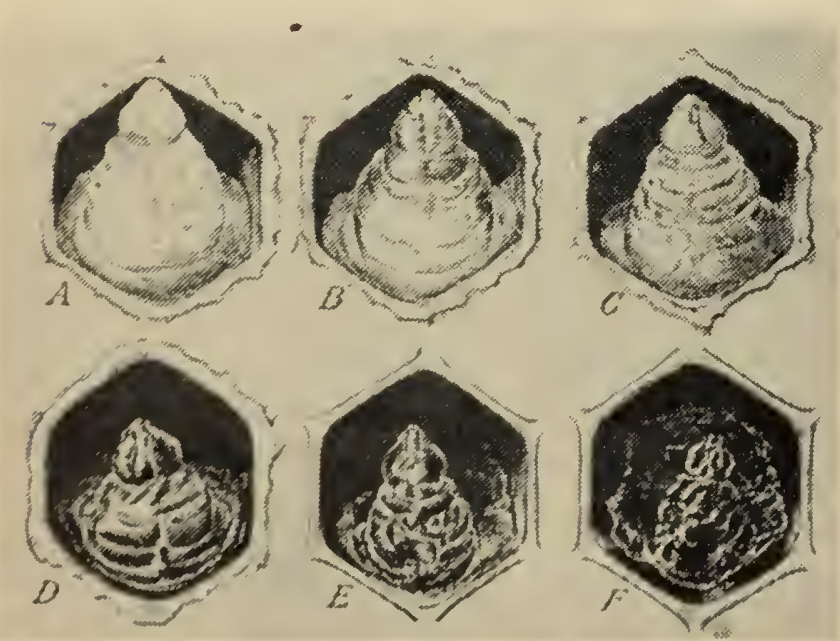

Symptoms of brood infected with sacbrood: $A$, front view of healthy larva at the age when death usually occurs from sacbrood; B to $F$, stages in the decay and drying of diseased larvae. From U.S.D.A. Cir. 392. tive in one case in which it was fed to a colony infected with this disease. The causative organism is known as Bacillus para-alvei.

Sacbrood. Occasionally a colony will have a few or many cells containing dead larvae showing symptoms different from those described for the other diseases. The larvae are generally attacked in the late larval or pupal stages, as in American foulbrood, and so are found primarily in sealed cells or in cells which have been uncapped by the bees. The skin of the infected larva remains intact; it does not adhere to the cell wall. The body contents are watery and flow to the posterior portion of the larva when it is held in a vertical position outside the cell; this gives rise to the name sacbrood. The dead larva remains with the dorsal, or upper, side along the lower wall, the head lying outward and extending upward. The tip of the head is generally black, while the rest of the body varies from gray to brown. The disease, which is caused by a virus, is mildly infectious. Although it sometimes reduces the strength of a colony, it is seldom serious. No definite treatment is recommended. Since some strains of bees seem more susceptible to sacbrood than others, it is advisable to change to queens of a different strain whenever the disease becomes prevalent. Queens should not be reared from a colony containing sacbrood. Sulfathiazole has no effect on this disease.

\section{Diseases of adult bees}

Nosema apis. Nosema disease is caused by a protozoan, Nosema apis (Zander). This organism attacks the epithelial lining of the midintestine and $\mathrm{fi}_{\text {- }}$ nally kills the adult so attacked. Little is known of its life history outside the honeybce or of its method of spread. Although it generally does not destroy a colony, it may reduce colony strength considerably. It is most common during the late spring period and usually dis- 
appears with settled warm weather. Bees affected with this parasite are often found in numbers in front of a hive, where many will be trembling and crawling about somewhat aimlessly. Many others will remain within the colony, badly affected. Often the wings become disjointed. In the later stages of infection, the bees are unable to $\mathrm{fly}$, and the dead may lie in quantities for some distance before the entrance. The midintestine of an infected bee is frequently swollen and is usually a dull grayish white. The tissues are softer and more easily crushed than in healthy bees.

Recent investigations in Canada by Katznelson and in the U. S. by Farrar indicate that fumagillin may be an effective treatment for Nosema disease. The references on page 86 should be consulted for further information. Nosema disease has not been serious in California.

Paralysis. Very little is known about the cause of this disease, nor have its symptoms been sufficiently defined for any particular ailment of the adult bee to be called paralysis. The same symptoms may be present in Nosema disease and in buckeye poisoning and in instances where neither of these two ailments is present. In symptoms generally associated with paralysis, the bees may become almost devoid of hair. They appear shiny and greasy, and their bodies are sometimes swollen with fecal material. The bees shake and shiver; their wings are often flattened and disjointed. Such bees are found before the entrances and on the bottom boards and combs of the colonies affected. The lighter strains of Italians seem to be more susceptible to paralysis than the darker strains. The disease seldom kills a colony, but it may reduce its numerical strength until the amount of honey stored is greatly curtailed.

In some instances, the disease appears to be caused by a virus infection. Susceptibility also is an inherited characteristic, which indicates that treatment can be effected by requeening infected colonies with less susceptible strains of bees and by not rearing queens from any queen mother whose bees exhibit any symptoms of this disease. The symptoms generally disappear if the affected colony is given emerging brood from other colonies and is then requeened with a young, vigorous queen. Reduction in the number of infected bees in a colony is frequently obtained by dusting sulfur liberally on the ground in front of the hive and also over the alighting board. Additional sulfur can also be dusted lightly over the tops of the frames and along the shoulders of the hive on which the frames hang.

\section{Poisoning and other losses}

Pesticides. Honeybees and other beneficial insects are killed, frequently, by many of the pesticides which are applied for the control of crop pests, and a serious loss of bees may result unless precautions are taken. Since some chemicals are more injurious to honeybees than others, those that are less toxic can be used when the control secured is approximately the same.

Honeybees are killed in several ways by these different poisons. Some of the chemicals kill on contact, or when taken internally, or as fumigants. Certain others make the bees so abnormal in their reactions that they lose much of their sense of coördination and orientation and thus get lost or die. Bees that are killed by dusts or sprays in the field do not endanger the bees in the hive. Nectar gatherers collecting contaminated nectar die in the field or before the nectar can be deposited as honey in the cells, thus safeguarding the purity of honey stored in the combs. Pollen bearers, however, can collect poisoned pollen, carry it back to their hives, and store it in the cells where it constitutes a serious danger to the hive bees as long as it remains in the hive.

The most highly toxic poisons are the arsenicals, parathion, malathion, hepta- 


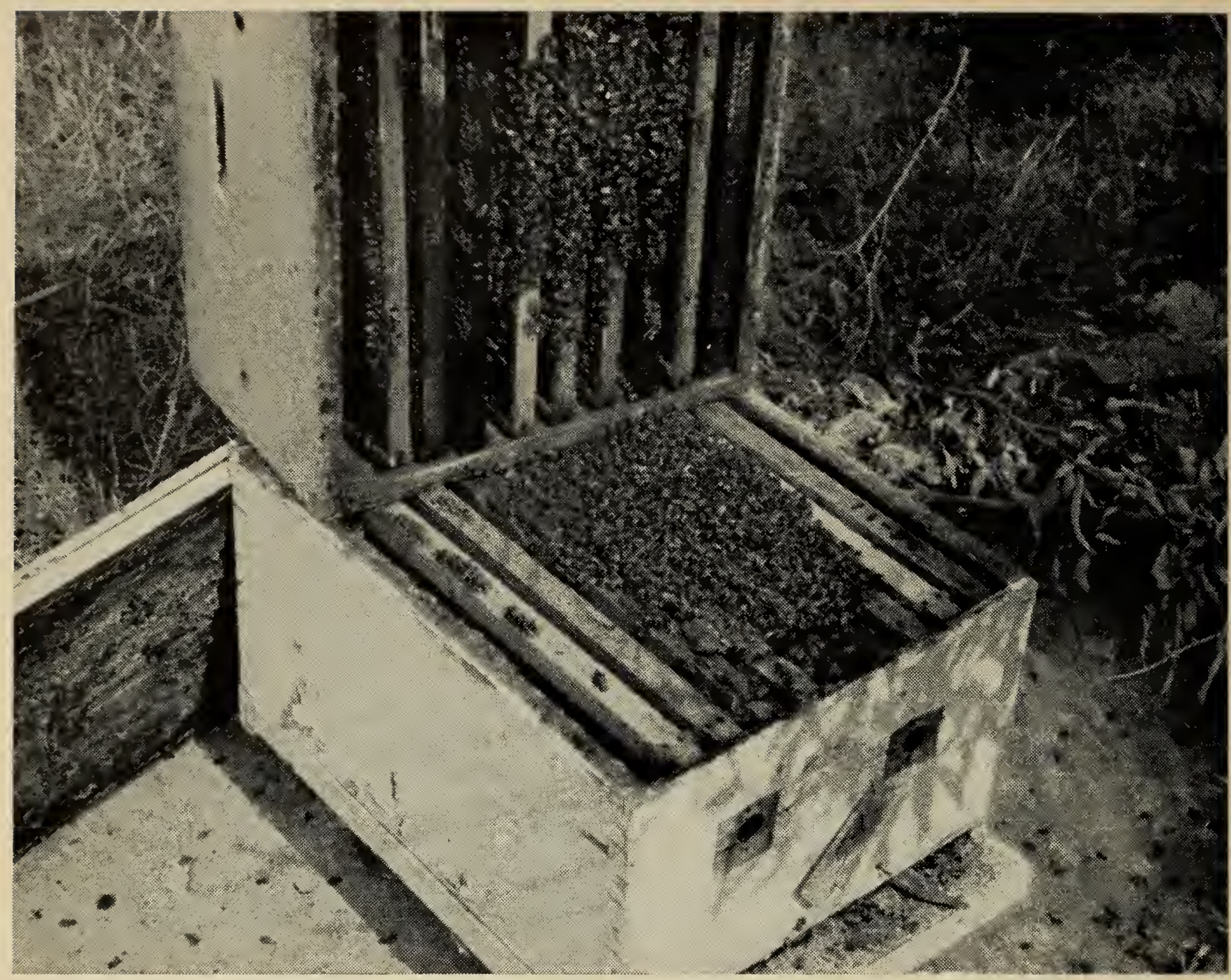

A colony weakened by spray poisoning. The colony strength has been reduced about 75 per cent, and the brood was injured by neglect.

chlor, benzene hexachloride '(BHC), EPN, lindane, chlordane, dieldrin, aldrin, metacide, and TEPP. Less toxic pesticides are systox, DDT, toxaphene, and DDD. Methoxychlor, aramite, and sulfur cause practically no injury. The extent of injury is frequently determined by the time of application, amounts applied, and total acreage covered. Dusts that drift over adjacent fields are far more dangerous than sprays. DDT and toxaphene will kill bees and reduce the colony populations below an economic level when they are applied frequently or when bees are in the field, but neither is as dangerous as several of the more toxic poisons.

The hazards of chemical poisoning to beneficial insects can be reduced to an economic level if: 1) least toxic materials are substituted for the more toxic compounds; 2) poisons are confined to the fields treated; 3) applications are made before or after the blooming period, or when the bees are not working in the field; 4) poison applications in diversified agricultural areas are limited to equipment which will apply minimum quantities of the pesticides in spray form during early morning or late afternoon.

Beekeepers should register the location of their apiaries with the Agricultural Commissioner each year, before November 1 , and then notify the Commissioner's office immediately after any loss from chemical poisoning is observed. They should become familiar with the pesticide program used in the area occupied by their colonies and avoid areas where the highly toxic pesticides are used.

Orchardists, seed growers, and farmers are becoming increasingly aware of the services rendered by bees in the pollination of a majority of agricultural crops 
and are insisting on the use of protective measures where possible.

Poisoned brood. Poison dusts broadcast by airplane are particularly dangerous to bees. Whatever method of application is used, however, bees may secure sufficient poison on pollen to cause the death of nurse bees and larvae. Usually the poisoned larvae die in all stages, and the trouble should not be confused with European foulbrood. Poisoned brood generally occurs all at once and may be present over an extended period. A chemical analysis of the dead larvae, adult bees, and pollen in the combs will indicate the kind of poison present.

Plant poisoning. The nectar or pollen of a very small number of plants causes intestinal, reproductive, or metabolic disturbances in the honeybee. In this state, the California buckeye and Veratrum (corn lily) are known to produce pollen or nectar injurious to the adult or larval stages of the honeybee. Locoweed has also caused serious losses of bees and brood in several instances. The California buckeye, however, is the most notable plant of this type because of the vast acreage it covers. It is particularly injurious in dry years in locations where it is abundant. In the foothills and up to 4,500-feet elevation, surrounding the Central Valley of California, beekeeping is extremely hazardous while this plant is in bloom.

The first injurious effects of buckeye pollen on the colony are noted within 7 to 10 days after the bees have started work on the blossoms. The brood becomes irregular in appearance because of the death of many young larvae. The egg-laying rate of the queen is greatly reduced; and after a few weeks an increasing number of her eggs do not hatch, or a majority of the young larvae die within 3 days after hatching. Some larvae produce adults with crippled wings or malformed legs and bodies. The queen may cease to lay entirely or may lay only drone eggs. At times the combs are de- void of brood except in the egg stage, and many of the eggs appear shriveled. The malformed bees crawl out of the hive, and the dead pile up in front of the hive. Some of the field bees show symptoms of paralysis; bees with black, shiny bodies are common. After a few weeks, the colony may become greatly weakened or die.

If a colony is removed from the buck. eye location, the queen may resume lay. ing in a fairly normal manner. The effects of the poisoning linger, however, as long as the buckeye pollen remains in the combs.

Honey produced from the California buckeye is edible, however, and produces no harmful effects when used for human food. In fact, no poisonous honey has ever been found in California; and this statement applies generally to most sections of the United States.

\section{Danger from other sources}

Chilled or starved brood. Sometimes in early spring a colony will expand its brood area beyond its ability to keep the brood warm during a sudden cold spell. If the cluster is forced to contract, the exposed larvae may die of chilling or starvation. Such conditions are generally distinguishable from the symptoms of the diseases described, and they should clear up quickly with a change in the weather, with feeding, or with the beginning of a nectar flow.

Dead drone brood in worker cell. Whenever a colony becomes hopelessly queenless, and the worker bees assume the egg-laying habit, many of the resulting larvae are neglected and allowed to die. This condition should be recognized readily because of the great amount of drone brood in worker cells at the time.

The wax moth. The larval forms of the greater wax moth, Galleria mellonella, destroy combs by burrowing through the cells, constructing silken tunnels as they go. The larvae feed on the pollen and waste materials found in the cells and spot their tunnels with excreta. The adult 


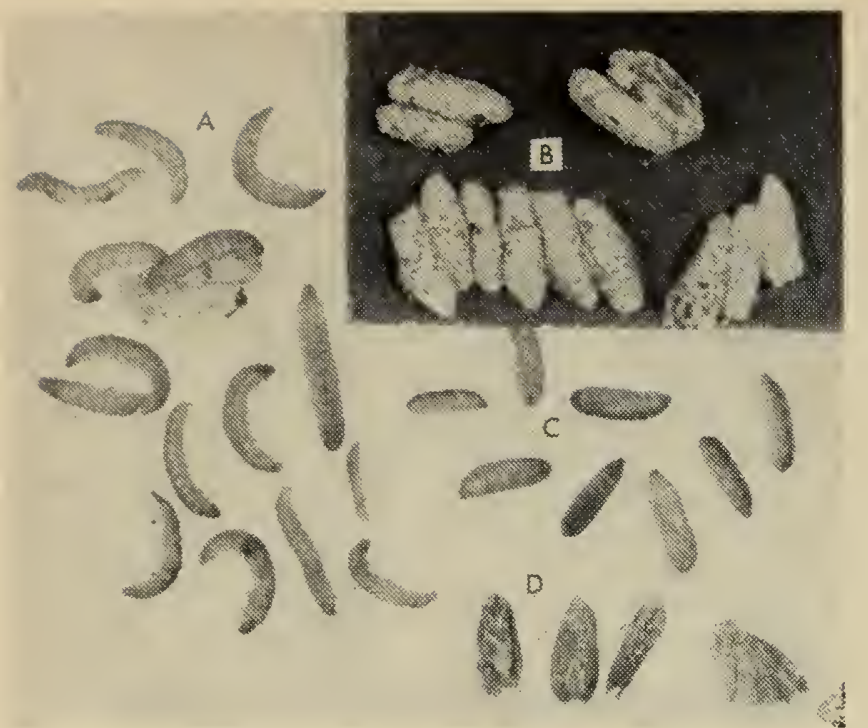

Stages of the greater wax moth: A, larvae; $B$, pupae in their cocoons; $C$, pupae removed from their cocoons; and $D$, adults.

female commonly lays 400 to 800 eggs, depositing them in small crevices about the hive, generally after dark. These hatch within 5 or more days, according to the temperature; and the larvae become ravenous feeders, reducing unprotected combs to a mass of webs and waste material within a short period of time. After the feeding period, the larvae spin their pupal cases in the comb, or migrate to the frames or walls of the hive. There they eat a depression in the wood before spinning their cocoons. In California, with favorable food and temperature, two or more generations may be produced within a single season.

Although combs in strong colonies of Italian bees are seldom affected by this pest, combs in storage are soon destroyed unless properly protected. Combs in weakened colonies are likewise attacked, but the wax moths are seldom the cause of the weakened condition of the colony. On the contrary, the wax moths are able to attack the combs because of the colony's weakened condition. Then, after the colony dies, the wax moth larvae destroy the combs.

Care of combs in storage. Storage combs can be protected by being placed in an airtight room and fumigated with burning sulfur. To make doubly sure that all larvae are killed, fumigate the combs twice, 10 days apart, to kill any larvae that may hatch after the first fumigation. If combs are left in the hives of strong colonies until cold weather, then are removed, fumigated, and stored in a cool place, there will be little danger of injury from wax moths during the winter.

Paradichlorobenzene, or Paracide, will repel the wax moths and kill their larvae. This chemical can be placed upon a piece of paper over each super of combs as the combs are stacked for storage. About a

Remains of a comb ruined by the wax moth.

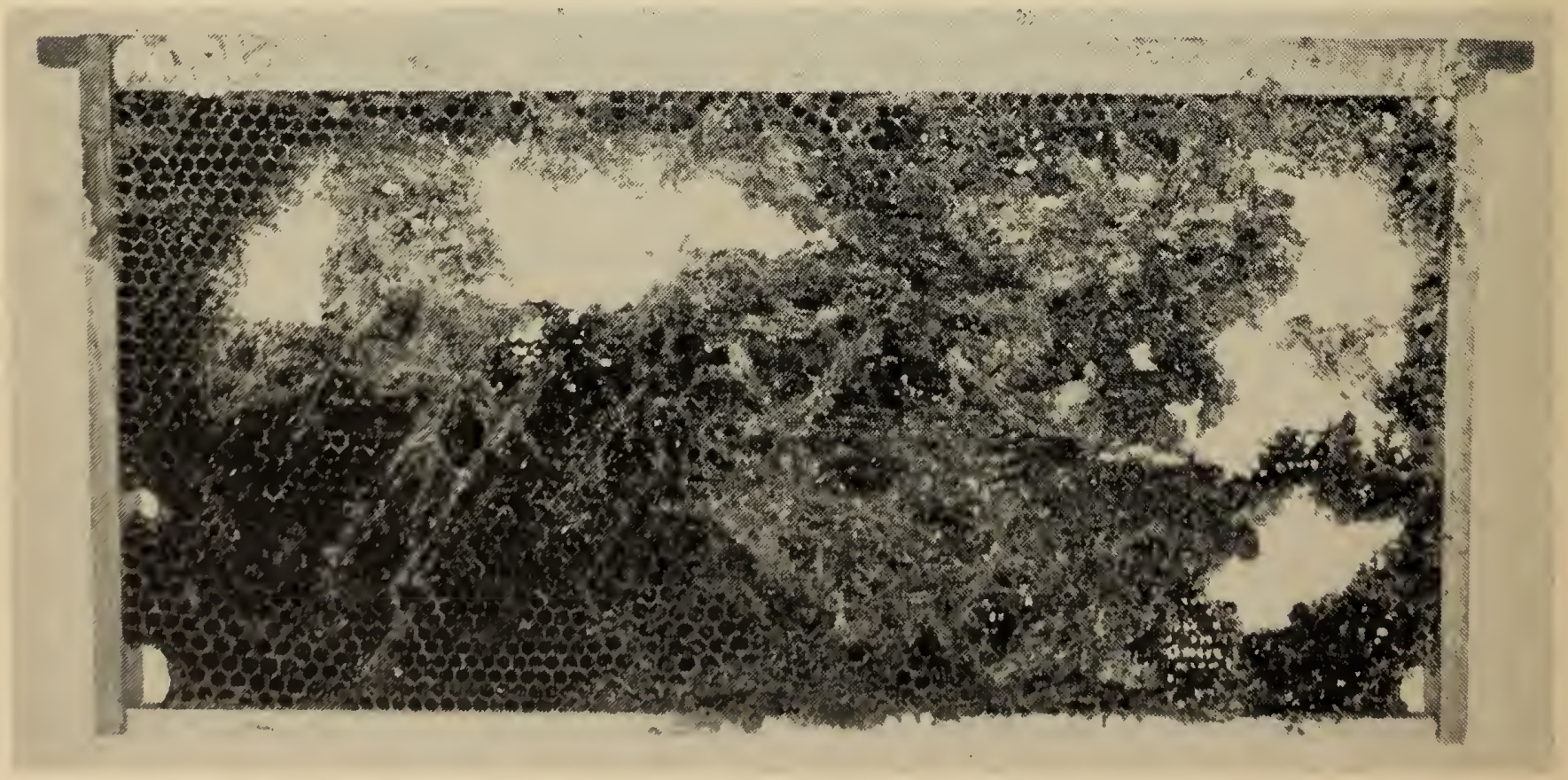


tablespoon for each super will be enough if the supers are made airtight. Cyanide gas, Cyanogas, and methyl bromide are also used as fumigants in killing the wax moth and other insect forms found in stored combs. Since cyanide and methyl bromide are extremely poisonous to people and animals, the gases must not be inhaled. Cyanide does not kill the eggs of the moth; therefore, two fumigations are necessary. Methyl bromide is sold in cans or cylinders in liquid form. It evaporates readily at $40^{\circ} \mathrm{F}$, with maximum efficiency in fumigation above $60^{\circ}$. It kills all stages of the wax moth, including the eggs. Exposures of 12 to 24, hours are recommended at the rate of $1 / 2$ pound per 1,000 cubic feet. For greatest safety to the operator, the cans of methyl bromide should be chilled in a refrigerator before they are perforated to release the gas in the comb room. Fumes of burning sulfur are effective in killing adults and larvae but do not kill eggs. For this reason, two fumigations, about 10 days apart, are necessary to kill all stages when sulfur fumes are used. It is one of the safest fumigants if precautions are taken to prevent fire.

Where only a few supers of combs are to be fumigated, carbon disulfide may be used. This is a heavy liquid which evaporates when exposed to air. One tablespoon of carbon disulfide should be used for each 10-frame body. As the fumes are heavier than air, the liquid should be placed in a pan inside a hive body on top of a stack of supers. The stack should not be more than five or six supers high for best results, and all joints should be made gastight with gummed paper for at least 12 hours. This gas is highly explosive, so any likelihood of ignition by spark or flame should be prevented. The gas is also poisonous to people and to animals and should be handled with care.

In all cases of fumigation, the room should be gastight. Ventilators should be arranged so that they can be opened from the outside to secure cross drafts in clear. ing the room of gas.

Other insects attacking combs. The lesser wax moth, Achroia grisella, is of little importance in California. Small forms of the greater wax moth are frequently mistaken for the lesser species. The Mediterranean flour moth, Ephestic Kühniella, and the Indian meal moth, Plodia interpunctella, sometimes attack the pollen of combs in storage; the larvae feed on the pollen but do not destroy the combs. The silken webs, confined primarily to the individual cells, are easily distinguished from the silken tunnels of the greater wax moth. The almond moth, Ephestia cautella, has also been reported to breed in the pollen of stored combs. The larvae of these insects work at lower temperatures than wax-moth larvae but can be controlled by the same methods.

\section{Animal pests}

Mice may be very destructive to combs in storage or on the hive in winter. Combs both on and off the hive should be protected from such depredations. Mice cannot injure the combs of a colony if a queen excluder is placed between the brood chamber and the bottom board during the fall and winter. A wire guard of $3 / 8$-inch mesh placed over the entrance also effectively protects a hive against mice during the fall and winter periods.

Skunks, although usually beneficial, may become a serious pest in an apiary during the dry seasons when other food is scarce. They visit the hives at night, scratch in the dirt in front of the hive or at the entrance, and eat the bees that investigate the disturbance.

Skunks may be controlled by trapping or poisoning. They do not detect small quantities of strychnine in inch-square pieces of drone brood placed beside the hive they have molested. In small apiaries they can be fenced out with 4 -foot poultry netting, the bottom foot of which is folded along the ground on the outside of the fence. 
Bears. Many reports have been received of the destruction of bee equipment by bears in mountain locations. Bears are very fond of the brood, as well as the honey, and often destroy small apiaries in unprotected places. This destruction can be prevented by the erection of a specially designed electric fence. Some beekeepers construct their bear fences differently from the one illustrated. They place the posts 6 feet apart and use 8 barbed wires, tightly stretched, 6 inches apart, the first starting at ground level. Every other wire is electrified and the others are well grounded. Some bear fences have every wire electrified for greater efficiency.

Miscellaneous pests. Toads, birds, dragonflies, ants, spiders, yellow jackets, and other enemies prey on bees and, under certain conditions, may seriously damage a colony. The amount of injury varies in different locations. Remedies

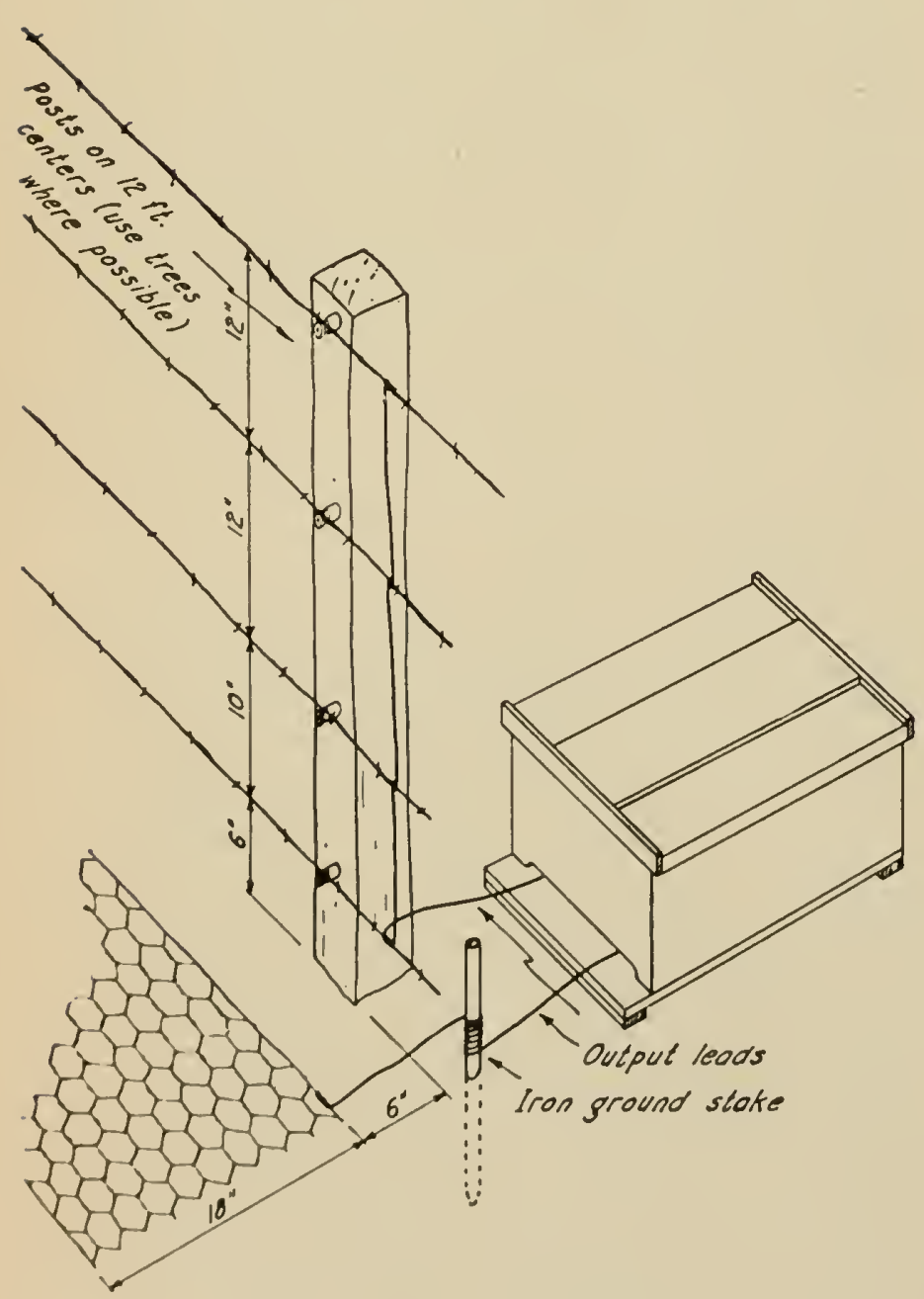

should be applied according to the nature of the trouble. Sometimes it may be advisable to move colonies to more favorable locations.

Of these miscellaneous pests, ants are undoubtedly the most injurious. Individual colonies can be protected by setting the hives on stands or benches with legs in cans of oil. Frequent inspections are necessary to see that leaves or grass have not made bridges over the oil. DDT dusts or sprays, chlordane, or various fumigants can be injected into ant hills or runways. Waste oil can be applied beneath the hives to deter ants from building their nests. Poison baits can also be used to reduce the ant populations in and near the apiary, but in using such poisons, you should remember that bees are attracted to and poisoned by most poison baits used in controlling ants. Therefore, the poison containers should be made inaccessible to bees.
One type of electric fence installation used to protect an apiary from the depredations of bear.s and other large animals. The battery and "controller" are housed in an empty hive or weatherproof box inside the enclosure. A fence of four wires and a ground of poultry netting are connected to the controller output and to a ground stake. The fence wires (on insulators) are connected in parallel to the output wire of the controller. From Journal of Wildlife Management, vol. 2 , no. 4 . 


\section{HONEY AND BEESWAX ... are two of the}

\section{major sources of income for many beekeepers. \\ Here are instructions for obtaining them}

\section{Chemical and physical properties of honey*}

Honey is the sweet, viscid secretion which is gathered by bees from the nectaries of flowers to be elaborated and stored in their combs for food. It is primarily a carbohydrate food, consisting principally of a solution of two invert sugars, dextrose and levulose. Its moisture content is generally less than 20 per cent. It contains, besides the two sugars mentioned, a small quantity of sucrose (seldom more than 8 per cent), aromatic bodies, minerals, enzymes, vitamins, plant pigments, acids, and other components as given in table $4 . \dagger$

* The American Honey Institute, Madison, Wisconsin, will supply additional information about honey on request.

$\dagger$ Data in this table were taken from: Eckert, J. E., and H. W. Allinger. Physical and chemical properties of California honeys. California Agr. Exp. Sta. Bul. 631.
In the chemical analysis of the honeys in table 4 , a total of 4.7 per cent of undetermined components was found. These substances, which may be present in minute amounts, include the following:

Beeswax

Pollen grains, partial sources of minerals, amino acids, and vitamins

Compounds that contribute to the color of honey:

Chlorophyll decomposition products

Plant pigments:

Carotin

Xanthophyll

Anthocyanin

Tannin or tannic acid

Colloidal particles

Aromatic bodies:

Terpenes, aldehydes, methyl anthranilate

Higher alcohols:

Mannitol, dulcitol, etc.

Maltose, rare sugars (sometimes melezitose)

Enzymes:

Invertase (converts sucrose into dextrose and levulose)

Diastase (converts starch to maltose)

Table 4. Composition of Common California Honeys

\begin{tabular}{|c|c|c|c|c|c|c|c|c|c|c|}
\hline Floral source & $\begin{array}{c}\text { Num- } \\
\text { ber of } \\
\text { sam- } \\
\text { ples } \\
\text { ana- } \\
\text { lyzed }\end{array}$ & $\begin{array}{l}\text { Mois- } \\
\text { ture }\end{array}$ & $\begin{array}{l}\text { Total } \\
\text { solids }\end{array}$ & $\begin{array}{c}\text { Total } \\
\text { sugars }\end{array}$ & $\begin{array}{c}\text { Levu- } \\
\text { lose }\end{array}$ & $\begin{array}{l}\text { Dex- } \\
\text { trose }\end{array}$ & $\begin{array}{c}\text { Su- } \\
\text { crose }\end{array}$ & Ash & $\begin{array}{l}\text { Dex- } \\
\text { trins }\end{array}$ & Acid \\
\hline Alfalfa. & 4 & 15.9 & 82.4 & 79.7 & 40.3 & 37.1 & 2.3 & 0.16 & 0.19 & 0.16 \\
\hline California buckwheat. & 3 & 15.1 & 83.3 & 77.2 & 42.0 & 36.6 & 1.9 & 0.14 & 0.99 & 0.17 \\
\hline Cotton. & 2 & 16.0 & 82.5 & 80.5 & 41.8 & 37.6 & 1.1 & 0.29 & 0.68 & 0.19 \\
\hline Eucalyptus. & 2 & 18.7 & 79.9 & 76.2 & 40.0 & 33.0 & 0.9 & 0.22 & 0.62 & 0.15 \\
\hline Lima bean. . & 7 & 15.6 & 82.8 & 82.2 & 40.7 & 35.3 & 3.5 & 0.13 & 0.23 & 0.15 \\
\hline Manzanita. & 5 & 16.8 & 81.7 & 76.5 & 38.9 & 34.9 & 2.7 & 0.26 & 1.17 & 0.12 \\
\hline Orange. . & 8 & 16.3 & 82.2 & 78.5 & 40.9 & 34.2 & 4.1 & 0.08 & 0.31 & 0.12 \\
\hline Sage. . & 8 & 16.0 & 82.4 & 77.1 & 42.8 & 31.8 & 2.4 & 0.11 & 0.72 & 0.11 \\
\hline Spikeweed. & 3 & 16.7 & 81.8 & 76.6 & 40.4 & 34.9 & 1.2 & 0.28 & 0.78 & 0.25 \\
\hline Yellow star thistle. & 11 & 15.8 & 82.7 & 78.1 & 39.5 & 34.4 & 4.3 & 0.10 & 0.77 & 0.17 \\
\hline Average composition of & & & & & & & & & & \\
\hline California honeys. & 106 & 16.4 & 82.1 & 77.5 & 40.4 & 34.5 & 2.5 & 0.21 & 0.91 & 0.16 \\
\hline
\end{tabular}


Catalase (decomposes hydrogen peroxide)

Inulase (converts inulin to levulose)

Vitamins:

Vitamin A

Vitamin B complex (needed in sugar metabolism) :

$\mathrm{B}_{1}$-Thiamine (antineuritic factor, antiberiberi)

$\mathrm{B}_{2}$-Riboflavin or vitamin $\mathrm{G}$ (antidenudation factor)

$\mathrm{B}_{6}$-Pyridoxin (growth and health)

Biotin-Vitamin H (nutrition, some relation to dermatitis)

Folic acid (growth and nutrition)

Nicotinic acid (cure and prevention for pellagra)

Pantothenic acid (growth and weight)

Vitamin C-Ascorbic acid (antiscorbutic factor, cure and prevention of scurvy).

The chemical and physical properties of a honey depend chiefly on its floral source, but they are also influenced by such factors as climate, soil, altitude, method of production, and preparation for market. The honeybee generally works on only one source at a time. A colony, however, may gather nectar from two or more sources before the surplus is extracted by the beekeeper, and thus produce a natural blend of two or more distinct flavors.

Honey is generally sold in liquid form or in the comb, as section or chunk honey; but an increasing demand is being developed for the granular or creamed form as well. Granulated honey of very small crystals is preferred by many people. Liquid honey will granulate fairly rapidly if a quantity of finely granulated honey (about 5 per cent) is thoroughly mixed with it, and the product stored in a cool place $\left(57^{\circ} \mathrm{F}\right)$. In mixing the fine crystals in the liquid honey, great care should be taken to prevent the incorporation of excess air bubbles. These will rise to the top and make an undesirable froth on the granulated product. The speed of normal granulation in honey apparently depends upon the levulose-dextrose ratio. Sage honey, high in levulose, will remain liquid for years without any trace of granulation. If it is blended with a honey that granulates readily, the blend will also granulate.

Determining the weight and moisture content. The weight of honey is directly proportional to its moisture con. tent. This, in turn, depends on the floral source, ripeness at the time of extraction, and subsequent evaporation. In California, honey that is completely capped before the combs are extracted will generally contain 17 per cent or less of moisture and will weigh 11.85 pounds or more per gallon. The moisture content and weight of honey can be determined by using a refractometer or a hydrometer, or by weighing a definite measure of honey. Available tables give the equivalents of weights, moisture content, and total solids, which are principally sugars. The refractometer requires only a single drop of honey and is the quickest and most accurate method of determining weight and moisture content. The refractive index can be used to indicate the total solids, moisture content, and weight of the honey examined. The cost of the instrument, however, is often prohibitive for the small producer or bottler. The moisture content of a honey may be determined by sending a sample for moisture analysis to the Apiculturist, University of California, Davis. The sample should be in a screw-capped container, carefully packed.

\section{Effect of heat on honey}

Granulated honey can be liquefied by heating it in a water-jacketed container. Honey darkens and loses some of its aroma when held too long at a high temperature. Generally, a temperature of $145^{\circ}$ to $160^{\circ} \mathrm{F}$ for one hour will cause little change in color or flavor, and this heat is suitable for all purposes of straining or liquefying for retail containers. Honey heated in this manner, bottled or canned while hot and then quickly cooled, will remain liquid longer than unheated honey. 


\section{Causes of fermentation in honey}

Practically all honeys contain sugartolerant yeasts, derived chiefly from the nectar and pollen of flowers. Honeys that are not well ripened in the hive before extraction contain a higher moisture content and are, therefore, more readily attacked by the action of yeasts.

Honey is generally thought to keep indefinitely, but recent investigations indicate that only when it is stored at $50^{\circ} \mathrm{F}$ or below will it keep for a long period. At this temperature the sugar-tolerant yeasts are practically inactive. At temperatures around $60^{\circ}$ granulated honey in particular is subject to fermentation and especially so if it has a moisture content of 19 per cent. This happens because in granulation the dextrose crystallizes while the levulose remains as a liquid film around the crystals. The formation of the dextrose crystals leaves a liquid phase favorable to the development of sugar-tolerant yeasts which may occur in honey that has not been pasteurized by heat. Fermentation results. A temperature of $60^{\circ} \mathrm{F}$ favors crystallization as well as fermentation, whereas $80^{\circ}$ $\mathrm{F}$ is said to be less favorable to both changes. Evidently, then, fermentation is tied up rather closely with granulation, moisture content, and temperature.

How to prevent fermentation. Honey should be extracted only when well ripened in the comb to assure a low moisture content. Yeasts in honey are killed by a temperature of $160^{\circ} \mathrm{F}$, and honey heated to this point will not ferment if kept in airtight containers. Honey will give off moisture in a dry, warm atmosphere but will absorb moisture under humid conditions.

\section{Change in color of honey in storage}

Honey will become darker when stored over a period of years. This change is hastened at the higher temperatures of many valley locations; too, some honeys are less stable than others in this respect.
Honeys which were originally white may thus become light amber or dark amber within five years, and the color will change to darker shades with the passage of time. Much of the original aroma and flavor will also be lost with increase in color. Actual chemical changes are unknown.

To avoid this destructive color change, honey should be stored in a cool place and consumed within three or four years of its production.

\section{Food value of honey}

Honey deserves a preferred place among sweets because the sugars, being in invert form, are readily assimilated. The presence of minerals, although in minute quantities, adds further to its desirability as a food. Honey also has a flavor and sweetness that tend to satisfy a craving for sweets without the use of large quantities of sugar. Its slightly laxative effect, when used to modify cow's milk in infant feeding, is considered a valuable point. Honey is used by manufacturers of bakery, confectionery, and preserving products, and in various medicinal formulas, skin lotions, and beauty creams. Its most familiar use, of course, is as a food in the home.

Although it is difficult to compare the food value of honey with unlike foods, such an attempt is made in the U.S.D.A. Agricultural Handbook No. 8, June, 1950 , and the results are given in table 5. In this table the moisture content of honey is listed as 18 when it is 18 per cent or below, and that of table syrup as 25 per cent moisture when most such syrups usually run 30 per cent moisture. The quantity used in each case is 100 grams or 3.52 ounces. One tablespoon of honey contains 100 calories.

Honey adds flavor as well as sweetness when used in food. One cup of honey weighs 12 ounces, of which $91 / 4$ ounces are sugar. In substituting honey for sugar in cakes or cookies, three factors should be considered-flavor, extra sweetness, 


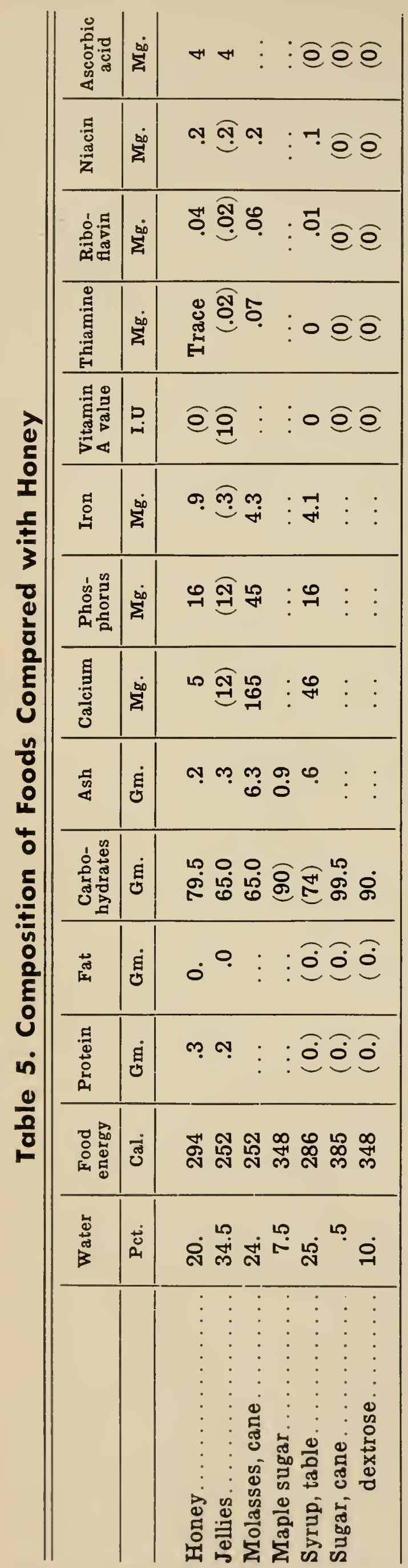

and noisture. A cup of honey is about one-sixth moisture. Since honey is hygroscopic-that is, it absorbs and retains moisture-honey cookies and cakes remain moist over a long period.

\section{Honeydew}

Honeydew is the sweet viscid excretion of plant-sucking insects, such as aphids and scale insects (Coccidae). That portion of the plant juice or sap which these insects cannot utilize is ejected in the form of a sweet liquid. It has a high sugar content and therefore is attractive to bees when sources of nectar are not available. The bees gather and elaborate these liquids in the same way they do nectar. The product looks like honey in many respects and is stored by the bees in exactly the same manner.

Honeydew honey varies from water white to very dark. It is usually more viscid than honey from a floral source, contains a lower percentage of invert sugars, and is higher in dextrins. It is rather variable in flavor, being more suitable for the bakery trade than for table use. In some years honeydew is more plentiful than in others and is produced in such quantities that it covers the leaves of trees and the ground underneath. In such seasons colonies have been reported to gather from 100 to 300 pounds of honeydew from this source. It usually sells at a lower price than floral honey, and producers should attempt to keep it separated from floral honeys. It is usually turbid in appearance and depreciates the quality and appearance of floral honey when blended with it.

The incense cedar, Libocedrus decurrens, is one of the principal sources of honeydew in California; the insect involved is Xylococcus macrocarpae (Coleman). It occurs on mountain slopes at elevations between 2,000 and 7,000 feet but yields most honeydew above 4,500 feet. The valley oak, Quercus spp., is another source of honeydew in northern California. 


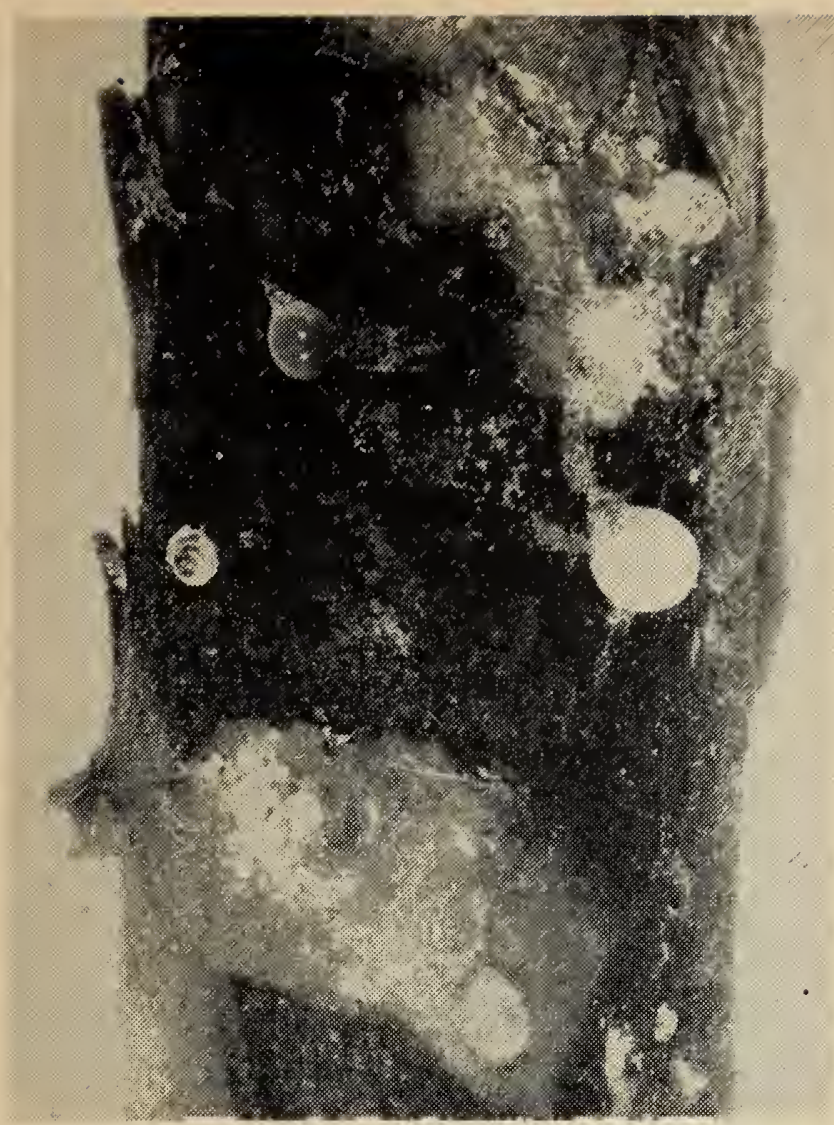

A portion of a branch from an incense cedar tree infested with Xylococcus macrocarpae, showing the accumulated drops of honeydew formed in the vicinity of the insects. The scales usually occur under pieces of bark and have a protective coating of silk. The honeydew is expelled through fine silken tubes. Courtesy of G. H. Vansell.

\section{Grading and processing honey}

Comb honey. Comb honey is graded according to the weight, cappings, cleanliness, and fullness of the combs. The federal standards divide the grades into U.S. Fancy, U.S. No. 1, and U.S. No. 2. The minimum weights are 12,11 , and 10 ounces, respectively. All combs must be firmly attached to all four sides of the section, free from granulation and fermentation, and the combs must not extend beyond the sides of the sections. The principal difference in the three grades is in appearance as it is affected by travel stain on the wood or cappings and the fullness of the combs.

To insure maximum cleanliness, the paraffin is scraped from the tops of the sections and all paraffin or burr combs are scraped from the edges and sides. The sections should be separated into groups by weight and appearance, and the weight and grade of each section must be stamped on its top. The address of the producer can be stamped on at the same time, if desired.

The sections can then be wrapped in cellophane wrappers and sealed against dust and insects. Sometimes boxes with cellophane openings are used. Such wrappings are available from bee supply houses. Comb honey sections are usually packed in cartons or wooden boxes clearly labeled as to their contents.

Considerable comb honey is produced in shallow frames or in sections larger than the "pound" sections, and grades should conform with those for comb honey sections, except for individual weights. Frame honey is sold frequently in special cartons or wrappings to a special trade.

Extracted honey. Federal standards for grades of extracted honey are based, primarily, on a score that includes consideration of flavor, absence of defects, clarity, and percentage of soluble solids (or moisture content). The grades specified are "U.S. Grade A" or "U.S. Fancy" -one that has not less than 81.4 per cent soluble solids (moisture content not more than 18.6 per cent) and scores not less than 90 points for flavor, absence of defects, and clarity; "U.S. Grade B" or "U.S. Choice" - one that has not less than 81.4 per cent soluble solids and scores not less than 80 points; "U.S. Grade C" or "U.S. Standard" - one that contains not less than 80 per cent soluble solids (moisture content not more than 20 per cent) and scores not less than 70 points; and "U.S. Grade D" or "Substandard" is the quality of honey that fails to meet the requirements of "U.S. Grade C" or "U.S. Standard."

Extracted honey need not be filtered when sold wholesale but must be as free from foreign particles as if strained through standard No. 80, No. 50, or No. 18 sieves for "U.S. Grade A," "U.S. Grade B," or "U.S. Grade C," respectively. 
As stated previously, honey cannot be filtered readily when cold but will run through the above sieves when heated to $110^{\circ}$ or $120^{\circ} \mathrm{F}$. This temperature will not discolor honey over a period of several hours. Since processors have to heat and strain honey to insure the cleanliness of their pack and to liquefy and blend different flavors, they prefer to have unheated honey in order to be assured that it has not been injured by heat. Air bubbles and a majority of the particles of wax and other foreign substances incorporated in honey during the extracting process will rise to the surface if the honey is allowed to stand in tanks for several days before canning. Large, squat tanks permit quicker clarification than deeper tanks. Honey that has been warmed to between $110^{\circ}$ and $120^{\circ} \mathrm{F}$ will clarify more quickly than colder honey.

Honey containers should be new, clean, and free from rust, especially on the in- side of the wholesale containers, as a small amount of old honey or rust in used containers can lower the grade.

When honey has started to granulate in the comb, the granules will cause the balance of the liquid honey to granulate more readily and will also retard its clarification. In such cases, it may be desirable to warm the honey as it leaves the extractor in order to facilitate clarification in the honey sump and in the tanks before granulation sets in.

Honey to be heated for processing is heated indirectly by placing the wholesale containers in a hot room, or in an oven heated by hot air, with the containers so placed that the honey will run from them as soon as it becomes fluid. It then is generally run or pumped to double-jacketed containers where it is completely liquefied by being heated to $160^{\circ} \mathrm{F}$, after which it is strained or bottled at a temperature of about $135^{\circ} \mathrm{F}$.

A view of a portion of the honey storage, filtering tanks and canning equipment located on the floor below the extracting equipment shown on page 44 . The arrangement emphasizes compactness, efficiency and cleanliness.

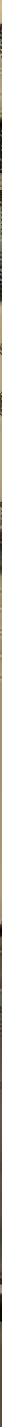


The containers may also be placed in a water bath which is heated directly by flame or by steam coils. The amount of heat should be controlled so that the water will not be heated above $160^{\circ} \mathrm{F}$. It usually takes 4 hours or more to liquefy honey in 5-gallon containers by this method. The honey is strained, allowed to clarify, and then bottled or canned at around $135^{\circ} \mathrm{F}$.

Some honeys are more easily injured by heat than others, and only experience will indicate to what temperature a honey can be heated for a given length of time without being injured in color and flavor.

While color plays no part in the grading of honey, the lighter-colored honeys usually bring higher prices than the darker colors. The color of honey is usually graded on the Pfund Color Grader and is divided into the following standards: water white, 8 or less; extra white, between 8 and 17; white, between 17 and 34 ; extra light amber, between 34 and 50; light amber, between 50 and 85; amber, between 85 and 114 ; and dark amber, over 114 millimeters.

\section{Marketing honey}

Commercial quantities of honey are sold usually to honey buyers who either process the honey for the retail or manufacturing trades, or who sell direct to processors either in the domestic market or in foreign countries. There is generally a surplus of honey available during the producing seasons or shortly after the honey has been extracted. Unless the price is controlled by subsidies, as is presently the case, the wholesale price is usually lower when there is a plentiful supply than later in the season when the offerings are slower. Even at present the price is higher for the lighter colors of table honey than for the darker colors having stronger flavors.

Beekeepers can secure loans on their honey either from local sources or from P.M.A. Commodity Credit Corporation (at present) if the honey meets a Grade C standard and is stored under approved conditions, which can be met by beekeepers in their own warehouses. These loans enable the beekeeper to secure cash to carry on his business without selling below market prices. Banks will advance loans on honey on the presentation of warehouse receipts showing the quantity and grades in storage.

Much honey is sold by the beekeeper direct to the consumer. This is especially true when the beekeeper manages fewer than 500 colonies as it provides an occupation during the time when he is not actively engaged in beekeeping.

Containers and labels. All containers and labels should be new and clean and conform in every respect with state and federal regulations. Present state marketing regulations can be secured from the State Department of Agriculture, Sacramento, upon request. They require that each label on a retail package should include the name of the contents, net weight, grade, color (when in opaque containers), and the name and address of the packer. If the floral source is mentioned, the contents of the container must be true to that source.

Coöperative marketing. There are a number of coöperative marketing organizations in the United States and some are located in California, enabling the producer to benefit by this type of marketing. Some processors and packers make contracts with producers which approximate some of the advantages of cooperative selling.

The California Honey Marketing Order has been adopted by California producers and handlers of honey and constitutes one form of coöperative marketing that influences a greater number in the industry than if it were simply a selling organization. The purpose of the present Honey Marketing Order is to assess and collect a uniform assessment from producers and honey handlers to promote the sale of honey through research and advertising. This marketing order for extracted honey 
limits assessments for both the producer and the handler to 5 cents per 60 pounds for the first year; in succeeding years they pay the maximum of 10 cents per 60 pounds. It is a type of self-help program that does not involve payment for its support from any other source than the industry itself which will share the benefits.

The various coöperative honey marketing organizations in the United States sold approximately $30,000,000$ pounds of honey in 1952, or about 8.5 per cent of the total production.

\section{Production and uses of beeswax}

Beeswax is produced from the digestion of honey or sugar syrup and the elaboration of the wax in four pairs of special wax glands located on the underside of the abdomen of the young worker bee. The virgin wax appears in the eight wax "pockets" as small white scales. The bees make their combs of these scales, working the cells in shape with their mandibles.

Wax production can be stimulated by feeding the bees sugar syrup or diluted honey. Commercial beeswax is produced by melting old or broken combs and the cappings removed during the extracting process. You should save the burr combs and pieces of broken combs, for the amount of wax thus secured is considerable.

At the close of the active season, it is a good policy to sort over all drawn combs and melt those that have too many drone cells or are broken or injured. Many beekeepers save their cappings and render all wax at the same time. The combs may be cut out of the frames and melted in boiling water in a copper, aluminum, or stainless steel container. Where many combs have to be rendered, a wax press will save much wax that would otherwise adhere to the cocoons in brood combs. A description of the various wax presses may be found in bee supply catalogs. The wax presses gener- ally use hot water or steam with pressure on the melted combs to remove the liquid wax. Cappings should be melted separately from darker brood combs, since they produce a lighter-colored wax.

Some commercial beekeepers use vats in which to melt the combs from the frames by steam. The melted wax falls into boiling water, from which it can then be dipped and strained into molds. The comb refuse is run through a press to remove the remainder of the wax. The boiling water washes out much of the color from the old combs and produces cleaner and lighter-colored wax. If the wax cakes are melted a second time in water in copper, aluminum, wooden, or stainless-steel vats, the liquid should be allowed to stand for some hours at a temperature just above the melting point. Many of the remaining impurities will settle to the bottom, and the clear wax can then be poured off into suitable buckets or molds.

The color of crude beeswax is attributed to extracts of pollen or propolis, and to the chemical action of iron oxides when the melted wax comes in contact with iron containers. It is not advisable to add burr combs or frame scrapings containing propolis to cappings or old combs for melting; even a small amount of propolis will reduce the value of beeswax for many purposes. Beeswax is used as an agent in pharmaceutical formulas, such as salves, ointments, cerates, camphor, ices, and pomades; for church candles, comb foundations, and dental impressions; in floor, furniture, stove, and shoe polishes; in electrical insulation, weather-proofing compounds, and in many other ways.

\section{Beekeepers' organizations}

Bcekeepers have formed county or regional associations in different parts of California and hold periodic meetings to exchange ideas of mutual interest. The mcmbers frequently pool their efforts in setting up cxhibits at state and county 


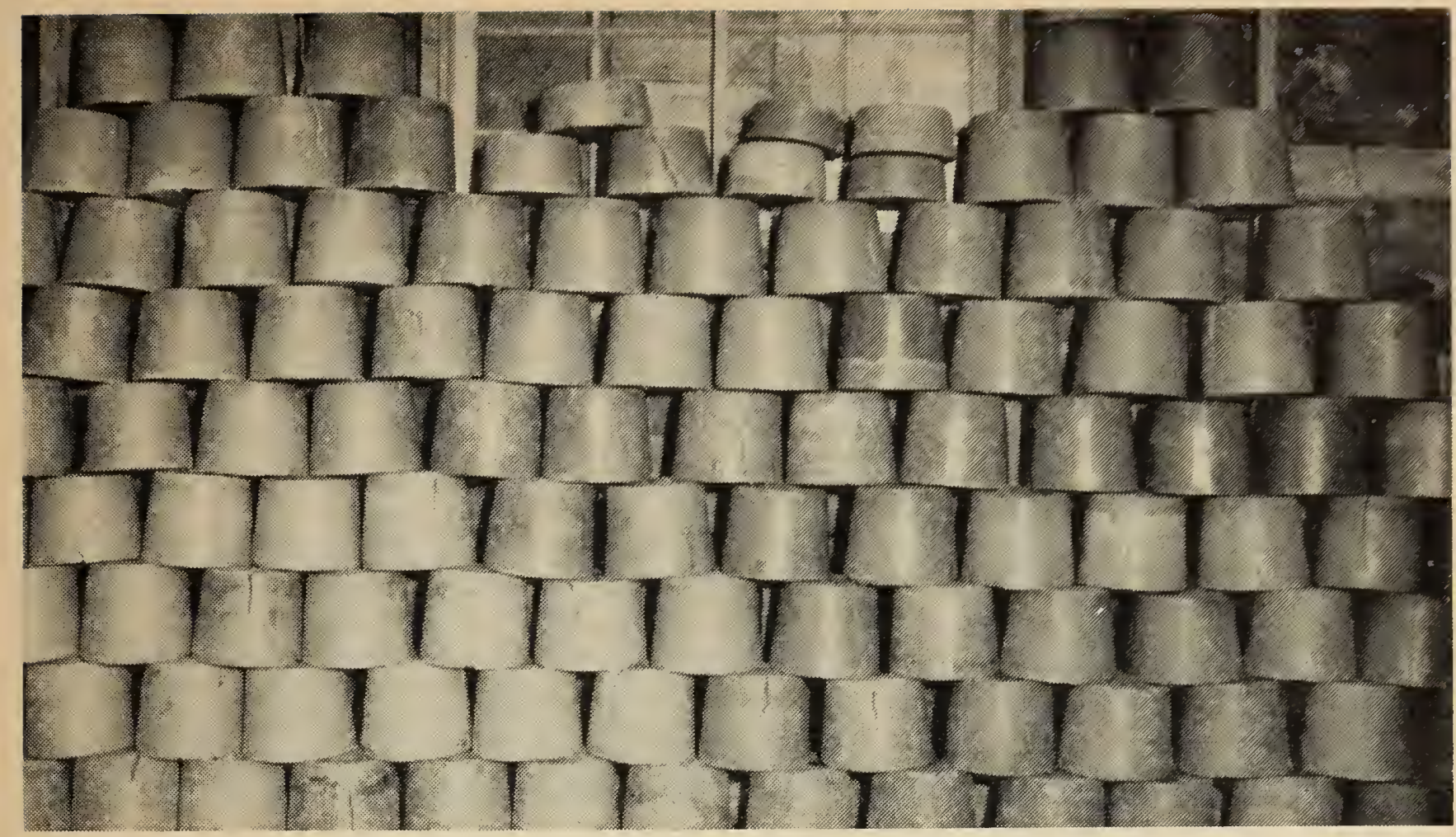

A large supply of commercial beeswax ready for market.

fairs, in improving equipment and methods of producing honey, and in considering county, state, and federal programs or legislation pertaining to beekeeping. These organizations and their members affiliate with the California State Beekeepers' Association, which was organized in Los Angeles on January 7, 1892.

There is also the National Beekeeping Federation to which individual beekeepers and associations can belong to further the interests of beekeeping on a national basis.

The California State Beekeepers Association holds an annual convention, usually during the early part of December, and rotates the meetings to different portions of the State for the convenience of the members.

The honey industry is served nationally by the American Honey Institute as a medium for honey publicity, the headquarters being located at Madison, Wisconsin. It is supported by voluntary contributions and memberships from beekeepers, bee supply manufacturers, the bee journals, honey coöperatives, and others interested in the bee and honey industries.

\section{California bee supply manufacturers}

The following bee supply manufacturers in California produce practically all of the beekeeping equipment the amateur or commercial beekeeper needs:

Diamond Match Company, Apiary Department, Chico or Los Angeles (General beekeeping supplies*)

Knorr Comb Foundation, Del Mar (Foundation and candles)

Miller Honey Company, Colton (Comb foundation)

Superior Honey Company, Los Angeles and Alhambra (General beekeeping supplies* and wax candles)

Other bee supply manufacturers with national distribution include the following:

Dadant \& Sons, Hamilton, Ill.

Walter T. Kelley \& Co., Clarkson, Kentucky

G. B. Lewis Co., Watertown, Wis.

A. I. Root Co., Medina, Ohio

Woodman Bee Supplies, Grand Rapids, Mich. Many of the products of these manufacturers are handled by the California manufacturers.

* Illustrated bee supply catalogs are available on request. 


\section{REFERENCES FOR FURTHER READING}

There is a wealth of good reading on bees and beekeeping in various libraries in the form of books, magazines, bulletins, and extension circulars. The Printing Office, U.S.D.A., Washington, D.C., will send a list of available bee publications, for sale at nominal cost. The magazines attempt to keep their readers informed of advances and discoveries relating to beekeeping as well as the seasonable operations in different parts of the country. Every beekeeper can well afford to have one or more textbooks on beekeeping and to subscribe to one or more of the bee journals.

Beekeeping periodicals published monthly:

American Bee Journal, Hamilton, Illinois

The Bee World, Salisbury House, London Wall, England

Gleanings in Bee Culture, Medina, Ohio

Modern Beekeeping, Clarkson, Kentucky

\section{Books}

Grout, Roy A., and others

1949. The hive and the honey bee. 652 p. Dadant and Sons, Hamilton, Illinois.

Killian, Carl

1951. Honey in the comb. 130 p. Journal Print Co., Carthage, Illinois.

Laidlaw, Harry H., and J. E. Eckert

1950. Queen rearing. 147 p. Dadant and Sons, Hamilton, Illinois.

Lovell, John H.

1926. Honey plants of North America. 408 p. A. I. Root Co., Medina, Ohio.

Pellett, Frank C.

1920. American honey plants. 297 p. American Bee Journal, Hamilton, Illinois.

1938. History of American beekeeping. 213 p. Collegiate Press, Ames, Iowa.

Root, E. R., H. H. Root, and M. J. Deyell

1950. ABC and XYZ of bee culture. 717 p. A. I. Root Co., Medina, Ohio.

Root, H. H.

1951. Beeswax. 154 p. Chemical Publishing Co., Brooklyn, N.Y.

Shaw, Frank R., and Stanley R. Whitehead

1951. Honey bees and their management. 169 p. D. van Nostrand Co., Inc., N.Y. 3.

von Frisch, Karl

1950. Bees, their vision, chemical senses, and language. 119 p. Cornell University Press. Ithaca, N.Y.

\section{Articles on antibiotics}

Eckert, J. E.

1953. The chemotherapy of foulbrood diseases of the honey bee. Gleanings in Bee Culture, $81: 12$, p. 718-758.

Farrar, C. L.

1954. Fumagillin for Nosema control in package bees. Amer. Bee Jour. 94:2, p. 52-60.

Katznelson, H., and C. A. Jamieson

1953. Recent developments in the control of American foulbrood and Nosema with antibiotics. Amer. Bee Jour. 93:10, p. 404-405.

Moffett, Jos. O.

1954. Preventing and controlling EFB. Amer. Bee Jour. 94:1, p. 14-15. 
Acid board, 41-42

Almond moth, 76

American foulbrood, 64-68

American Honey Institute, 85

Antibiotics, 68

Ants, 76

Apiary, arrangement, 7-8; inspection laws, 61 ; location, 7, 10-11; registration and identification, 61

Aureomycin, 69

Bears, 76

Bee, brush, 15; dances, 29 ; escape, 15, 40-41 ; journals, 86 ; stings, 4 ; suit, 14-15; supply manufacturers, 85

Beekeeping, amount of investment, 5 ; as a hobby, 6 ; extent of industry in California, 1

Bees in trees or walls, 52-53

Beeswax, as a source of income, 2; production, processing, and uses, 2, 84

Brood, arrangement, 24; cell color, 24; chilled, 73 ; cycle, 24-25; diseases, $62-70$; poisoned, 73; rearing, 21, 26, 28; starved, 73

Buckeye (California), 7, 73

Cages, queen, 33 ; package bee, 36

California Apiary Inspection Act, 61

California Honey Marketing Order, 83-84

California State Beekeepers' Association, 85

Calories in honey, 77

Candy, for bees, 54; for queen cage, 34

Cappings, $44-45$

Carbolic acid, 41-42

Carbon disulfide, 75

Carniolan bees, 20

Caucasian bees, 19-20

Cell cups, artificial, 57

Chemical and physical properties of honey, 7778

Chemical poisoning, 71-72

Chilled brood, 73

Climate, effect on bees, 31 ; on nectar secretion, 7,11 ; see also temperature, seasonal management

Clothing, 14-15

Cluster, cold weather, 28-29; swarm, 26

Colonies, fall care, 34-35; in pollination, 7, 52; in queen rearing, $57-58$; number in an apiary, 10 ; spring care, 35

Colony, cell-building, 57 ; cycle of the year, 2629 ; food requirements, 24 ; increase, 38 ; inspection, 24, 30-31 ; morale, 22 ; nest arrangement, 24-26; population, 20, 28; sales, $2-3$; social structure, 20-24; transferring from buildings or trees, $52-53$; uniting, 52

Colony management, in comb honey production, 46 ; in extracted honey production, $39-42$; in swarm control,"38
Comb, building, 24; color, 25; foundation, 15, 39

Comb honey, colony management for, 46 ; equipment, 13-15; processing and grading, 81 ; rcmoval from hive, 40-42; sections, 45-46; supers, $39-40$

Combs, care in storage, 75 ; cleaning, 44 ; melting, 66, 84; uncapping, 43, 44-45

Communication among bees, 29

Containers, for comb honey, 81; for extracted honey, 83

Cooking with honey, 79-80

Coöperative marketing, 83-84

Cyanide gas, 75

Cyanogas, 65, 75

Cycle of the year, 26-29

Dances of bees, 29

Dequeening, 32-33

Diseases, 61-71; of adults, 70-71; of brood, 6270 ; table of symptoms, $62-63$

Drone-laying queen, 60,73

Drone, 22-23; cells, 25; dead drone brood in worker cells, 73 ; eggs, 21-22; killed by workers, 28

Dysentery, 53

Eggs, attachment, 24; fertilization, 21; number laid per day, 24

Egg-laying, fluctuations of, 21

Embedding wire, 15

Entrance screens, 50

Entrance size, for nucleus hive, 38 ; if robbing prevalent, 37 ; in winter, 35

Enzymes of honey, 77-78

Equipment for beekeeping, 5, 13-17

Escape board, 41

Eucalyptus, 11

European foulbrood, 68-69

Excluders, see queen excluders

Extracted honey, grades, 81; granulation, 78; marketing, 83 ; processing, 42-45; removal from hive, 40-42; supering for, 39-40; wholesale containers, $82-83$

Extracting equipment, 15; honey extractors, $42-$ 43 ; portable outfits, $48-49$

Fall, activities of bees, 28; condition of colony for wintering, 34-35

Feeders, 54-55

Feeding, in queen rearing, 60 ; of larvae, 24; of package bees, 36 ; of queen, 21

Fermentation in honey, 79

Fidelity of bees to food sources, 30

Fire, apiary protection, 11; hazards in the honey house, 48-49

Food, chamber, 35; of bees, 24; for package bees, 36 ; queen-cage candy, 34; supplements, $53-54$; winter needs of bees, 34-35 
Food value of honey, 79-80

Foulbrood, American, 64-68; European, 68-69; parafoulbrood, 69-70

Foundation, for combs and sections, 15; of hives, 7

Frames, assembling and wiring, 16; handling, 30-31

Friction-top pail, 54-55

Fumigation of combs, 73

Glands of worker bee, food, 24; wax, 84

Gloves, 15

Grades of honey, 81

Granulated honey, 78

Heat, effect on honey, 78-79; in processing, 8283

Heredity, 22

Hive, arrangement, 7, 10; assembling, 15-17; covers, 14; entrance direction, 10 ; hoists, 51 52 ; location, 7, 10-11; moving, 50-52; number in apiary, 10; tool, 14, 30; types, 13; winter care, 35

Hive manipulations, for comb honey, 46; for extracted honey, 38-42; for package bee production, 36-37

Hoffman frame, 16, 57

Honey, as bee food, 24; average annual crop, 2; cappings, 44-45; color, 43, 79, 83; composition, 77-78; containers and labels, 83; cooperatives, 83-84; extractor, 42-43; flavor, 7, 78; food value, 79-80; grading and processing, 81-83; granulated, 78 ; house, $47-48$; in queen-cage candy, 34; marketing, 83 ; moisture content, 78; poisonous, 73; pump, 43; section, 45-46; straining, 43; sump, 48; supplements, 53-54; uses, 79; weight, 78; yeasts of, 79

Honeydew, 80

Honey plants, see nectar and pollen plants

Importation of bees, $1,60,64$

Inbreeding, 58

Incense cedar, 80-81

Income from bees, 2,6

Increase, 38

Indian meal moth, 76

Inspection, after colony installation, 24; apiary inspection laws, 61 ; certificate of disease resistance, 5 ; fall and wintcr, 35 ; periodic examinations by beekeeper, 31

Introducing cages, 33-34

Introduction of qucen, 32-34.

Invert sugars in honcy, 77

Investment for the beginner, 4-5

Isle of Wight diseasc, 61

Italian bees, 18-19

Labels for honey containers, 83

Langstroth hive, 13

Larvac, feeding of, 24

Laying workers, 73
Laws, apiary inspection, 61 ; importation, 60,64 ;

AFB control, 65, 66; marketing, 83

Legume seed production, 3

Liquid honey, 43, 78

Liquefying granulated honey, 78

Loans for beekeepers, 83

Location of apiary, 7, 10-11

Locoweed, 73

Mailing cage, 32,34

Manipulation of hives, for comb honey, 46; for extracted honey, 38-42; for package bee production, 36-37

Marketing honey, 83-84

Mating of queen, 21

Mechanical hive hoists, $51-52$.

Mediterranean flour moth, 76

Methyl bromide, 75

Mice, 76

Migratory beekeeping, 6, 50-52; regulations governing, 61-64

Moisture content of honey, 78, 79

Moving hives, see migratory beekeeping

National Beekeeping Federation, 85

Nectar and pollen plants, 7-13; table of comparative values, 12 ; table of distribution, 8-9

Nectar, composition of, 24

Nest arrangement, 24-26

Nitrous oxide, 52

Nosema apis, 70-71

Nuclei, in increase, 38 ; in queen rearing, $57-58$

Nurse bees, 21 ; diet of, 24

Opening a hive, $30-31$

Organizations of beekeepers, 84-85

Orientation, flights, 29; to surroundings, 52

Outapiaries, 7, 10; winter stores for, 34

Package bees, feeding, installation, and care, 36-37; production, 3 ; sales, 2

Paradichlorobenzene (Paracide), 75

Parafoulbrood, 69-70

Paralysis, 71 ; in buckeye poisoning, 73

Pesticides, 71-73

Pests, 76

Pfund color grader, 83

Plant poisoning, 73

Poisoning, 70-73; register hives for spray notification, 61

Pollen, collcction chart, 23; colony $\cdot$ needs, 24; composition of, 24 ; for package bees, 36; stores for wintering, 34-35; supplements, 56; traps, 55-56; see also nectar and pollen plants

Pollination services, fidelity of bces to food sources, 30 ; rentals, 3 ; locations, 7, 52

Population of colony, normal, 20 ; fall, 28

Portable extracting plants, $48-49$

Processing honey, 81

Propolis, source, 20; uses, 28-30

Protection of hives, from flood and fire, 11 ; from heat, 10-11; from cold, 35 
Queen, care of, 31-34; colony needs in fall, 35 ; excluders, 13-14, 46; how to find, 31-32; in comb honey production, 46; in swarm control, 38; in swarming, 26-28; introduction, 32-34; life cycle, 21-22; marking, 32; number of eggs laid by, 24; rearing, 57-60; records, 31 ; sales, 3 ; testing, 58

Races of bees, 18-20

Rearing of queens, from swarm cells 38 ; from artificial cells, 57

Records, hive, 31, 53; production, 39

Refractometer, 78

Registration of hives, 61

Rentals for pollination services, 3

Requeening, 32-34, 39, 58; with package bees, 37

Robbing, forestalled by nectar flow, 31 ; seasonal occurrence, 35,67

Robbing, protection from, during feeding, 54, 55 ; of extracted combs, 40,44 ; of newly established hives, 37 ; with acid board, 42

Royal jelly, 21, 24

Sacbrood, 70

Sales, of colonies, package bees, and queens, 2 ; of honey, 83

Sanitation in the honey house, 48

Scout bees, 23-24, 29

Screens for hives, 15,50

Seasonal activities, 26-29; management, 34-35

Shipping bees, in packages, 36 ; in queen cages, 34

Skunks, 76

Smoke, use in opening the hive, 30-31

Smoker, 14, 30, 48-49

Solar wax extractor, 44

Soybean flour, 56

Sprays, see pesticides

Spring activities, 26; examination, 35

Spur embedder, 16

Starved brood, 73

Stimulative feeding, 53-56

Stings, 4 ; of queen, 21,22

Stock improvement, 58-60

Storage of honey, 79

Strainers for honey, 41, 81-82

Streptomycin, 69
Substitutes, for honey, 53-.54; for pollen. 56

Sugars in honey, 7 ?

Sulfathiazole, 65-68

Supering, 39-40

Supersedure, cells, 21 ; queen, 22, 28

Supplementary feeding, 53-56

Swarming, 26-28; pollen in relation to. 38 : prevention and increase, 37-38; queen in relation to, 57; reduced by requeening, 39-40

Syrups, 53-54

Temperature, effect on bees, 39 ; effect on combs, 30-31, 41; effect on fermentation, 81; effect on foundation, 16; for honey storage, 79 ; for brood rearing, 31 ; for liquefying honey, 78 : for melting cappings, 44; for package bees, 36 ; for straining honey, 48 ; in honey extraction, 43 ; in processing, $82-83$; of bee, $10-11$; of normal brood nest, 31

Terramycin, 69

Transferring, bees from buildings or trees, 5253 ; larvae in queen rearing, 57

Uncapping knife, 43

Uniting colonies, 52

Untested queens, $3,32,58$

Uses of honey, 79; of beeswax, 84

Veils, 14

Veratrum (corn lily), 73

Vitamins in honey, 78

von Frisch, Karl, 29

Wax, see beeswax

Wax moth, greater, 73-74: lesser, 75-76

Weak colonies strengthened with package bees, 37

Weather, see climate

Weight, of colony, 20; of hives, 38; of honey, 78; of package bees, 36

Windbreaks, 10

Winter, cluster, 28-29; feeding, 53-54; losses, 11 ; preparation for, 34-35

Wire embedders, 16

Wiring frames, 16

Worker bee, 23-24; food requirements of, 24

Yeasts in honey, 79

In order that the information in our publications may be more intelligible, it is sometimes necessary to use trade names of products or equipment rather than complicated descriptive or chemical identifications. In so doing, it is unavoidable in some cases that similar products which are on the narket under other trade names may not be cited. No endorsement of named products is intended nor is criticism implied of similar products which are not mentioned. 

Co operative Extension work in Agriculture and Home Econonics, College of Agriculture, University of California, and United States Depurtment of Agriculture
co opterating. Uiotributed in furtherace of the Arts of Congress of May 8 , und June 30, 1914.J. Earl Coke, Director, Culifornis Agricultural Extension Service. 


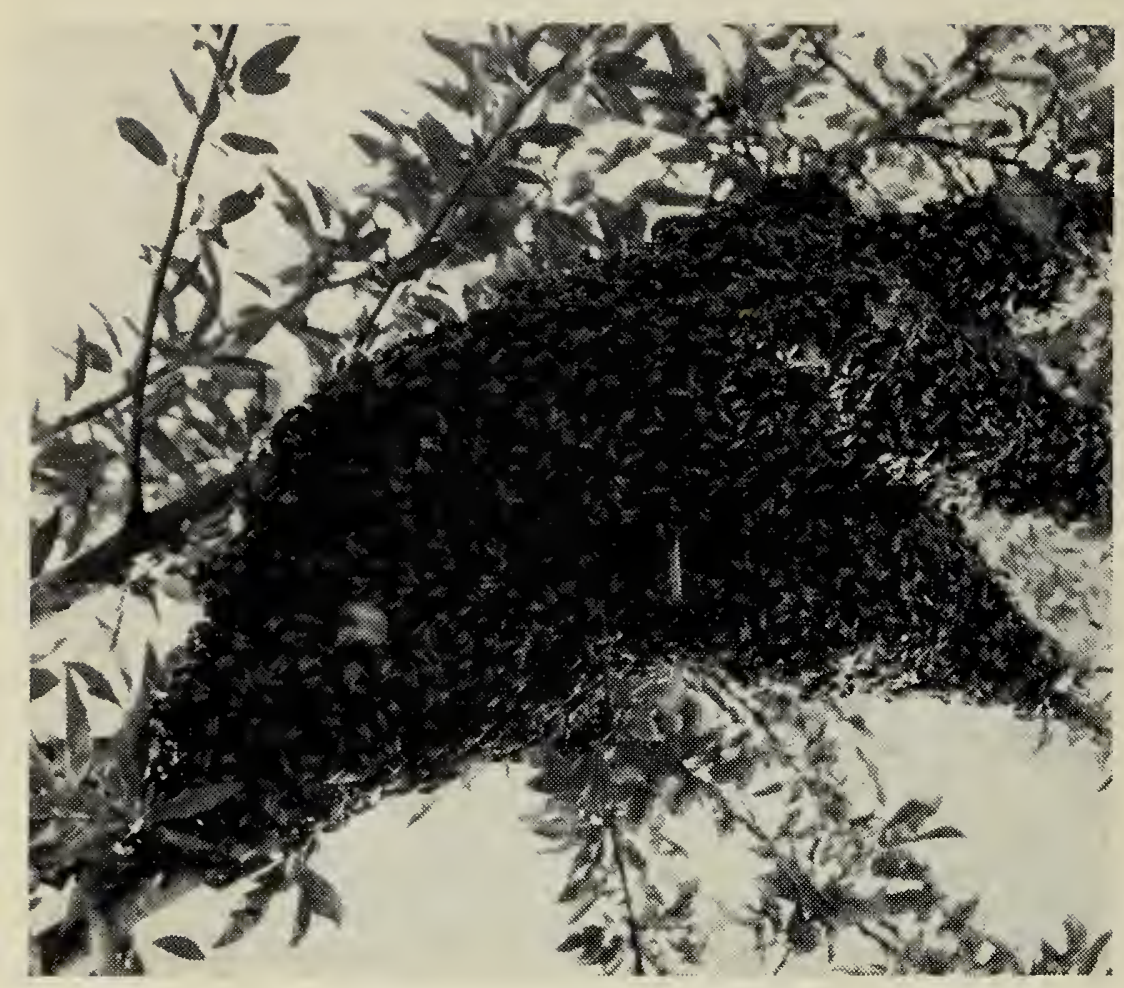

Amateurs and professionals alike will find this manual helpful. Here, in one booklet, are covered such subjects as:

The points to consider before going into beekeeping as a hobby or profession.

The life story of the honeybee.

The rearing of queens.

Diseases and enemies of bees.

Manipulation of the hive.

Marketing the products.

For a list of manuals on other agricultural or floricultural subjects, write to Agricultural Publications, 22 Giannini Hall, University of California, Berkeley 4. 